\title{
Techniques for Treating Uncertainty and Risk in the Economic Evaluation of Building Investments
}

Harold E. Marshall

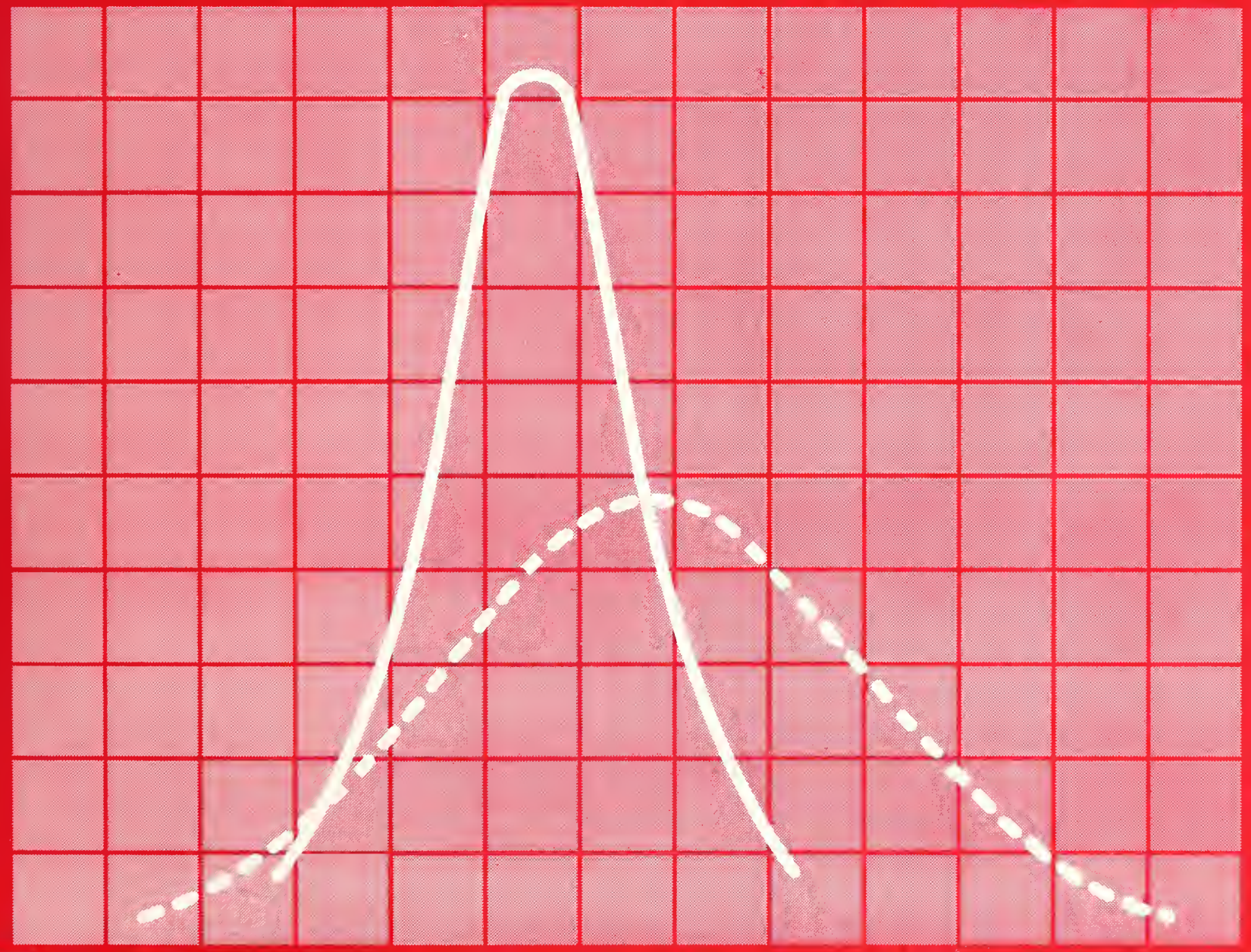

QC

100

.057

S. DEPARTMENT OF COMMERCE ational Institute of Standards and Technology ST Special Publication 757 



\section{NIST Special Publication 757}

\section{Techniques for Treating Uncertainty and Risk in the Economic Evaluation of Building Investments}

\section{Harold E. Marshall}

Applied Economics Group

Mathematical Analysis Division

Center for Computing and Applied Mathematics National Engineering Laboratory

National Institute of Standards and Technology

Gaithersburg, MD 20899

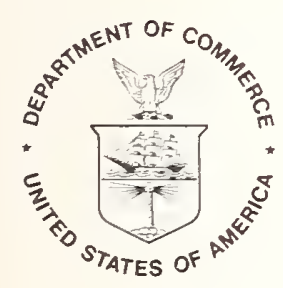

September 1988

U.S. Department of Commerce

C. William Verity, Secretary

National Institure of Standards and Technology Ernest Ambler, Director
NOTE: As of 23 August 1988, the National Bureau of Standards (NBS) became the National Institute of Standards and Technology (NIST) when President Reagan signed Into law the Omnibus Trade and Competitiveness Act. 
Library of Congress

Catalog Card Number: 88-600584

National Institute of Standards

and Technology

Special Publication 757

97 pages (Sept. 1988)

CODEN: XNBSAV
U.S. Government Printing Office

Washington: 1988
For sale by the Superintendent of Documents, U.S. Government Printing Office, Washington, DC 20402 


\section{PREFACE}

This is the fifth in a series of National Institute of Standards and Technology (NIST), formerly the National Bureau of Standards (NBS), reports on recommended practices for applying economic evaluation methods to building decisions. ${ }^{1}$ The previous four dealt with the theory and application of six economic methods of analysis: life-cycle costing, net benefits, benefit-to-cost and savings-to-investment ratios, internal rate of return, and payback. These reports were used as the bases for recommended standard practices published by the American Society for Testing and Materials (ASTM). Economic measures described from applying these methods in project evaluations were presented in the NBS reports and ASTM standards primarily in single-value, deterministic terms as if all input values were certain.

This report differs from the earlier ones in that it focuses on techniques that account for uncertainty in input values and techniques that measure the risk that a project will have a less favorable economic outcome than what is desired or expected. In addition, the report considers techniques for incorporating risk attitudes of decision makers in selecting efficient projects.

${ }^{1}$ The previous four reports are as follows: Rosalie T. Ruegg, Stephen R. Petersen, and Harold E. Marshall, Recommended Practice for Measuring Life-Cycle Costs of Buildings and Building Systems, National Bureau of Standards Interagency Report 80-2040, June 1980; Harold E. Marshall and Rosalie T. Ruegg, Recommended Practice for Measuring Benefit/Cost and Savings-to-Investment Ratios for Buildings and Building Systems, National Bureau of Standards Interagency Report 81-2397, November 1981; Harold E. Marshall, Recommended Practice for Measuring Net Benefits and Internal Rates of Return for Investments in Buildings and Building Systems, National Bureau of Standards Interagency Report 83-2657, October 1983; and Harold E. Marshall, Recommended Practice for Measuring Simple and Discounted Payback for Investments in Buildings and Building Systems, National Bureau of Standards Interagency Report 84-2850, March 1984. 



\section{ACKNOWLEDGMENTS}

Thanks are due the members of ASTM who have participated in the Building Economics Subcommittee meetings and thereby have helped determine the framework of this paper. Special appreciation is extended to Tung Au, Robert E. Chapman, Sieglinde K. Fuller, Barbara C. Lippiatt, Margaret S. Murray, Stephen R. Petersen, Rosalie T. Ruegg, Barry Stedman, James B. Weaver, and Stephen F. Weber for their helpful technical comments on the paper; to David Rosoff for supplying data for one of the case examples; to Robert E. Chapman for writing and executing computer programs that produced the simulations and some of the graphs; and to Laurene Linsenmayer for typing the final manuscript. 



\section{GLOSSARY}

Adjusted Internal Rate-of-Return (AIRR)--The compound rate of interest that discounts the terminal values of costs and benefits of a project over a given study period so that costs equal benefits, where terminal values are computed at a specified reinvestment rate. The AIRR method is used to measure project worth.

Annual Value (Annual Worth)--Project costs or benefits expressed as uniform annual amounts, taking into account the time value of money.

Base Time (Base Year)--The date (usually the beginning of the study period) to which benefits and costs are converted to time equivalent values when using the present value method.

Benefit-to-Cost Ratio--The ratio of benefits to costs, where both are discounted to present or annual values. The BCR method is used to measure project worth.

Breakeven Analysis--A technique for determining the minimum or maximum value that a variable can reach and still have a breakeven project; i.e., a project where benefits (savings) equal costs.

Capital Asset Pricing Model (CAPM)--The capital asset pricing model explains how assets should be priced according to their calculated risk and expected returns. It indicates what the return on an asset should be, based on that asset's risk.

Cash Flow--The stream of costs and benefits resulting from a project investment.

Certain Equivalent Factor(CEF)--The factor by which uncertain project returns are multiplied to determine the "certainty equivalent" amount a decision maker finds equally acceptable.

Certainty Equivalent Technique--A technique used to adjust economic measures of project worth to reflect risk exposure and risk attitude. Estimated project returns are multiplied by a certainty equivalent factor (CEF) to determine the "certainty equivalent" amount a decision maker finds equally acceptable.

Coefficient of Variation (CV)--The ratio of the standard deviation to the mean.

Constant Dollars (Real Dollars)--Dollars of uniform purchasing power tied to a specified time.

Contour Lines--Line segments that connect the various rays of a spider diagram.

Cost Effective--The condition whereby the present value benefits (savings) of an investment alternative exceeds its present value costs.

Cumulative Distribution Function (cdf)--A function that shows on the y axis the probability of a value being less than or equal to the corresponding value on the $\mathrm{x}$ axis.

Current Dollars--Dollars of nonuniform purchasing power, in which actual prices in the market are stated for any given time. With no inflation or deflation, current dollars will be identical to constant dollars.

Decision Analysis--A technique for making economic decisions in an uncertain environment that allows a decision maker to include alternative outcomes, risk attitudes, and subjective impressions about uncertain events in an evaluation of investments. Decision analysis typically uses decision trees to represent decision problems. 
Decision Tree--A decision flow diagram (in the shape of a tree) that is used to represent all possible outcomes, costs, and probabilities associated with a given decision problem. The tree serves as a road map to clarify possible alternatives and outcomes of sequential decisions.

Differential Price Escalation Rate--The expected percent difference between the rate of increase assumed for a given item of cost (such as energy), and the general rate of inflation.

Discount Factor--A multiplicative number that is used to convert costs and benefits occurring at different times to a common time. Discount factors are calculated from a discount formula for a given discount rate and study period.

Discount Rate--The minimum acceptable rate of return used in discounting benefits and costs occurring at different times to a common time. Discount rates reflect the investor's time value of money (or opportunity cost). Real discount rates reflect time value apart from changes in the purchasing power of the dollar (i.e., inflation or deflation) and are used to discount constant dollar cash flows. Nominal discount rates include changes in the purchasing power of the dollar and are used to discount current dollar cash flows.

Discounting--A procedure for converting a cash flow that occurs over time to an equivalent amount at a common time.

Economic Evaluation Methods--Various ways in which project benefits and costs can be combined and presented to describe measures of project worth. Examples are life-cycle costs (LCC); net benefits (NB) or net savings (NS); benefit-to-cost ratio (BCR) or savings-to-investment ratio (SIR); and adjusted internal rate of return (AIRR).

Future Value (Future Worth)--The value of a cost or benefit at some time in the future, taking into consideration the time value of money.

Inflation--A rise in the general price level. Inflation can also be described as a decline in the general purchasing power of a currency.

Internal Rate of Return--The compound rate of interest that, when used to discount a project's cash flows, will equate costs and benefits.

Investment Costs--The costs associated with acquiring an asset, including such items as design, engineering, purchase, and installation.

Life-Cycle Cost (LCC)--The sum of all discounted costs of acquiring, owning, operating and maintaining a building project over the study period. Comparing life-cycle costs among mutually exclusive projects of equal performance is one way of determining relative cost effectiveness.

Mathematical/Analytical (M/A) Technique--A technique of obtaining probability functions for economic measures of project worth without the repeated trials of simulation.

Mean $(\mu)$--A statistical measure of central tendency. Specifically, the arithmetic mean is the sum of individual values for a group of items divided by the number of items in the group. It may also be referred to as the "average" or "typical" value in a distribution.

Mean-Variance Criterion--A technique for evaluating the relative risk and return when choosing among competing projects. The mean-variance criterion dictates that the project with the higher mean (i.e., expected value of project worth) and lower standard deviation be chosen. This presumes that decision makers prefer less risk to more risk. 
Minimum Acceptable Rate of Return--The minimum percentage return required for an investment to be economically acceptable.

Modified Uniform Present Value Factor (UPV*)--The discount factor used to convert an annual amount escalating at a constant rate to a time-equivalent present value.

Mutually Exclusive--A condition where the acceptance of one alternative precludes acceptance of others.

Net Benefits (Savings)--The difference between benefits (savings) and costs, where both are discounted to present or annual values. The NB method is used to measure project worth.

Nominal Discount Rate--See Discount Rate.

Non-Mutually Exclusive Project--A project whose acceptance does not preclude acceptance of others.

Payback Period--The time it takes for an investment's cumulative benefits or savings from a project to pay back the investment and other accrued costs.

Portfolio Analysis--A technique used to seek the combination of assets with the maximum return for any given degree of risk (i.e., variance of the return), or the minimum risk for any given rate of return.

Present Value (Present Worth)--The time-equivalent value at the base time of past, present, or future cash flows.

Probability Density Function (pdf)--The derivative of a continuous, cumulative distribution function. The area under the pdf must equal 1.

Real Discount Rate--See Discount Rate.

Real Dollars--See Constant Dollars.

Resale Value (Salvage Value)--The monetary amount expected from the sale of an asset at its time of disposal, less disposal costs.

Retrofit--The modification of an existing building or facility to include new systems or components.

Risk-Adjusted Discount Rate (RADR)--A discount rate that has been adjusted to account for risk. When using the RADR technique, projects with anticipated high variability in distributions of project worth have their net benefits or returns discounted at higher rates than projects with low variability.

Risk Analysis--The body of theory and practice that has evolved to help decision makers assess their risk exposures and risk attitudes so that the investment that is "best for them" can be selected. (Note that this definition is restricted to the types of analyses described in this report, and is not necessarily consistent with how the term is used in reference to analyses in such areas as the environment or health.)

Risk Attitude--The willingness of decision makers to take chances or gamble on investments of uncertain olitcome. Risk attitudes are generally classified as risk averse, risk neutral, or risk taking. Risk averse decision makers would prefer a sure cash payment to a risky venture with known expected value greater than the sure cash payment. Risk neutral decision makers act on the basis of expected monetary value. They would be indifferent between a sure cash payment and a risky venture with expected value equal to the sure cash payment, and would therefore accept a fair gamble. Risk takers prefer a risky venture with known expected value to a sure cash payment equal to the expected value.

Risk Averse (RA)--See Risk Attitude. 
Risk Exposure--The probability of investing in a project whose economic outcome is different from what is desired (the target) or what is expected.

Risk Neutral (RN)--See Risk Attitude.

Risk Taking (RT)--See Risk Attitude.

Salvage Value--See Resale Value.

Savings-to-Investment Ratio (SIR)--The ratio of present value savings to present value investment costs. Also computed as the ratio of annual value savings to annual value investment costs. The SIR method is used to measure project worth.

Sensitivity Analysis--A technique for measuring the impact on project outcomes of changing one or more key input values about which there is uncertainty.

Single Present Value Factor (SPV)--The discount factor used to convert future benefit and cost values to time-equivalent present values

Simulation--A technique that can be used to determine risk exposure from an investment decision. To perform this type of simulation, probability functions of the input variables are required.

Spider Diagram--A graph that presents a snapshot of the potential impact, taking one input at a time, of several uncertain input variables on project outcomes.

Standard Deviation $(\sigma)$--The square root of the variance. The standard deviation indicates the extent to which items in a distribution differ from the mean value.

Study Period (Time Horizon)--The length of time over which an investment is evaluated.

\section{Time Horizon--See Study Period.}

Time Value of Money--The time-dependent value of money arising both from the real earning potential of an investment over time and from changes in the purchasing power of money (i.e., inflation or deflation).

Uncertainty--Uncertainty (or certainty) as used in this report refers to a state of knowledge about the variable inputs to an economic analysis. If the analyst is unsure of input values, there is uncertainty. If the analyst is sure, there is certainty.

Uniform Present Value Factor (UPV)--The discount factor used to convert uniform annual values to a timeequivalent present value.

Utility Function--A function that shows how utility (i.e., satisfaction) varies with money or income. The utility function shows the decision maker's risk attitude.

Variance $\left(\sigma^{2}\right)$--A statistical measure of dispersion about the mean. The square root of the variance is the standard deviation. 


\section{ABBREVIATIONS AND SYMBOLS}

\begin{tabular}{|c|c|c|c|}
\hline AIRR & adjusted internal rate of return & UPV & uniform present value (worth) factor \\
\hline BCR & benefit-to-cost ratio & UPV* & $\begin{array}{l}\text { modified uniform present value (worth) } \\
\text { factor }\end{array}$ \\
\hline CAPM & capital asset pricing model & & \\
\hline $\operatorname{cdf}$ & cumulative distribution function & $\mu$ & mean or expected value \\
\hline $\mathrm{CEF}$ & certainty equivalent factor & $\sigma$ & standard deviation \\
\hline $\mathrm{CV}$ & coefficient of variation & $\sigma^{2}$ & variance \\
\hline EMV & expected monetary value & & \\
\hline EMV'er & $\begin{array}{l}\text { decision maker who acts on the basis of } \\
\text { expected monetary value }\end{array}$ & & \\
\hline HVAC & heating, ventilating, and air conditioning & & \\
\hline $\mathrm{kWh}$ & kilowatt hour & & \\
\hline LCC & life-cycle cost & & \\
\hline MARR & minimum acceptable rate of return & & \\
\hline NB & net benefits & & \\
\hline NS & net savings & & \\
\hline NBS & National Bureau of Standards & & \\
\hline NIST & $\begin{array}{l}\text { National Institute of Standards and } \\
\text { Technology (formerly NBS) }\end{array}$ & & \\
\hline $\mathrm{M} / \mathrm{A}$ & mathematical/analytical & & \\
\hline pdf & probability density function & & \\
\hline RA & risk averse & & \\
\hline RADR & risk-adjusted discount rate & & \\
\hline RN & risk neutral & & \\
\hline $\mathrm{RT}$ & risk taking & & \\
\hline SIR & savings-to-investment ratio & & \\
\hline SPV & single present value (worth) factor & & \\
\hline
\end{tabular}




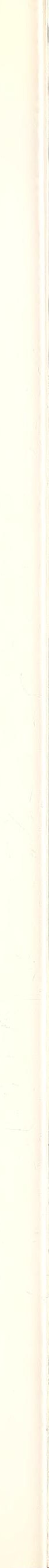




\section{CONTENTS}

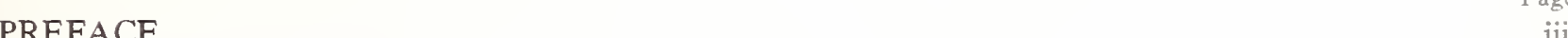

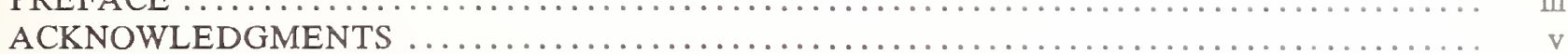

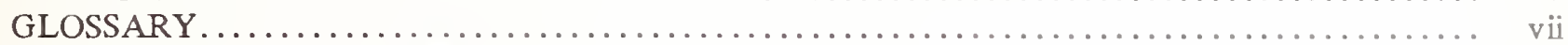

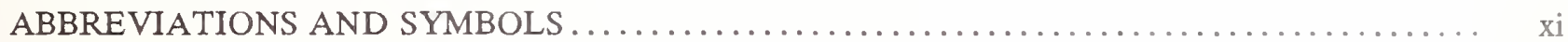

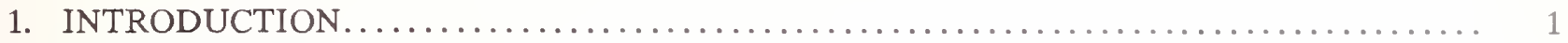

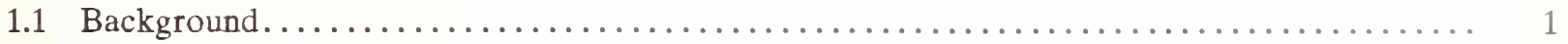

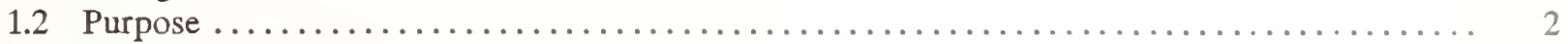

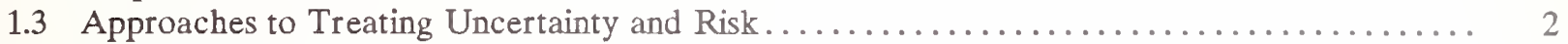

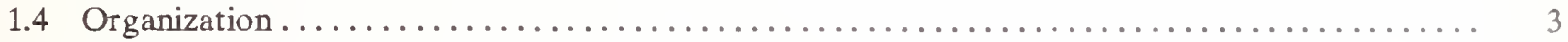

2. METHODS OF ECONOMIC ANALYSIS AND PROBLEM ILLUSTRATIONS ......... 5

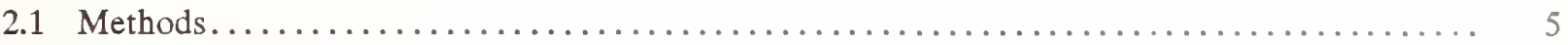

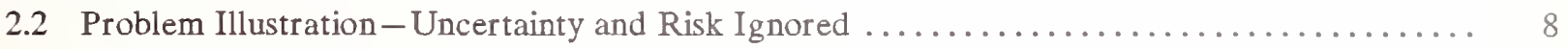

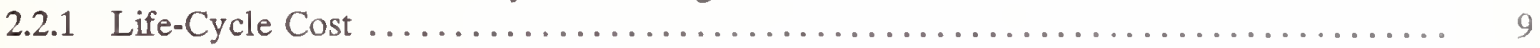

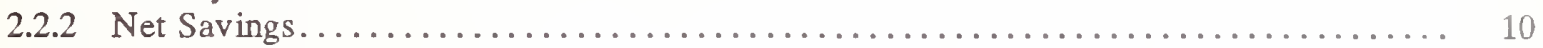

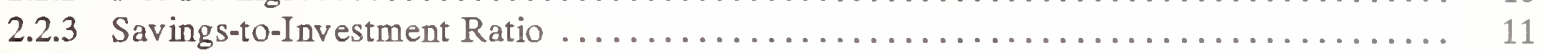

2.2.4 Adjusted Internal Rate of Return............................. 11

3. RISK EXPOSURE AND RISK ATTITUDE............................. 13

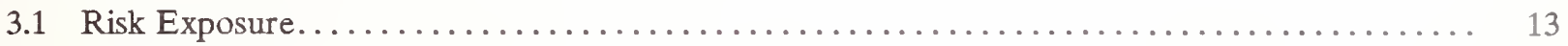

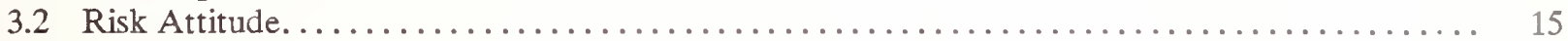

4. TECHNIQUES THAT DO NOT USE PROBABILITY .................... 23

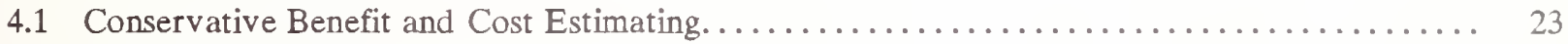

4.2 Breakeven Analysis . . . . . . . . . . . . . . . . . . . . . . . . . . . . . 23

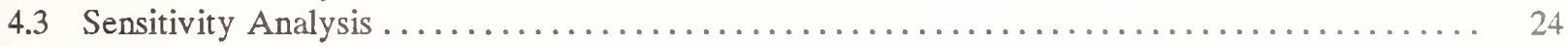

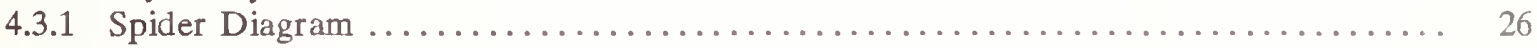

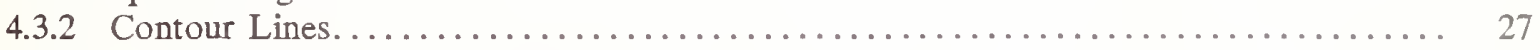

4.3.3 Spider Diagrams for Competing Projects ......................... 29

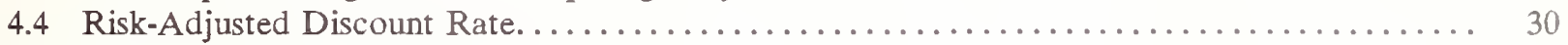

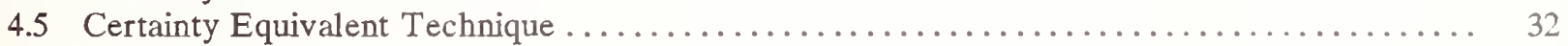

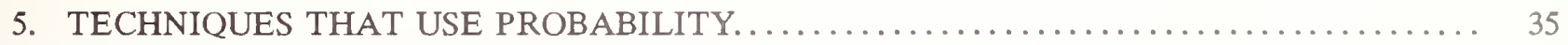

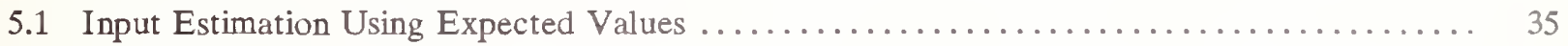

5.2 Mean-Variance Criterion and Coefficient of Variation ......................... 36

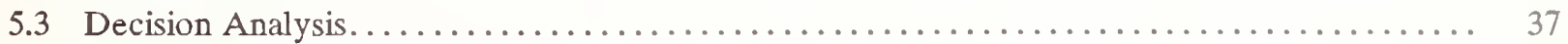

5.3.1 Decision Analysis of Energy Conservation Investment ................. 37

5.3.2 Advantages and Disadvantages of Decision Analysis ................... 41

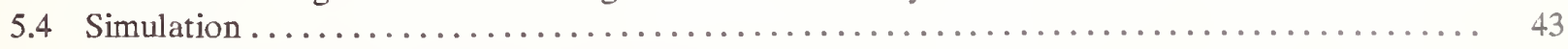

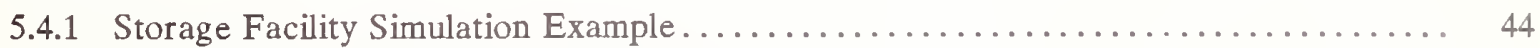

5.4.2 Construction Contingency Simulation Example.................... 52

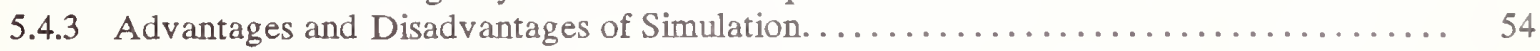

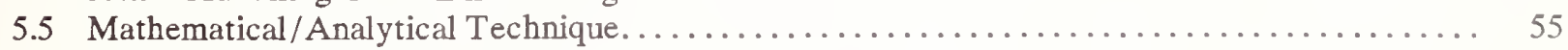

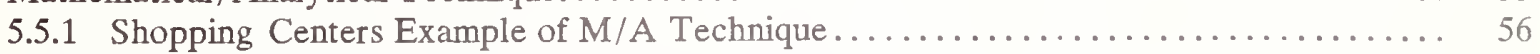

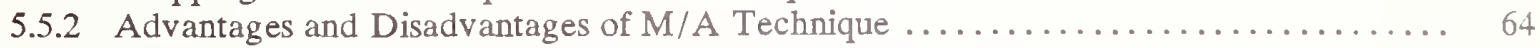

5.5.3 M/A Technique Used with the CEF and RADR Techniques ............... 65

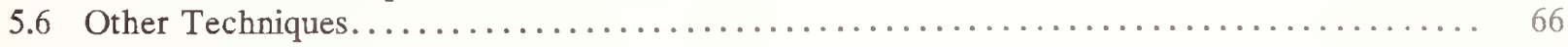

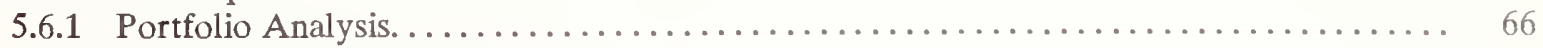

5.6.2 Capital Asset Pricing Model ................................ 67

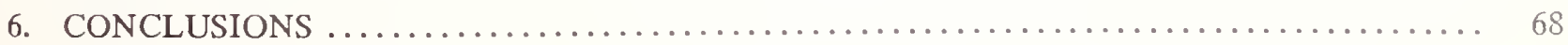


APPENDIX A. Formulas for Calculating Economic Measures..................... 73

APPENDIX B. Constructing a Utility Function.............................. 75

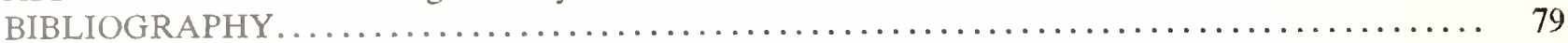

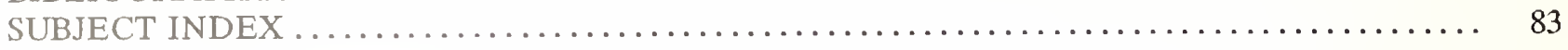




\section{LIST OF TABLES}

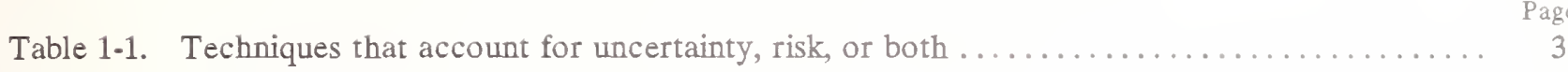

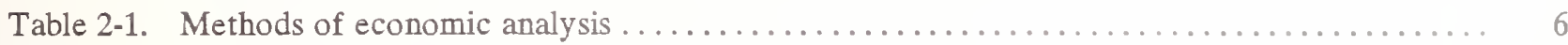

Table 2-2. Examples of building investment decisions that are evaluated with economic analysis.... 7

Table 2-3. Data for evaluating new-technology building component..................... 9

Table 4-1. A firm's certainty equivalent factor table for use in adjusting net cash flows from

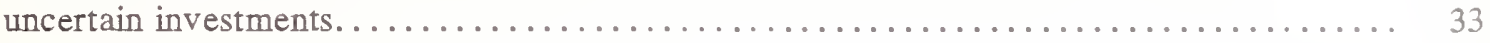

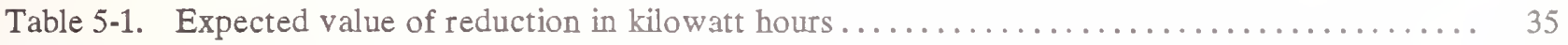

Table 5-2. Fixed investment and retrofit package cost for buildings I and II............. 38

Table 5-3. Possible benefit outcomes and their estimated probabilities of occurrence for the six

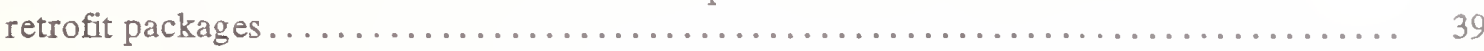

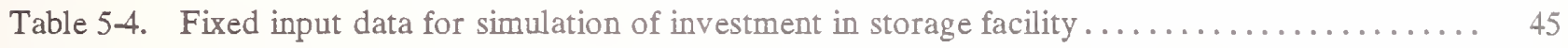

Table 5-5. Assumptions for the economic evaluation of the limited-partnership shopping centers..... 56

Table 5-6. Probability distributions and means, by year, for net cash flows from shopping centers.... 58

Table 5-7. Standard deviations, by year, for net cash flows from shopping centers ........... 60

Table 5-8. Data for constructing probability density function of present value net cash flows

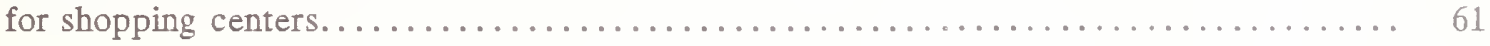

Table 5-9. Data for constructing cumulative distribution function of present value net cash

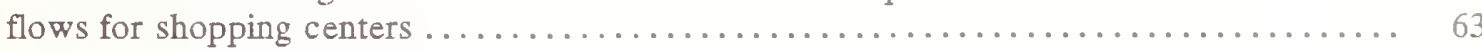

Table 6 -1. Characteristics of techniques for treating uncertainty and risk................ 69

Table A-1. Formulas useful for measuring the economic worth of building investments .......... 73

Table B-1. Data for plotting utility functions $\ldots \ldots \ldots \ldots \ldots \ldots \ldots \ldots \ldots \ldots \ldots \ldots \ldots \ldots \ldots \ldots \ldots \ldots$ 


\section{LIST OF FIGURES}

Figure 3 1 - Probability destribution of

Figure 3-2. Cumulative distribution function of benefit-to-cost ratio $\ldots \ldots \ldots \ldots \ldots \ldots \ldots \ldots$

Figure 3-3. Probability density functions of benefit-to-cost ratio for projects A and B ....... 16

Figure 3-4. Cumulative distribution functions of benefit-to-cost ratio for projects A and B ..... 17

Figure 3-5. Intermingled probability density functions of benefit-to-cost ratio for projects C

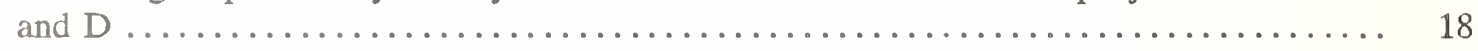

Figure 3-6. Cumulative distribution functions of benefit-to-cost ratio for projects C and D ..... 18

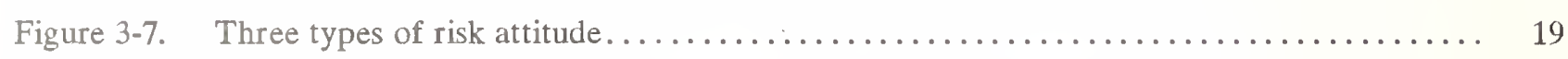

Figure 3-8. Utility function showing both risk averse (RA) and risk taking (RT) attitudes....... 21

Figure 4-1. Sensitivity of net benefits of projects A and B to discount rate............. 25

Figure 4-2. Spider diagram showing sensitivity of the adjusted internal rate of return to variations

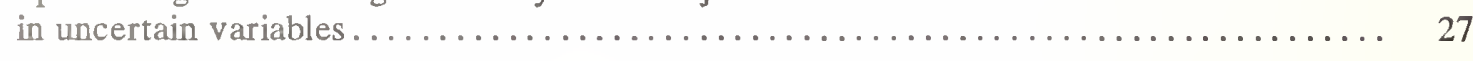

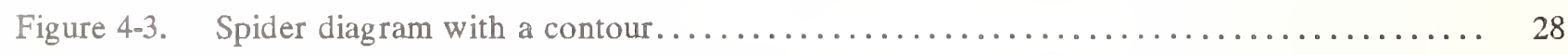

Figure $4-4$. Spider diagrams for competing projects........................... 29

Figure $5-1 . \quad$ Decision tree for conservation investment $\ldots \ldots \ldots \ldots \ldots \ldots \ldots \ldots \ldots \ldots \ldots \ldots .40$

Figure 5-2. Probability distribution of net benefits for alternative outcomes from R2 ....... 42

Figure 5-3. Cumulative distribution function of net benefits for alternative outcomes from R2 .... 43

Figure 5-4. Probability density function of number of units rented $\ldots \ldots \ldots \ldots \ldots \ldots \ldots \ldots \ldots$

Figure 5-5. Probability density function of present value operating costs.............. 46

Figure 5-6. Probability density function of present value resale price $\ldots \ldots \ldots \ldots \ldots \ldots \ldots \ldots \ldots$

Figure 5-7. Probability density function of present value of land preparation and construction

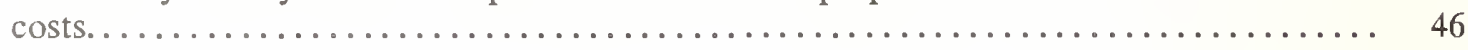

Figure 5-8. Cumulative distribution function of net benefits for the storage facility.......... 49

Figure 5-9. Cumulative distribution function of benefit-to-cost ratio for the storage facility....... 50

Figure 5-10. Cumulative distribution function of adjusted internal rate of return for the storage

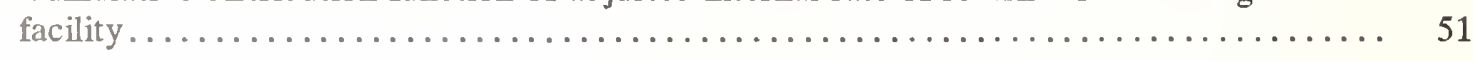

Figure 5-11. Two cumulative distribution functions of net benefits for the storage facility....... 52

Figure $5-12$. Contingency/risk graph for construction project $\mathrm{X} \ldots \ldots \ldots \ldots \ldots \ldots \ldots \ldots \ldots \ldots \ldots$ 
Figure 5-13. Probability density function of present value net cash flows for shopping centers....... 62

Figure 5-14. Cumulative distribution function of present value net cash flows for shopping centers... 63

Figure B-1. Three types of risk attitude: data and fitted functions $\ldots \ldots \ldots \ldots \ldots \ldots \ldots \ldots \ldots$ 


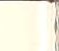




\section{INTRODUCTION}

\subsection{Background}

Investments in long-lived projects such as buildings are characterized by uncertainties regarding project life, operation and maintenance costs, revenues, and other factors that affect project economics. Since future values of these variable factors are generally not known, it is difficult to make reliable economic evaluations.

The traditional approach to project investment analysis is to apply economic methods of project evaluation to "best estimates" of project input variables as if they were certain estimates and then to present results in single-value, deterministic terms. When projects are evaluated without regard to uncertainty of inputs to the analysis, decision makers have insufficient information to measure and evaluate the risk of investing in a project having a different outcome from what is expected.

Although the technical literature treats uncertainty and risk analysis extensively, ${ }^{2}$ a recent survey shows that applications are still far behind theoretical capabilities. ${ }^{3}$ Several reasons might be hypothesized for this lag in implementation. First, practicing analysts anticipate high costs and time-consuming analyses in evaluating risk. Yet computers reduce considerably the costs and time for risk analysis. Second, analysts are concerned about the lack of data. The more uncertain the input data, however, the more helpful it would be to account for the uncertainty and to evaluate the associated risk. Third, decision makers, particularly top managers in corporations or government agencies, are reluctant to accept these techniques because they are not confident that the techniques will help them make better decisions. This reluctance may stem in part from a lack of understanding of the techniques. A comprehensive examination of the different approaches to treating uncertainty and risk in project evaluation would show how the application of risk analysis techniques to uncertain data can improve management decision making.

This report is intended as the basis for a new ASTM standard on how to account for uncertainty and risk in economic evaluations of buildings and building components. The approach is tutorial and relatively comprehensive to build understanding of the appropriate concepts and techniques among engineers,

${ }^{2}$ See, for examples, W. Fellner, Probability and Profit (Homewood, Illinois: Richard D. Irwin, Inc., 1965); Frank H. Knight, Risk, Uncertainty, and Profit (New York, New York: Harper and Row, 1965); D. Hertz, "Risk Analysis in Capital Investment," Harvard Business Review, January 1964, pp. 95-106; E. C. Capen, "The Difficulty of Assessing Uncertainty," Journal of Petroleum Technology, August 1976, pp. 843850; Michael W. Curran, "Range Estimating for Plaudits and Profits," Baltimore Engineer, April 1986, pp. 6-8; Raymond P. Lutz and Harold A. Cowles, "Estimation Deviations: Their Effect Upon the Benefit-Cost Ratio," The Engineering Economist, Vol. 16, No. 1, pp. 22-42; F. J. Weston and E. F. Brigham, Managerial Finance (Hinsdale, Illinois: The Dryden Press, 1981); T. Au and T. P. Au, Engineering Economics for Capital Investment Analysis (Boston, Massachusetts: Allyn and Bacon, Inc., 1983); J. J. Clark, T. J. Hindelang, and R. E. Pritchard, Capital Budgeting: Planning and Control of Capital Expenditures (Englewood Cliffs, New Jersey: Prentice-Hall, Inc., 1984); Jack Hirshleifer and David L. Shapiro, "The Treatment of Risk and Uncertainty," ed. Robert Haveman and Julius Margolis, 2nd ed., Public Expenditure and Policy Analysis, 1977, pp. 180-203; J. E. Matheson and R. A. Howard, "An Introduction to Decision Analysis," Readings in Decision Analysis (Menlo Park, California: Stanford Research Institute, 1977, pp. 7-43); and Howard Raiffa, Decision Analysis: Introductory Lectures on Choices Under Uncertainty (Reading, Massachusetts: Addison-Wesley, 1970).

${ }^{3}$ See, for examples, Suk H. Kim and Edward J. Farragher, "Current Capital Budgeting Practices," Management Accounting, June 1981, pp. 26-28; Edward J. Farragher, "Capital Budgeting Practices of NonIndustrial Firms," The Engineering Economist, Vol. 31, No. 4, Summer 1986, p. 298; and C. Gurnani, "Capital Budgeting: Theory and Practice," The Engineering Economist, Vol. 30, No. 1, Fall 1984, pp. 32-33. 
architects, and economists of the American Society for Testing and Materials (ASTM) Subcommittee who will develop the new standard. The report is also intended for professionals, educators, students, and managers who are interested in applying these techniques to the economic evaluation of buildings.

\subsection{Purpose}

The report has two purposes. The first is to describe in depth various techniques for treating uncertainty and risk in project evaluation. The second is to describe advantages and disadvantages of each technique to help the decision maker choose an appropriate one for a given problem.

Although the focus is on buildings and building components, the techniques described in this report are equally applicable to non-building investments. These same principles apply in the evaluation of any capital budget expenditure whose future stream of benefits, revenues, savings, or costs is uncertain.

\subsection{Approaches to Treating Uncertainty and Risk}

The numerous treatments of uncertainty and risk that appear in the technical literature come from various fields including decision analysis, finance, statistics, and economics. For example, the financial literature defines business risk, investment risk, portfolio risk, cataclysmic risk, financial risk, systematic risk, and unsystematic risk.

For purposes of this paper, however, uncertainty and risk are defined as follows. Uncertainty (or certainty) refers to a state of knowledge about the variable inputs to an economic analysis. If the analyst is unsure of input values, there is uncertainty. If the analyst is sure, there is certainty. Sensitivity analysis is an example of a technique that accounts for uncertainty. It provides a range of measures of project worth that corresponds to a range of possible input values.

Risk refers either to risk exposure or risk attitude. Risk exposure is the probability of investing in a project that will have a less favorable economic outcome than what is desired (the target) or from what is expected. ${ }^{4}$ Probability distributions of measures of project worth describe risk exposure. Simulation is an example of a technique that can be used to build probability distributions that show risk exposure.

Risk attitude, also called risk preference, is the willingness of a decision maker ${ }^{5}$ to take a chance or gamble on an investment of uncertain outcome. The implications of decision makers having different risk attitudes is that a given investment of known risk might be economically acceptable to an investor who is a risk taker, but totally unacceptable to another investor who is risk averse. Decision analysis is an example of a technique that uses utility functions to account for risk attitude.

Table 1-1 presents 10 techniques for treating uncertainty and risk described in this report. All of the techniques account in some way for uncertainty in input values, but not all treat risk. Furthermore, not all of the techniques in table 1-1 that account for risk treat both risk exposure and risk attitude.

Also included in the report, but not shown in table 1-1, are some techniques for evaluating risk and return used in managing stock portfolios. These hold some promise as techniques for evaluating portfolios of building assets.

${ }^{4}$ The risks listed earlier from the financial literature are in the risk-exposure category. Many applications of risk analysis treat exposure risk exclusively.

${ }^{5}$ A decision maker or investor can be an individual (e.g., chief executive officer) or a group (e.g., board of directors). 
No single technique in table 1-1 can be labeled the "best" technique in every situation for treating uncertainty, risk, or both. What is best depends on the following: availability of data, availability of resources (time, money, expertise), computational aids (e.g., computer services), user understanding, ability to measure risk exposure and risk attitude, risk attitude of decision makers, level of risk exposure of the project, and size of the investment relative to the institution's portfolio.

Table 1-1. Techniques that account for uncertainty, risk, or both

\author{
1. Conservative Benefit and Cost \\ Estimating \\ 2. Breakeven Analysis \\ 3. Sensitivity Analysis \\ 4. Risk-Adjusted Discount Rate \\ 5. Certainty Equivalent Technique
}

6. Input Estimation Using Expected Values

7. Mean-Variance Criterion and Coefficient of Variation

8. Decision Analysis

9. Simulation

10. Mathematical/Analytical Technique

\title{
1.4 Organization
}

Chapter 2 introduces four common economic methods for evaluating building investments: life-cycle costing; net benefits or net savings; benefit-to-cost ratio or savings-to-investment ratio; and adjusted internal rate of return. Appropriate applications for each are specified. Widespread use of the methods in building evaluations is documented.

An investment problem is analyzed using each of the four methods in the simple, deterministic approach to capital investment analysis in which uncertainty and risk are ignored in the formal analysis. These problem examples are presented for two reasons. First, they introduce the methods to readers who are not familiar with them. This is important because these are the methods with which the techniques for treating uncertainty and risk are later illustrated. Second, the examples of the methods with no treatment of uncertainty and risk provide a baseline against which advantages and disadvantages of the 10 techniques listed in table 1-1 can be compared. (Readers familiar with the four economic methods and their appropriate applications may prefer to pass over chapter 2.)

Chapter 3 provides statistical and economic bases for interpreting the techniques for treating uncertainty and risk. First, it explains the concept of risk exposure and how it can often be quantified with cumulative distribution functions and statistical measures of dispersion. Then it introduces the concept of risk attitude and describes how utility functions can be used to assign values to project outcomes that reflect decision makers' attitudes toward risk taking.

The 10 techniques for treating uncertainty and risk are presented in chapters 4 and 5 . Chapter 4 focuses on techniques that treat uncertainty and/or risk with single- or multiple-value data. Chapter 5 focuses on techniques that employ probability distributions of data. In each chapter the techniques are presented generally in order of increasing complexity. Advantages and disadvantages are described for each technique. 
Chapters 4 and 5 also provide case examples of building investment problems that illustrate specific techniques for treating uncertainty and risk. Since relatively brief treatments are given to the theory underlying each technique, case examples are relied upon in part to explain the techniques. Actual project data and typical building problems are used to some extent to provide "real-world" illustrations of building investment decisions. Note, however, that the economic results for any case example relate only to defined conditions and cannot be generalized for that type of investment.

Chapter 6 concludes the report with a table of comparative characteristics for all of the techniques and guidance on how to choose among the techniques. Appendix A provides a table of formulas for the four economic methods (life-cycle costing, net benefits, benefit-to-cost ratio, and adjusted internal rate of return) with which risk analysis might properly be applied. And appendix B explains and illustrates the process of deriving a utility function for measuring risk attitude. 


\section{METHODS OF ECONOMIC ANALYSIS AND PROBLEM ILLUSTRATIONS}

This chapter describes four standard methods of economic analysis and their use in the private and public sectors. It also provides numerical illustrations of each method applied to a building investment problem. The techniques for treating uncertainty and risk described in chapters 4 and 5 are used in conjunction with these economic methods. Thus an understanding of the methods is necessary to use the techniques described in chapters 4 and 5. The numerical illustrations also make clear the deterministic nature of typical applications of the methods.

\subsection{Methods}

Table 2-1 lists four common methods ${ }^{6}$ used in evaluating capital investment projects, the unit measure of project worth used for each of the methods, and the appropriate applications for each. ${ }^{7}$ These traditional methods are used in evaluating four basic types of building decisions: accepting or rejecting a given building investment, choosing the cost-effective design of a building or component, choosing the costeffective size of a building or component, and choosing the economically efficient combination of projects competing for a limited budget. Examples of some of these types of decisions for the building industry are given in table 2-2.

Both industry and government use the methods in table 2-1 for making building (as well as non-building) investment decisions. For example, the American Society for Testing and Materials (ASTM), with over 30,000 members representing industry, government, and academia, has published through its building economics subcommittee standard practices for each of the methods in table 2-1.8 Professional societies, such as the American Institute for Architects (AIA) ${ }^{9}$ and the American Society of Heating, Refrigerating, and Air Conditioning Engineers (ASHRAE) ${ }^{10}$ also have published guidelines for making economic evaluations of buildings and building components using methods listed in table 2-1.

Federal, state, and local government agencies use the economic methods in the analysis of building design and operation. The Department of Energy was directed by Executive Order and legislation to provide "practical and effective" methods and procedures to Federal agencies for estimating life-cycle costs and savings of proposed energy conservation and renewable energy projects and for comparing their cost effectiveness in a uniform and consistent manner among agencies. ${ }^{11}$ These methods and procedures were developed for the Department of Energy at the National Institute of Standards and Technology. ${ }^{12}$ They are now being applied to more than 400,000 Federal buildings.

${ }^{6}$ Those readers who are familiar with the methods described in table 2-1 may prefer to go directly to chapter 3.

${ }^{7}$ Payback period is left out because it is not an appropriate technique for making many kinds of investment decisions.

${ }^{8}$ American Society for Testing and Materials, Annual Book of Standards, Vol. 04.07 (Philadelphia, Pennsylvania: ASTM, 1987).

${ }^{9}$ See Harold E. Marshall and Rosalie T. Ruegg, Simplified Energy Design Economics: Principles of Economics Applied to Energy Conservation and Solar Energy Investments in Buildings, National Bureau of Standards Special Publication 544, Reprinted by American Institute of Architects, January 1980.

${ }^{10}$ American Society of Heating, Refrigerating and Air-Conditioning Engineers, Inc., "Life-Cycle Costing," ASHRAE Handbook, Chapter 42 (Atlanta, Georgia: ASHRAE, 1984).

${ }^{11}$ U.S. Congress, National Energy Conservation Policy Act, November 1978, Title V, Part 3, Sec. 545(a).

${ }^{12}$ See Rosalie T. Ruegg, Life-Cycle Costing Manual for the Federal Energy Management Program. National Bureau of Standards Handbook 135 (Rev. 1987), November 1987, and Rosalie T. Ruegg and Stephen R. Petersen, Comprehensive Guide for Least-Cost Energy Decisions, National Bureau of Standards Special Publication 709, January 1987 for these methods and procedures. 
Table 2-1. Methods of economic analysis ${ }^{\mathrm{a}}$

Unit Measure

of Worth

Applications

(1) Life-Cycle Cost (LCC)

and

(2) Net Savings (NS)

$\$$

$\$$

* Determine if a project should be accepted,

* Choose the size or scale of a project, and

or

Net Benefits (NB)

$\$$

* Choose among alternative project designs competing for a given purpose.

(3) Benefit-to-Cost (BCR)

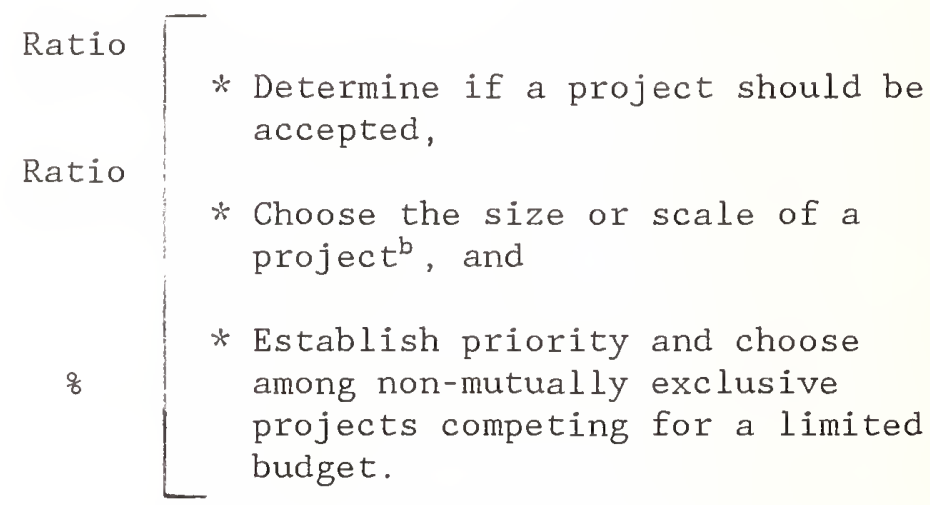

(4) Adjusted Internal Rate of Return (AIRR) ${ }^{\mathrm{c}}$

$$
\text { or }
$$

Savings - to-Investment (SIR)

$$
\text { and }
$$

a See appendix A for formulas for these methods.

bFor this application, marginal BCRs (SIRs) or AIRRs are required.

cThe internal rate of return adjusted for reinvestments of investment earnings at explicit rates is used throughout this report. This differs from the traditional internal rate of return which makes the unlikely assumption that reinvestments achieve the same rate earned on the original investment. For a comparison of the adjusted and traditional internal rates of return, see Marshall, Harold E., "Advantages of the Adjusted Rate of Return," Cost Engineering, Vol. 28, No. 2, February 1986, pp. 32-37. 
Table 2-2. Examples of building investment decisions that are evaluated with economic analysis

Type of Decision

Example

Acceptance/Rejection

* Will the purchase of a particular rental warehouse be profitable?

* Is a time clock system for managing HVAC equipment cost effective?

* Is a solar hot water system cost effective?

* Is a fire sprinkler system cost effective?

* Will insulation be cost effective for a water heater?

Design

* Which heating system among several alternatives is most cost effective?

* Which plumbing system is most cost effective?

* What kind of insulation (e.g., foam, fiberglass, cellulose) is most cost effective?

* Is single, double, or triple glazing most cost effective?

* Which floor finish (e.g., carpeting, tile, wood) is most cost effective?

* Which wall type (e.g., masonry, wood frame, curtain wall) is most economical?

Size

* What is the economically efficient level (R-value) of insulation in the walls and above the ceiling of a house?

* How many square feet of collector area and what storage volume should be provided for a solar energy system?

Priority

* What combination of investments in a given building (e.g., new water heater, new floor tile, and new lighting system) is economically preferred when each is justifiable on economic grounds, but insufficient funds are available to pay for all of them? 
The General Services Administration, responsible for providing all Federal space, uses the life-cycle cost (LCC) economic method in routine investments as well as in determining whether to build or lease new space. State and local government agencies are also implementing economic evaluation methods both for facilities and procurement. Twenty-six states were using economic evaluation methods by $1981 .{ }^{13}$

Risk exposure and risk attitude are seldom treated in these public evaluations. The ASTM recommended practices, the Department of Energy guidelines, and the state and local government procedures, however, do treat uncertainty in that they recommend sensitivity analysis.

The absence of risk analysis in practice does not suggest any shortcoming in the economic methods described in table 2-1. The methods are generally well known and accepted. The possible weakness in capital investment analysis in practice is in failing to account adequately for uncertainty and risk when using the methods, thereby giving decision makers an incomplete economic picture. The following problem illustrates typical applications of economic methods without consideration of uncertainty and risk.

\subsection{Problem Illustration - Uncertainty and Risk Ignored}

An economic analysis is presented for determining if a new-technology building component should be accepted. The component could be a new kind of roofing system, a new type of heating/cooling element, or any other item that is being considered either for a new building or for a building retrofit. The newtechnology component is evaluated with each of the four economic methods listed in table 2-1: life-cycle cost (LCC), net savings (NS), savings-to-investment ratio (SIR), and adjusted internal rate of return (AIRR). The formulas for computing the economic measures are based on those in appendix A. With the exception of eq (2.4) for the AIRR, however, all equations in chapter 2 are expressed in a slightly different form from appendix A to allow the use of discount factors in calculating present values of specific costs and benefits.

Table 2-3 lists the assumptions for the building problem to which the four economic methods will be applied. The new-technology component costs $\$ 6,000$ more than the existing-technology alternative, but saves $\$ 500$ annually in maintenance. The new-technology component is expected to last at least 20 years, the study period for the analysis, while the existing-technology component is expected to last only 10 years. Thus no replacements are required for the new-technology component, but one replacement at the end of 10 years can be expected for the existing-technology component. No salvage value is expected for either component. All costs are expressed in constant dollars. The real discount rate and minimum acceptable rate of return (MARR) are 10 percent. The analysis is for a public building, so taxes need not be considered. 14

It is assumed that the components perform equally well. Thus the problem is to determine if it is cost effective to invest an additional $\$ 6,000$ for a new-technology component in order to avoid extra replacement and annual maintenance costs required by installing the existing-technology component. Table 2-1 indicates this acceptance/rejection problem to be an appropriate application for any of the four methods.

${ }^{13}$ Alphonse Dell'Isolla and Stephen J. Kirk, Life-Cycle Costing for Design Professionals (New York, New York: McGraw-Hill, 1981), p. 174.

${ }^{14}$ Taxes should be included in an economic analysis if the building is owned by a tax-paying institution because taxes typically play a significant role in the building's economic performance. Taxes are not included for most of the examples here in order to simplify and focus on exposition of the methods and techniques. In section 5.4.1 on simulation, however, a comprehensive analysis including tax effects is presented to illustrate how an after-tax treatment is done. 
Table 2-3. Data for evaluating new-technology building component ${ }^{2}$

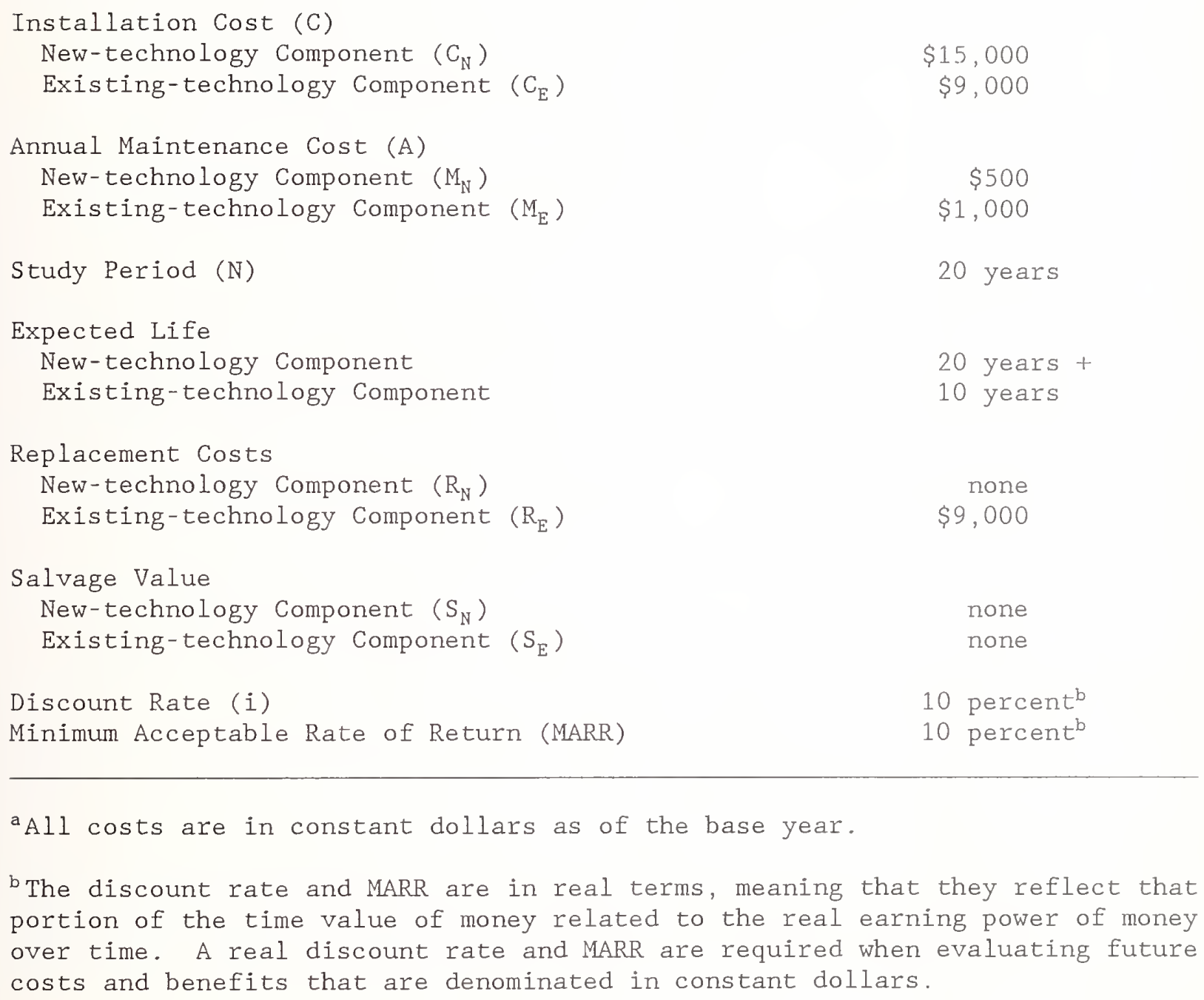

${ }^{a}$ All costs are in constant dollars as of the base year.

b The discount rate and MARR are in real terms, meaning that they reflect that portion of the time value of money related to the real earning power of money over time. A real discount rate and MARR are required when evaluating future costs and benefits that are denominated in constant dollars.

\subsubsection{Life-Cycle Cost}

The LCC is calculated for the existing-technology and new-technology components using eq (2.1), where all amounts have been converted to present values. The cost-effective component will be the one with the lower LCC.

$\mathrm{LCC}=\mathrm{C}+\mathrm{R}+\mathrm{A}$

where $\mathrm{LCC}=$ present value of life cycle costs,

$\mathrm{C}=$ present value of installation costs,

$\mathrm{R}=$ present value of replacement costs, and

$A=$ present value of maintenance, repair, and other annual costs. 
Since C occurs at the base time, it is already in present value terms. Since R occurs in the future, it has to be discounted to present value. Maintenance, repair, and other costs occurring on an annual basis must be converted to present values. The following calculations take the time value of money into consideration in arriving at the $\mathrm{LCC}$ of the existing-technology component $\left(\mathrm{LCC}_{\mathrm{E}}\right)$ and of the new-technology component $\left(\mathrm{LCC}_{\mathrm{N}}\right)$.

$$
\begin{aligned}
\mathrm{LCC}_{\mathrm{E}} & =\mathrm{C}_{\mathrm{E}}+\mathrm{R} \\
& =\$ 9,000+\left(\mathrm{RPV}_{\mathrm{N}}=10, \mathrm{i}=10 \%\right)(\$ 9,000)+\left(\mathrm{UPV}_{\mathrm{N}}=20, \mathrm{i}=10 \%\right)(\$ 1,000) \\
& =\$ 9,000+(0.3855)(\$ 9,000)+(8.514)(\$ 1,000) \\
& =\$ 9,000+\$ 3,470+\$ 8,514
\end{aligned}
$$

$\mathrm{LCC}_{\mathrm{E}}=\$ 20,984$

The LCC of using the existing-technology component is estimated to be $\$ 20,984$. Note that the word "estimate" is used. This is because typically the values of replacement, repair, maintenance, and component life are uncertain, and therefore the LCC estimate will be uncertain.

The LCC for the new-technology component is computed the same way.

$$
\begin{array}{rlrl}
\mathrm{LCC}_{\mathrm{N}} & =\mathrm{C}_{\mathrm{N}}+\mathrm{R}_{\mathrm{N}}+\mathrm{A}_{\mathrm{N}} \\
& =\$ 15,000+0 & +\left(\mathrm{UPV}_{\mathrm{N}}=20, \mathrm{i}=10 \%\right)(\$ 500) \\
& =\$ 15,000+0 & +(8.514)(\$ 500) \\
& =\$ 15,000+0 & +\$ 4,257 \\
& =\$ 19,257 &
\end{array}
$$

Since the LCC of the new-technology component is estimated to be less than that of the existingtechnology component, it appears cost effective to purchase the new-technology component.

\subsubsection{Net Savings}

Net savings (NS) can also be used to determine if the new-technology component is cost effective. ${ }^{15}$ Given that LCCs have already been calculated for the two components, the NS from using the new-technology component can be determined by subtracting the LCC with the new-technology component ( $\left.\mathrm{LCC}_{\mathrm{N}}\right)$ from the LCC with the existing-technology component (LCCE), as shown in eq (2.2).

$\mathrm{NS}=\mathrm{LCC}_{\mathrm{E}}-\mathrm{LCC}_{\mathrm{N}}$

NS $=\$ 20,984-\$ 19,257$

$\mathrm{NS}=\$ 1,727$

Since the NS for using the new-technology component instead of the existing-technology one is a positive amount, the analysis indicates the new technology to be a cost-effective investment.

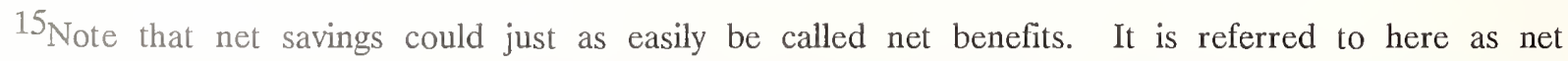
savings only because the benefits from investing in the new-technology component are in the form of maintenance and replacement savings. 


\subsubsection{Savings-to-Investment Ratio}

The savings-to-investment ratio indicates a project is cost effective if the ratio is greater than 1.0. Equation (2.3) can be used to calculate the SIR.

$\operatorname{SIR}=(\Delta M+\Delta R) / \Delta C$,

where $\Delta \mathrm{M}=\mathrm{M}_{\mathrm{E}}-\mathrm{M}_{\mathrm{N}}$,

$$
\begin{aligned}
& \Delta \mathrm{R}=\mathrm{R}_{\mathrm{E}}-\mathrm{R}_{\mathrm{N}}, \text { and } \\
& \Delta \mathrm{C}=\mathrm{C}_{\mathrm{N}}-\mathrm{C}_{\mathrm{E}} .
\end{aligned}
$$

If the new-technology component is cost effective, the savings it generates through reductions in maintenance and replacement costs must exceed the associated increase in initial costs (all in present value terms). The following calculation shows that the decline in $\mathrm{M}$ and $\mathrm{R}$ exceed by a factor of 1.29 the $\$ 6,000$ extra cost of the new-technology component.

$$
\begin{aligned}
\operatorname{SIR} & =((\$ 8,514-\$ 4,257)+(\$ 3,470-\$ 0)) /(\$ 15,000-\$ 9,000) \\
& =(\$ 4,257+\$ 3,470)) / \$ 6,000 \\
& =\$ 7,727 / \$ 6,000 \\
& =1.29
\end{aligned}
$$

Thus the new component is cost effective based on the SIR estimate.

\subsubsection{Adjusted Internal Rate of Return}

The last method illustrated is the adjusted internal rate of return (AIRR). The AIRR earned on the newtechnology component must be greater than the minimum acceptable rate of return (MARR) for the investment to be cost effective. Equation (2.4) can be used to calculate the AIRR.

$$
\operatorname{AIRR}=-1.0+(1+\mathrm{r})(\mathrm{BCR})^{1 / \mathrm{N}}
$$

where $r=$ the rate of return on reinvestments of cash savings, which is equal to 10 percent (the discount rate) for this problem.

The following calculation produces an AIRR of 11.4 percent. This exceeds the MARR of 10 percent and therefore suggests that the new component is cost effective.

$$
\begin{aligned}
\operatorname{AIRR} & =-1.0+(1+0.1)(1.29)^{1 / 20} \\
& =-1.0+1.1(1.0128) \\
& =0.114
\end{aligned}
$$

All four of the economic measures suggest that the project is cost effective. This is not surprising, since all four should give consistent results when properly applied. Note, however, that all of the measures are 
based on the following uncertain variables: (1) the year in which the existing-technology system is to be replaced, (2) the year in which the new-technology system is to be replaced, (3) the dollar cost of the capital replacement of the existing-technology component, (4) annual maintenance and repair costs of the existing-technology component, and (5) annual maintenance and repair costs of the new-technology component.

Variations in any of these variables from their assigned values could make the new-technology component uncconomic. For example, if the old-technology component did not have to be replaced, or the dollar costs of replacement for it were less than $\$ 9,000$, or the difference in annual maintenance costs were less than $\$ 500$, or any combination of the above, then investing in the new-technology component would be less desirable and in fact might not be cost effective. Thus it becomes apparent that using "best guess" estimates in a deterministic approach to evaluating capital investments may lead to uneconomic investment choices.

This does not mean, however, that single-value, deterministic measures of project worth are not useful. If input data and measures of worth are not expected to vary much, applying the methods without accounting for uncertainty and risk may be appropriate.

On the other hand, where wide variations in project worth are possible, and where decision makers have a strongly positive or negative attitude towards risk taking, techniques are needed to extend the methods to account for variability in measures of project worth. Chapter 3 defines risk exposure and risk attitude, shows how they can be measured, and thereby provides the basis for understanding the techniques for treating uncertainty and risk described in chapters 4 and 5. 


\section{RISK EXPOSURE AND RISK ATTITUDE}

Decision makers faced with investment choices under uncertain conditions are concerned with two aspects of risk. The first is risk exposure. It is the probability of investing in a project whose economic outcome is different from what is desired (the target) or what is expected. ${ }^{16}$ The second is risk attitude. It is the willingness of decision makers to take chances or gamble on investments of uncertain outcome. The fact that decision makers have different risk attitudes means that an investment with a given level of risk exposure might be economically acceptable to an investor who is a risk taker, but totally unacceptable to another investor who is more risk averse.

Risk analysis is the body of theory and practice that has evolved to help decision makers assess their risk exposures and risk attitudes so that the investment that is "best for them" can be selected. This section distinguishes between risk exposure and risk attitude, discusses how risk exposure can be measured with probability distributions, and describes how utility functions can be generated and used to account for risk attitude.

\subsection{Risk Exposure}

A probability distribution quantifies risk exposure by showing probabilities of achieving different economic worth values. Figure $3-1$ is a discrete probability distribution ${ }^{17}$ that shows graphically for a building investment a profile of probabilities for the benefit-to-cost ratio (BCR). Each bar of the histogram shows on the vertical axis the probability of the investment achieving the corresponding $\mathrm{BCR}$ on the horizontal axis. The mean (expected value) of the $\mathrm{BCR}$ is 2.0. This suggests that the most likely measure of worth will well exceed the 1.0 BCR that is normally regarded as the minimum hurdle necessary for project acceptance.

Other values for the BCR are possible, however, including a value less than 1.0. Having the standard deviation and mean for the distribution helps the decision maker determine the likelihood that the actual $\mathrm{BCR}$ is within acceptable bounds around the mean. The smaller the spread of the distribution, as measured by the standard deviation, the tighter the distribution is around the mean value and the smaller is the risk exposure associated with the project.

It is known that in a normal distribution the probability is 68.26 percent, 95.46 percent, and 99.73 percent respectively that the actual value will be within one, two, and three standard deviations of the mean. Assuming the discrete probability distribution in figure 3-1 approximates a normal distribution, we can estimate the probability of the BCR being within any one of the standard deviation ranges. The standard deviation for figure $3-1$ is found to be 0.72 by the following eq:

$$
\sigma=\underset{S=1}{\left(\sum\left(B C R_{S}-\mu\right)^{2} \cdot P_{S}\right)^{1 / 2},}
$$

${ }^{16}$ Measuring the probability of the project's economic worth being less than the target value reveals the risk of accepting an uneconomic project. Another type of risk exposure that some decision makers are concerned about is the probability of passing up a good investment. For example, measuring the probability of the project's economic worth being greater than the target value reveals the risk of rejecting an economic project. The risk of accepting an uneconomic project is focused on here.

${ }^{17}$ The discrete probability distribution is also called probability function and probability mass function. 


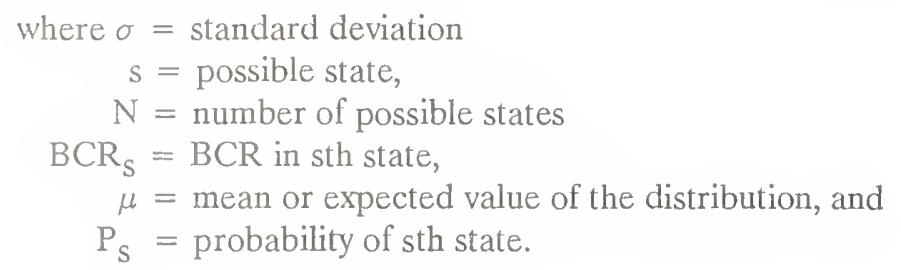

Thus we know, for example, there is a 68.26 percent probability that the BCR will lie in the range of 1.28 $(2.0-0.72)$ to $2.72(2.0+0.72)$.

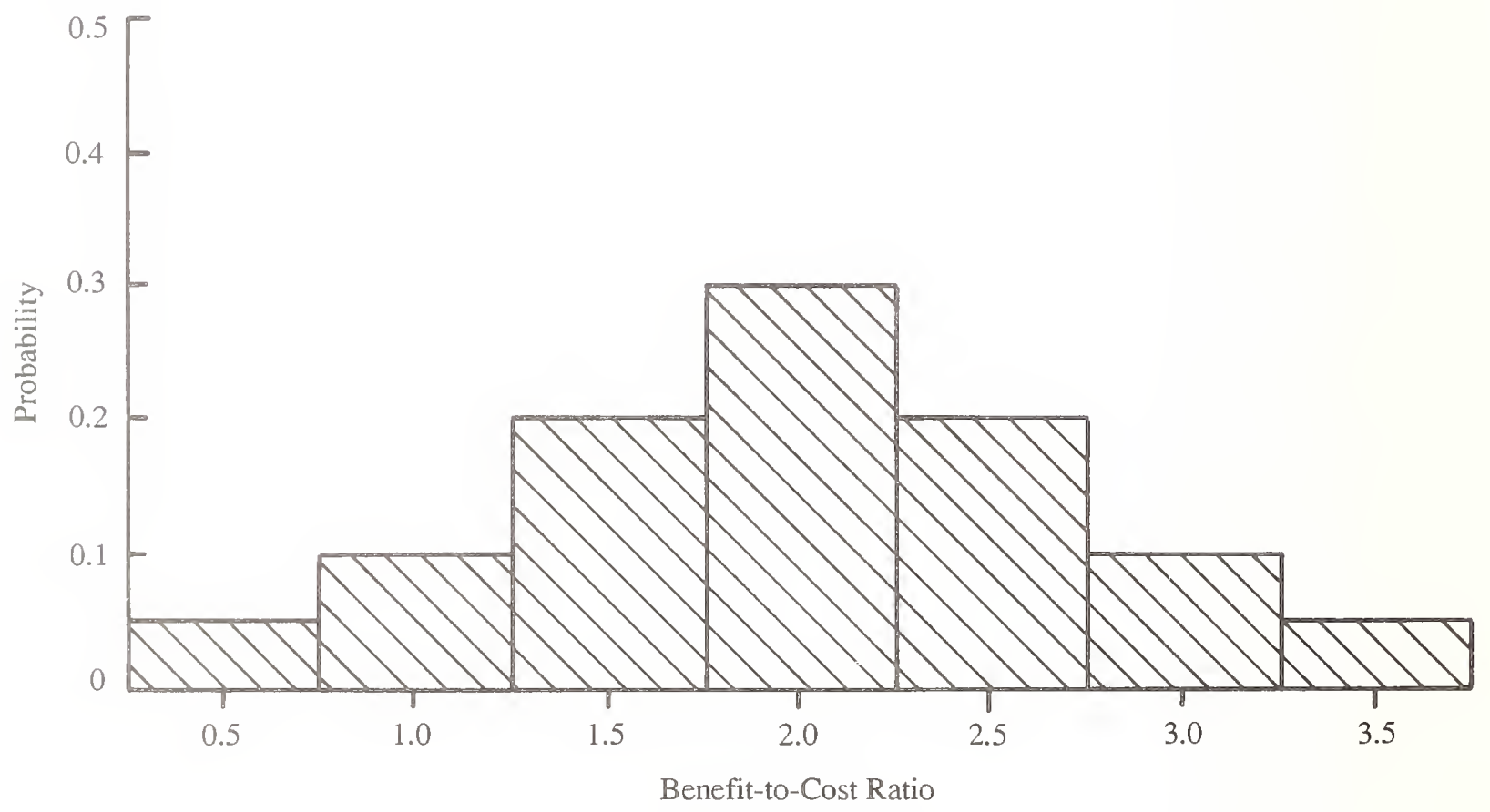

Figure 3-1. Probability distribution of benefit-to-cost ratio.

Although the probability distribution in figure 3-1 does not reveal directly the probability of choosing a project having a BCR less than some target value (say, less than the expected value of 2.0 in this case), it is easily transformed to the cumulative distribution function (cdf) in figure 3-2 which does. ${ }^{18}$ Any percent on the vertical axis in figure 3-2 is read "less than." The function relating BCRs to cumulative probabilities is upward sloping, indicating that the probability of the BCR being less than any given BCR value on the horizontal axis increases as the given BCR value increases.

The probability (or risk of exposure) of the BCR being less than 1.0 is 5 percent in figure 3-2. Or, said another way, the probability of the project earning positive net benefits or at least breaking even is 95 percent. The probability that the BCR is less than the target value (expected value) of 2.0 is 35 percent.

${ }^{18}$ See chapter 5 for a detailed description of how to build a cdf from a probability density function. 


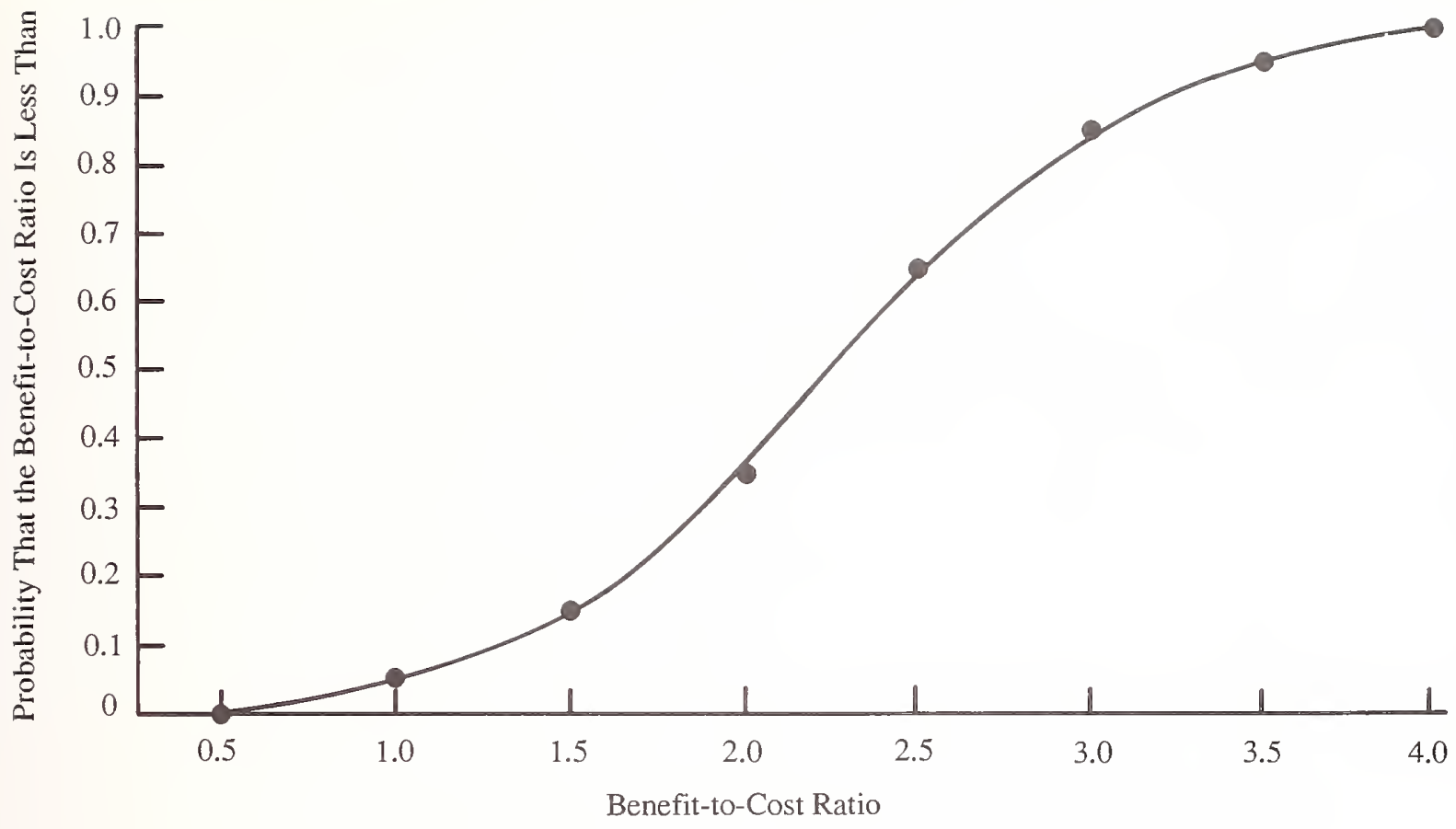

Figure 3-2. Cumulative distribution function of benefit-to-cost ratio.

Probability and distribution functions provide considerably more information about risk exposure than deterministic approaches described in chapter 2 that assume certainty and provide single-value measures of project worth. But the functions in themselves do not treat risk attitude. That is, they show only risk exposure. Different decision makers, individuals or institutions, ${ }^{19}$ may respond differently to any given profile of risk exposure. Thus, to make efficient choices when investment outcomes are uncertain, decision makers also need to consider their unique risk attitudes.

\subsection{Risk Attitude}

There are two general approaches decision makers might follow to incorporate risk attitudes in their project evaluations. First, they can examine the distribution profile, mean, and standard deviation of the measure of project worth to assess their risk exposure, and then make a decision on the basis of their subjective or intuitive perception of whether they are prepared to accept the degree of risk exposure indicated. This informal approach allows for the consideration of risk attitude, but lacks any standard procedure for measuring personal or institutional risk attitude when making a choice. For example, if the investment decision is to accept or reject a single project, this approach will often be adequate. Thus the project described by figure $3-2$ is likely to be deemed cost effective by all but the most risk averse decision makers since there is little probability of a BCR less than 1.0.

${ }^{19}$ An entity such as a corporation has a risk attitude just like an individual. To determine it, however, may be difficult. One approach is to use the risk attitude of the chief executive officer as a proxy for the corporation. Another is to use the attitude of the board of directors. 
Even where several projects are being compared, the informal approach for considering risk attitude may be adequate. Although the preferred choice may not be obvious from an examination of probability density functions ( $\mathrm{pdfs})^{20}$ for individual projects, it may become obvious when functions for alternative projects are superimposed as shown in figures 3-3 and 3-4. Here the probability profiles are a good index to project choice because project A clearly has "stochastic dominance" over project B. That is, for every BCR value in figures 3-3 and 3-4, there is as high or higher probability that project A will exceed that BCR than will project B. In other words, for every BCR, there is as high or higher probability that project B will provide a lower or equal BCR than project $\mathrm{A}$. Thus the project alternative whose function is farthest to the right is the preferred alternative. (Note that if life-cycle costs of alternatives were measured on the horizontal axis instead of BCRs, the alternative farthest to the left would be preferred because the objective function would be to minimize life-cycle costs rather than to maximize the BCR.)

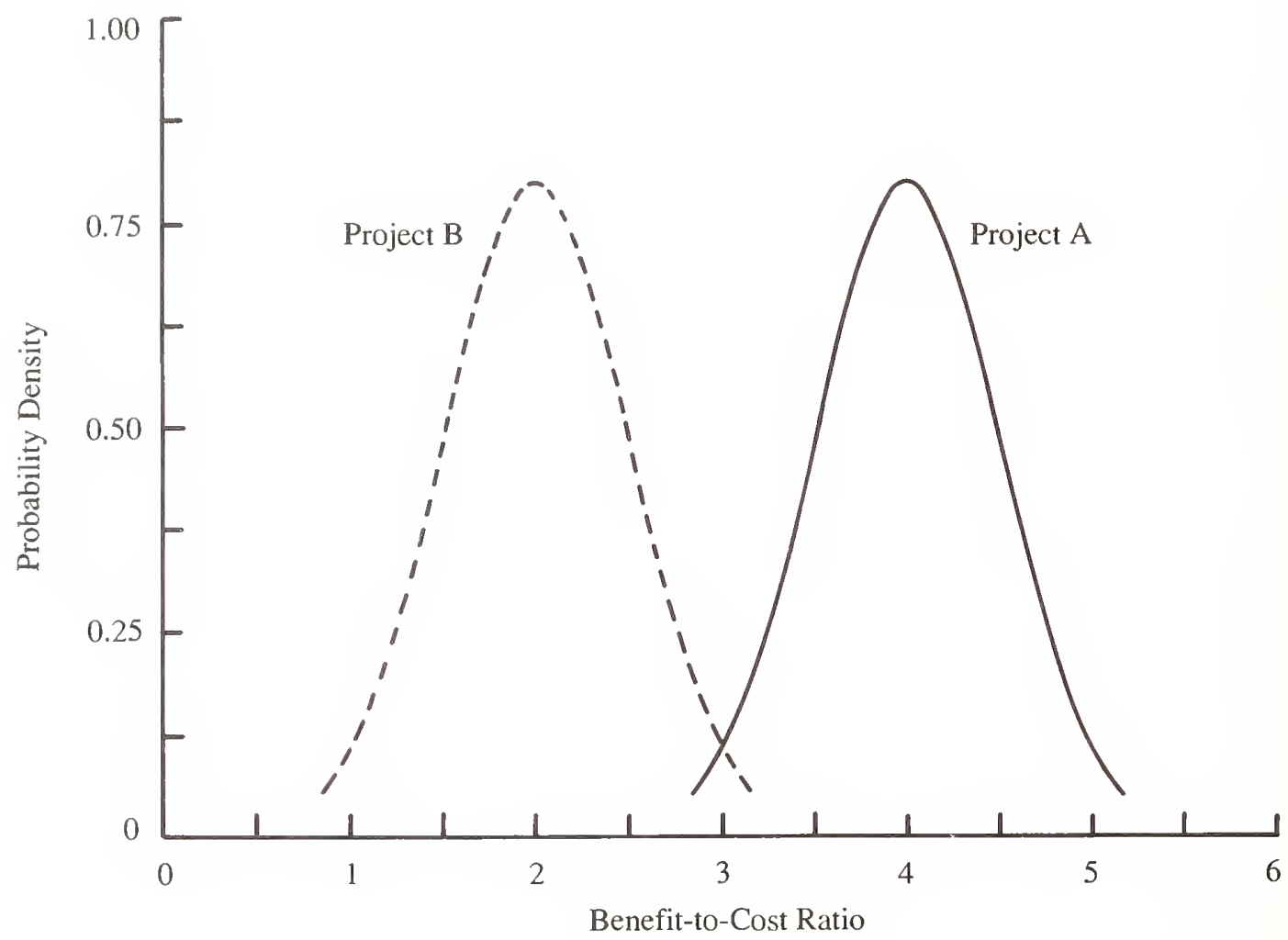

Figure 3-3. Probability density functions of benefit-to-cost ratio for projects A and B.

${ }^{20}$ The probability density function (pdf) is the derivative of a continuous, cumulative distribution function. The area under the pdf must equal 1. 


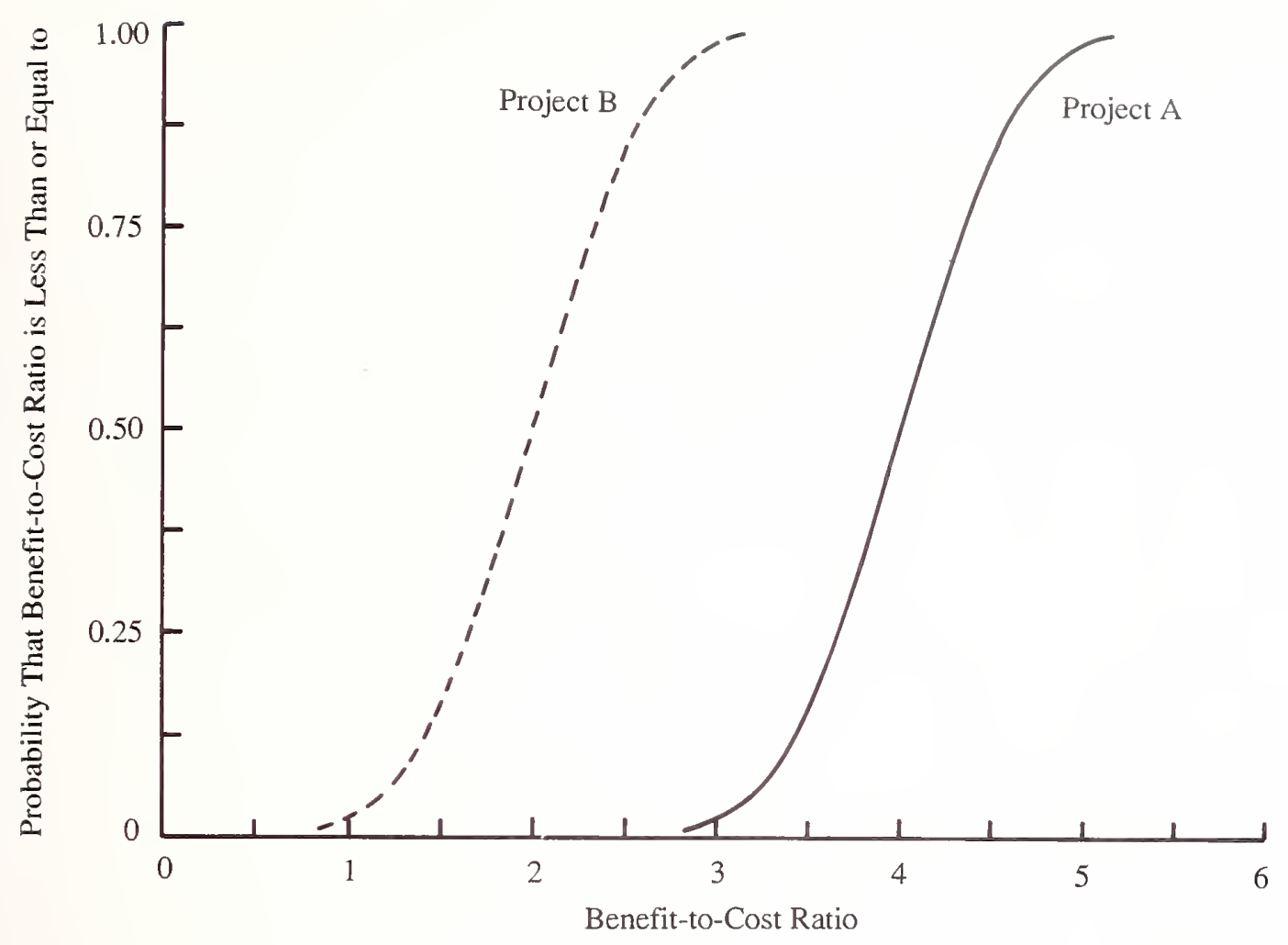

Figure 3-4. Cumulative distribution functions of benefit-to-cost ratio for projects A and B.

The second approach for considering risk attitude is considered formal because it employs a standard procedure for measuring the decision maker's attitude towards risk and then uses that measure in evaluating the economic worth of a risky project. The need for a formal technique is illustrated by the intermingled distributions shown in figures 3-5 and 3-6. Although project D has the larger mean, it also has the larger variance. That is, the project with the greater expected return also has the greater variance or risk of exposure. There is no clear indication of stochastic dominance or project preference. Some procedure for including risk attitude in project evaluation is required to establish project preference in this case.

The remainder of this chapter describes conceptually how risk attitude can be measured and interpreted through the application of utility theory. Appendix B describes in detail how to construct utility functions.

Risk attitude is measured by the tradeoffs decision makers will make between uncertain money payoffs of known probability and sure money payoffs. These tradeoffs are determined by asking decision makers to specify how much sure money (the certainty equivalent) must be received to make them indifferent between the certainty equivalent and the expected value of a given amount that is not certain. For example, if a person were given a choice between a lottery, say with a 50 percent probability of winning $\$ 1,000$ and a 50 percent probability of winning nothing, and a sure or certain amount of money, there would be some amount of that certain payment at which the decision maker would be indifferent between the lottery and the sure payment. The revealed tradeoffs between the expected value of the lottery and the sure payment determine whether a decision maker is risk neutral, risk averse, or a risk taker. Once several such tradeoffs have been specified, a relationship between money and utility can be determined. ${ }^{21}$

${ }^{21}$ Utility here means simply the satisfaction a decision maker receives from given quantities of money. 


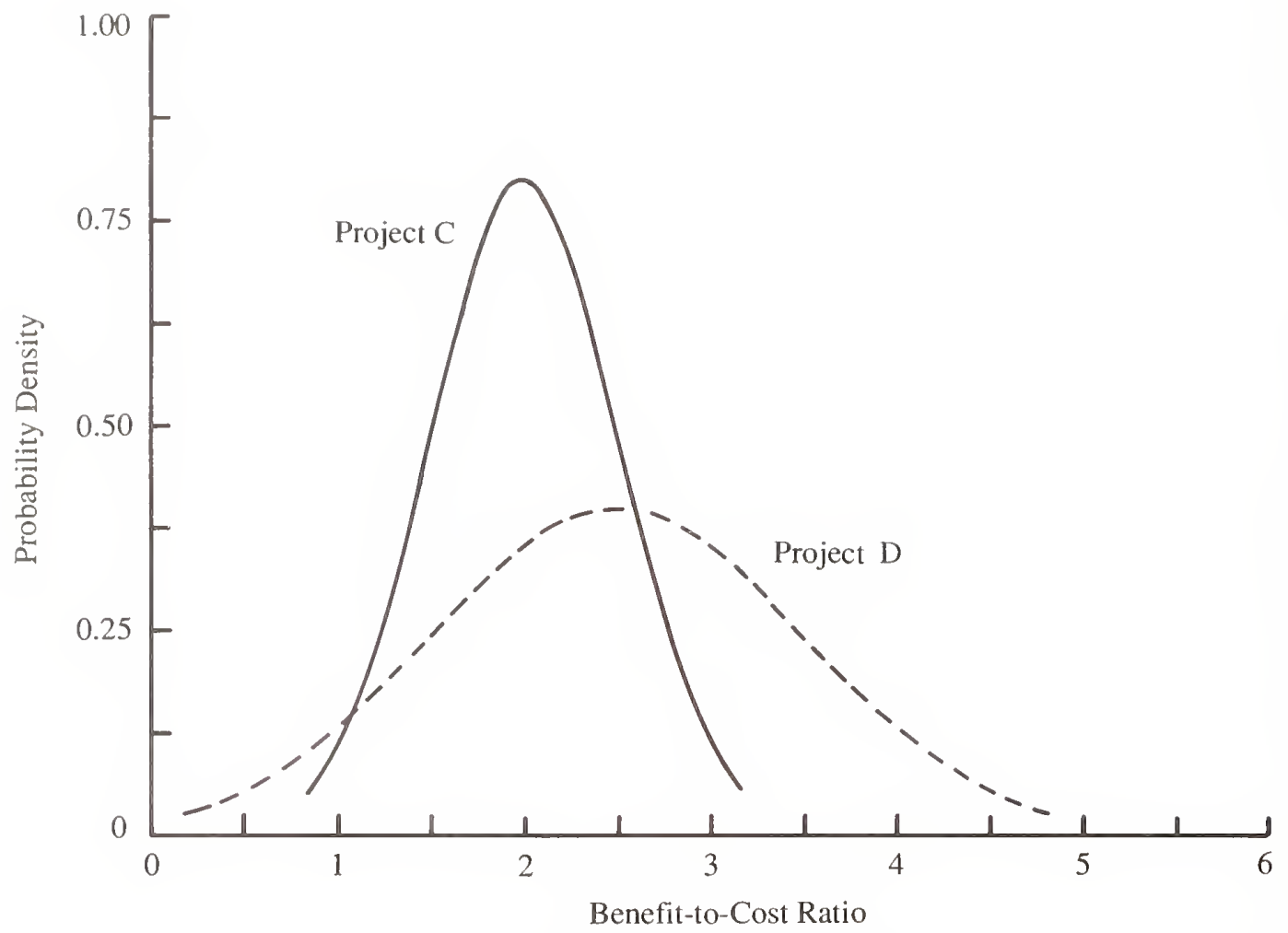

Figure 3-5. Intermingled probability density functions of benefit-to-cost ratio for projects $\mathrm{C}$ and D.

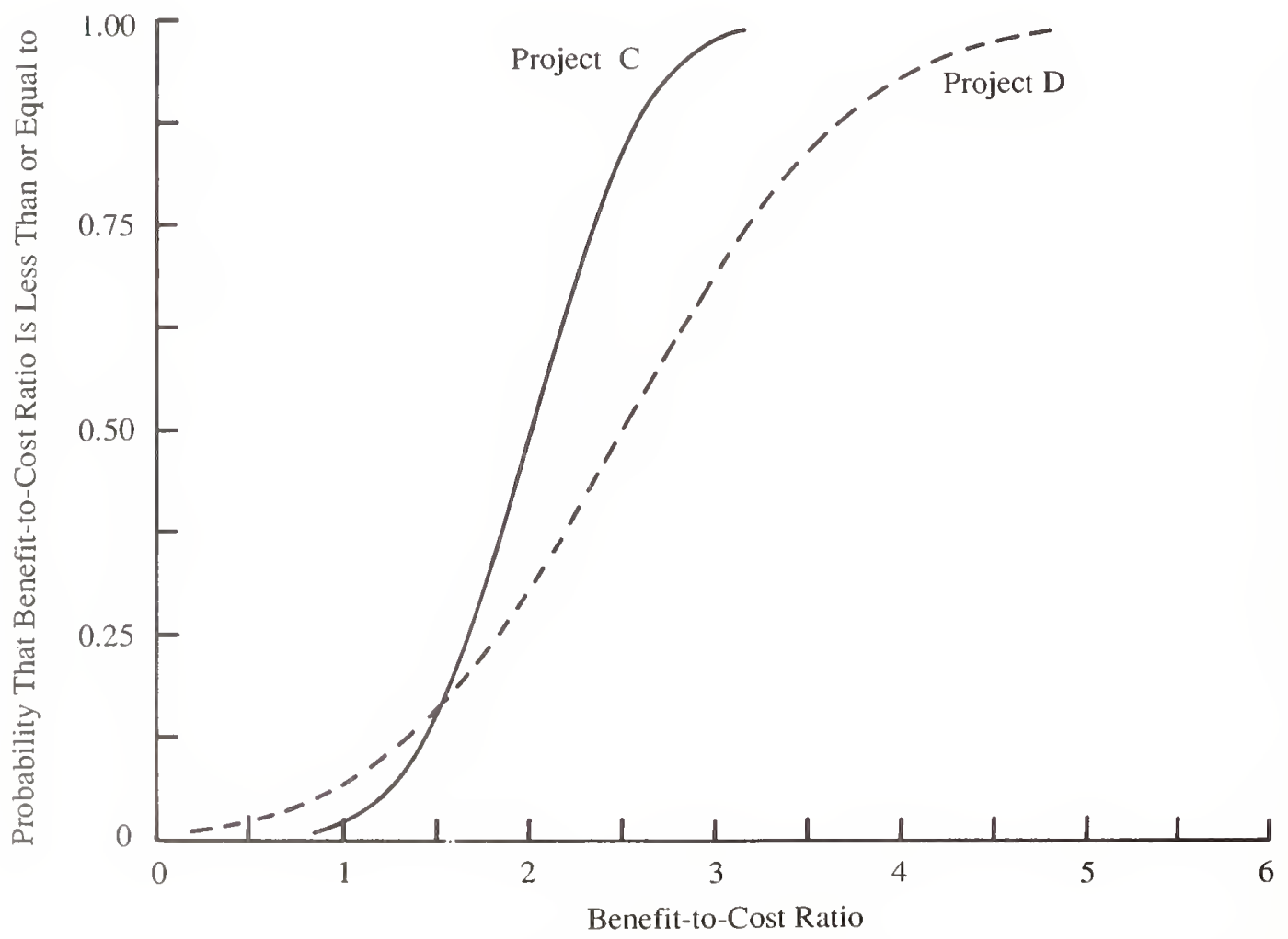

Figure 3-6. Cumulative distribution functions of benefit-to-cost ratio for projects C and D. 
A graph of this money-utility relationship, called a utility function, can be used to show the decision maker's risk attitude. ${ }^{22}$ There are formal techniques for using utility functions in conjunction with the economic methods described in chapter 2. These techniques help decision makers choose among competing projects that do not exhibit stochastic dominance like $C$ and $D$ in figures 3-5 and 3-6.

Figure 3-7 shows three shapes of utility functions. ${ }^{23}$ Each shape represents one of three different risk attitudes--risk neutral, risk averse, and risk taking. Utility values, displayed on the vertical axis, are arbitrary units used to measure the degree of utility or satisfaction associated with a given amount of money shown on the horizontal axis. ${ }^{24}$ The utility function reflects a particular relationship between satisfaction, a subjective value, and monetary amounts. Thus the utility function is unique to one individual, firm, or institution. Each decision maker is likely to have a different utility function.

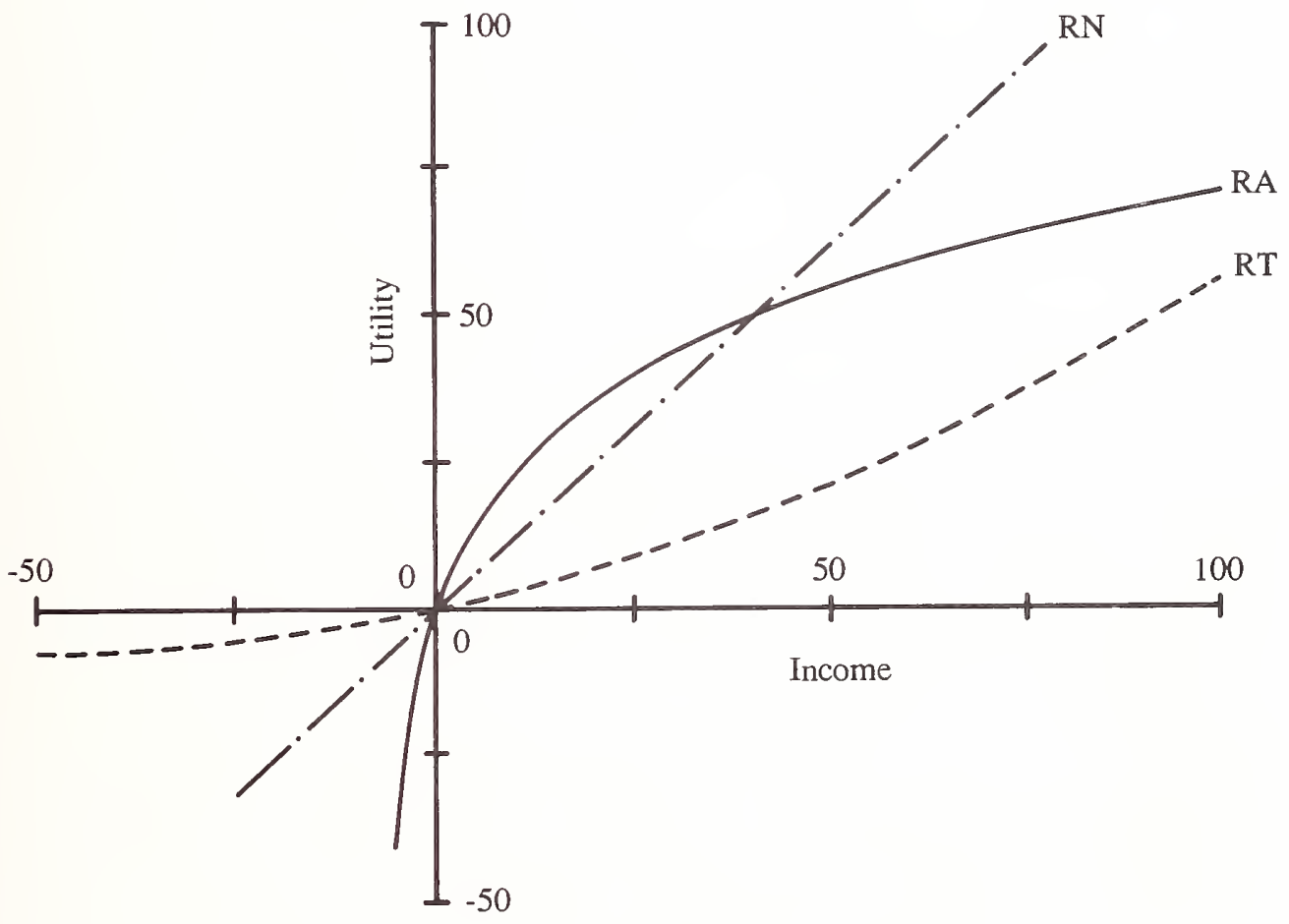

Figure 3-7. Three types of risk attitude.

$$
\begin{aligned}
& \mathrm{RN}=\text { risk neutral, } \\
& \mathrm{RA}=\text { risk averse, and } \\
& \mathrm{RT}=\text { risk taking }
\end{aligned}
$$

${ }^{22}$ Because utility theory is used to measure risk attitude, the literature often uses the term "utility theory" when treating the subject of risk attitude.

${ }^{23}$ Appendix B describes in detail how the functions in figure 3-7 were derived.

${ }^{24}$ Note that relative utility--not absolute utility--is being measured. An individual could assign any two utility values on the vertical axis to any two dollar amounts on the horizontal axis. However, once those have been assigned, there exists a unique utility value for every other dollar amount. 
In using the utility function in an economic analysis, it is assumed that a decision maker will be indifferent among investments with the same expected utility, and prefer investment A to investment B if the expected utility is greater for A than B. ${ }^{25}$ The procedure for using the utility function to choose among alternative investments can be generally described as follows: ${ }^{26}$ (1) find from the function, for each investment alternative, utility values that correspond to each dollar-valued outcome in the probability distribution of potential outcomes; (2) find the expected utility value (the sum of outcome utilities weighted by outcome probabilities) for each investment; and (3) select the investment with the maximum expected utility.

Given this general background on the construction and use of utility functions, the three utility functions in figure 3-7 can now be interpreted in some detail. For the straight-line utility function (RN), each additional, fixed increment of income yields a constant increase in utility; i.e., the marginal utility of income is constant. The decision maker is considered risk neutral because the gain or loss of a large amount of money would yield the same increase or decrease respectively in utility per dollar as would the gain or loss of a small amount of money.

Since the shape of the utility function is dependent on tradeoffs between uncertain money payoffs of known probability and sure money payoffs, it is also helpful to consider risk attitude directly in terms of how a decision maker reacts to such gambles. Decision makers who are risk neutral are called EMV'ers because they act on the basis of expected monetary value (EMV). ${ }^{27}$ For example, the worth or EMV of the lottery described earlier is calculated as follows:

$$
\mathrm{EMV}=0.5(\$ 1,000)+0.5(\$ 0.00)=\$ 500 .
$$

An EMV'er would be indifferent to the lottery or a sure cash payment of $\$ 500$. Hence, the decision maker is risk neutral in the sense of being willing to accept a "fair" gamble. The utility function for a riskneutral decision maker is a straight line, because there is a constant tradeoff between satisfaction in utility and dollar amounts. An implicit assumption in many economic analyses is that decision makers are EMV'ers. Thus there is no explicit consideration of risk attitude because maximizing the expected value of net benefits is assumed to be equivalent to maximizing expected utility.

If the utility function bends over to the right (RA in fig. 3-7), the decision maker is risk averse. Increasingly large dollar amounts are required to achieve constant increments of utility; i.e., the marginal utility of income is diminishing. This means that a decision maker would prefer a sure payment that is less than the expected value of the lottery to the chance of participating in the lottery. In other words, the amount the decision maker is willing to pay for the lottery ticket will be less than its expected value because of aversion to the risk of the lottery's outcome. This implies that decision makers regard marginal payoffs to be worth less (i.e., to be of less utility), per dollar, as total payoffs increase. Thus, to determine the true value of investments for risk-averse decision makers, economic analyses must account for decreasing satisfaction of higher payoffs with corresponding decreases in marginal utility. Since empirical studies have shown that most corporate decision makers are in the risk-averse category, ${ }^{28}$ accounting for risk attitude is a significant consideration in project evaluation.

${ }^{25}$ The utility theory described in this chapter evolved from that published in The Theory of Games and Economic Behavior, by John von Neuman and Oskar Morgenstern (Princeton, New Jersey: Princeton University Press, 1944).

${ }^{26}$ This procedure is most descriptive of decision analysis, one of the techniques described in chapter 5. Note that if the measure of worth is not dollars (e.g., a BCR measure) then the projected benefits and costs are first transformed to utility units before computing the measure of worth.

${ }^{27}$ Raiffa, Decision Analysis, p. 9.

${ }^{28}$ See, for examples, Carl S. Spetzler, "Establishing a Corporate Risk Policy," 1986 Proceedings of the American Institute of Industrial Engineers (Norcross, Georgia: AIIE, 1986), and Ralph O. Swalm, "Utility Theory--Insights into Risk Taking," Harvard Business Review, Nov./Dec. 1966, pp. 123-136. 
If the utility function bends upward to the left (RT in fig. 3-7), the decision maker is a risk taker. Successively smaller dollar amounts are required to achieve constant increments in utility; i.e., the marginal utility of income is increasing. This implies that the decision maker would actually pay a premium for a lottery ticket, i.e., a value greater than the expected value of the lottery. The reason is that the decision maker regards project payoffs to be worth more (i.e., to have more utility), per dollar, as the total payoffs increase. Thus, to determine the true value of investments for risk takers, economic analyses must account for increasing marginal satisfaction of higher payoffs with corresponding increases in marginal utility.

Behavior of decision makers implies that more than one risk attitude is possible, depending on the monetary stakes. For example, many low-income persons are willing to buy insurance at a premium greater than the expected value of a loss without insurance (sign of risk averter) and at the same time to play the lottery at worse than fair odds (sign of risk taker). This suggests a utility function with risk averting and risk taking segments, as shown in figure 3-8.29

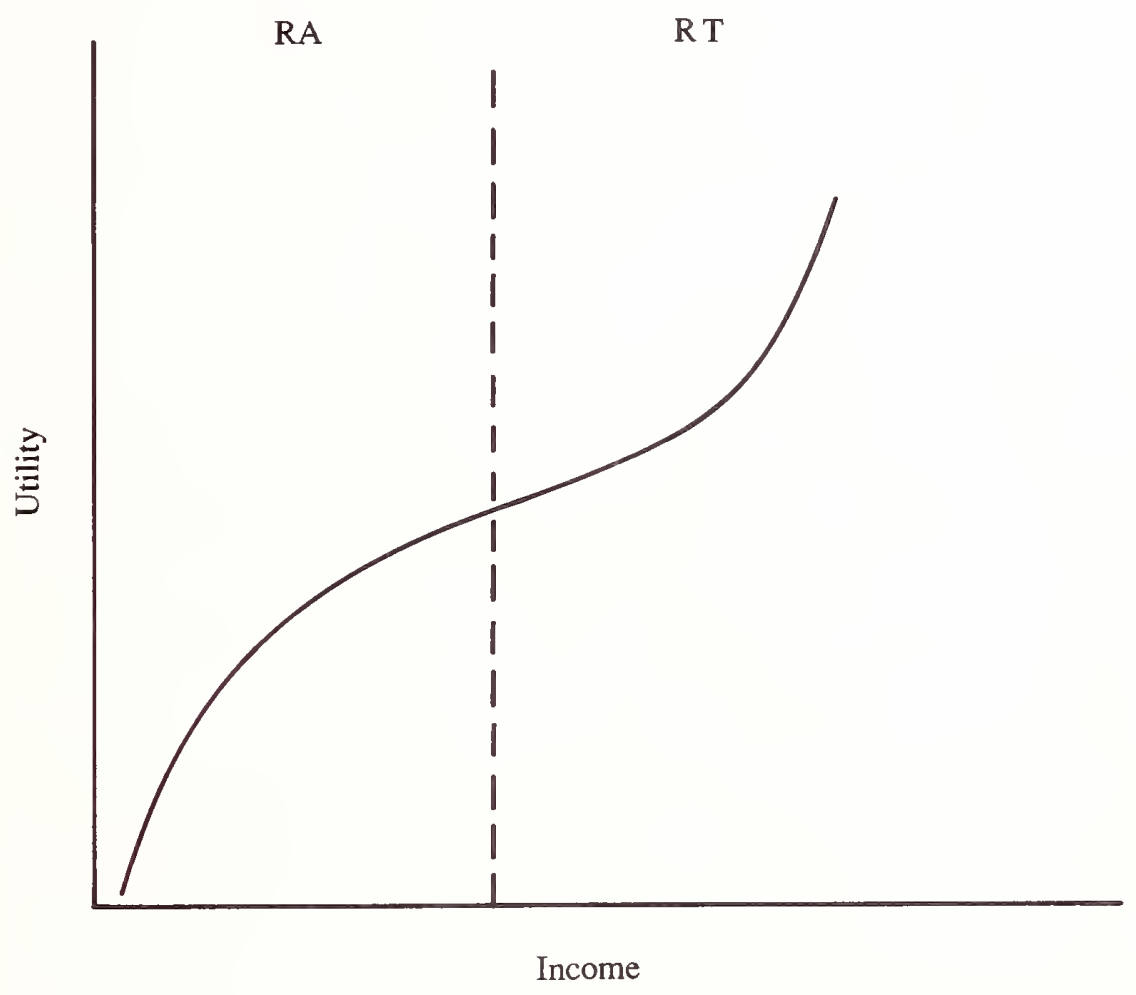

Figure 3-8. Utility function showing both risk averse (RA) and risk taking (RT) attitudes.

Note that expected utility analysis based on subjective utility functions will not necessarily predict the way decision makers will actually choose among alternative investments. Decision makers are not expected to act rationally and consistently in every investment situation with respect to their revealed utility-money functions. Friedman and Savage point out that decision makers do not, in fact, calculate utilities before making every choice. ${ }^{30}$ However, utility analysis is still useful as long as decision makers generally act as

${ }^{29}$ Milton Friedman and L. J. Savage discuss at length various shapes of utility functions in "The Utility Analysis of Choices Involving Risk," Readings in Price Theory (Homewood, Illinois: Richard D. Irwin, Inc., 1952), pp. 57-96.

30 Tbid., p. 86. 
if they had compared expected utilities and as if they knew the odds for the economic choices being evaluated. Under these conditions, a firm or institution can use utility theory in a normative or prescriptive role to establish risk policy that will consistently direct management to investments that support the firm's or institutions's risk attitude.

Several factors have limited the application of risk attitude adjustments in practice. First, many decision makers consider the technique impractical for their institution. This may be due in part to a lack of understanding and to an unwillingness to give up some opportunities for personal judgment in project evaluation. Second, there is often considerable difficulty in determining an organization's risk attitude. This arises for a couple of reasons. Because individual decision makers may not want to be bound by an organization's risk policy, they may be unwilling to cooperate in defining that policy. Also, because individuals are often risk averters in their personal frame of reference, they may have difficulty in identifying an institutional risk attitude where a more risk-taking attitude might be appropriate.

The use of risk attitude adjustments in project evaluation, however, does have merit. Competent professional assistance in helping decision makers develop and implement a risk policy would overcome many of the limiting factors described earlier. There is a sound theoretical basis for including risk attitude adjustments. And a firm or institution that can establish a risk policy that consistently directs management to investments that support the firm's or institution's risk attitude will select better projects over the long run.

In the next two chapters, various techniques of treating risk exposure and risk attitude are described and illustrated. Some techniques, such as the mathematical/analytical technique, focus on risk exposure, whereas others, such as the risk-adjusted discount rate, account for risk attitude as well as risk exposure. A confusion is often created by the literature because the term "risk analysis" is used sometimes to describe exclusively either risk exposure or risk attitude, and other times to describe both. Thus in these illustrations it will be made explicit in each case whether risk exposure, risk attitude, or both are treated. 


\section{TECHNIQUES THAT DO NOT USE PROBABILITY}

Chapter 4 describes five techniques that treat uncertainty and risk in project evaluation without using probability or cumulative distribution functions. Techniques that use such functions are examined in chapter 5. In both chapters, advantages and disadvantages of each technique are described, and the extent to which each technique accounts for risk exposure and risk attitude is discussed.

\subsection{Conservative Benefit and Cost Estimating}

A simplistic approach to accounting for the uncertainty of input values is to be conservative in their estimation so that any error in prediction will likely be an underestimation of project economic worth. This is accomplished by intentionally estimating benefits on the low side, costs on the high side, or both. Or, when estimating values of parameters on which benefits and costs depend, such as the discount rate or project life, the parameter estimates would be made in the direction that lowers expected benefits and raises expected costs.

The more conservative are benefit and cost estimates, the more assurance one has that a project estimated to be cost effective will in fact be so. This technique is most useful when a decision maker suffers a great penalty for selecting an uneconomic project, but incurs no penalty for rejecting economic projects. However, if a firm were using this technique to determine its bids on construction projects, it would be unlikely to win many contracts in a competitive market. The technique provides no measure of the risk of making an uneconomic decision, and it will actually bias decision makers against choosing many projects that would in fact be economic.

The greater the risk exposure perceived by the decision maker, and the more risk averse the decision maker, the more conservative will be the benefit and cost estimates. With this technique there is no clear distinction between adjustments for handling risk exposure and risk attitude.

\subsection{Breakeven Analysis}

When an uncertain variable is critical to the economic success of a project, decision makers sometimes want to know the minimum or maximum value that variable can reach and still have a breakeven project; i.e., a project where benefits (savings) equal costs. For example, the breakeven value of an input cost variable is the maximum amount one can afford to pay for the input and still break even compared to benefits earned. A breakeven value of an input benefit variable is the minimum amount the project can produce in that benefit category and still cover the projected costs of the project.

To perform a breakeven analysis, an equation is constructed wherein the benefits are set equal to the costs for a given investment project, the values of all inputs except the breakeven variable are specified, and the breakeven variable is solved for algebraically.

Suppose a decision maker is deciding whether or not to invest in a piece of energy conserving equipment. The derivation of the formula for computing breakeven investment costs for the equipment is as follows: ${ }^{31}$

$$
\begin{aligned}
& S=C \\
& C=I+O \& M+R \\
& S=I+O \& M+R \\
& I=S-O \& M-R
\end{aligned}
$$

${ }^{31}$ All costs and benefits are in present value terms. 
where $S$ = savings (benefits) in reduced energy costs from using the equipment,

$\mathrm{C}=$ all costs associated with the equipment,

$I=$ investment costs of the equipment,

$O \& \mathrm{M}=$ operation and maintenance costs of the equipment, and

$\mathrm{R}=$ replacement costs for the equipment.

By rearranging terms, the breakeven investment "unknown" is isolated on the left side of the equation. Substitution of known values for the terms on the right side allows the analyst to solve for the breakeven value. For example, if $S=\$ 20,000, O \& M=\$ 2,500$, and $R=\$ 1,000$, then

$$
\begin{aligned}
& I=\$ 20,000-\$ 2,500-\$ 1,000, \text { or } \\
& I=\$ 16,500 .
\end{aligned}
$$

This means that $\$ 16,500$, the breakeven value, is the maximum amount that can be paid for the energyconserving equipment and still recover all costs through energy savings.

An advantage of breakeven analysis is that it can be computed quickly and easily with limited information. It also simplifies project evaluation in that it gives just one value to decision makers to use as a benchmark for comparison against the predicted performance of that uncertain variable. Breakeven analysis helps decision makers assess the likelihood of achieving the breakeven value and thereby contributes implicitly to the analysis of project risk.

A disadvantage is that it provides no probabilistic picture of input variable uncertainty or of project risk exposure. Furthermore, it includes no explicit treatment of risk attitude.

\subsection{Sensitivity Analysis}

Sensitivity analysis measures the impact on project outcomes of changing one or more key input values about which there is uncertainty. For example, a pessimistic, expected, and optimistic value might be chosen for an uncertain variable. Then an economic analysis could be performed for each of the three values to see how the outcome changes as they change, with other things held the same.

Sensitivity analysis can also be performed on different combinations of input values. That is, several variables are altered at once and then a measure of worth is computed. For example, one scenario might include a combination of all pessimistic values, another all expected values, and a third all optimistic values. Examining different combinations would be required if the uncertain variables were interrelated.

The following illustration of sensitivity analysis treats an accept/reject decision. Consider a decision on whether or not to install a programmable time clock to control heating, ventilating, and air conditioning (HVAC) equipment in a commercial building. The time clock would reduce electricity consumption by turning off that part of the HVAC equipment that is not needed during hours when the building is unoccupied. Using the BCR as the economic method, the time clock would be acceptable on economic grounds if its BCR were greater than 1.0. The energy reduction benefits from the time clock, however, are not certain. They are a function of three factors: the initial price of energy, the rate of change in energy prices over the life cycle of the time clock, and the number of kilowatt hours $(\mathrm{kWh})$ saved. Assume that the initial price of energy and the number of kWh saved are relatively certain, and that the sensitivity of the $\mathrm{BCR}$ is being tested with respect to the following three values of energy price change: a low rate of energy price escalation (slowly increasing benefits from energy savings); a moderate rate of escalation (moderately increasing benefits); and a high rate of escalation (rapidly increasing benefits). These three assumed values of energy price change might correspond to our projections of pessimistic, expected, and optimistic values. Three BCR estimates result from repeating the BCR computation for each of the three energy price escalation rates. For example, BCRs of $0.8,2.0$, and 4.0 might result. Whereas a deterministic 
approach might have generated the BCR estimate of 2.0, now it is apparent that the BCR could be significantly less than 2.0, and even less than 1.0. Thus accepting the time clock could lead to an inefficient outcome.

There are several advantages of sensitivity analysis. First, it shows how significant a single input variable is in determining project outcomes. Second, it recognizes the uncertainty associated with the input. Third, it gives information about the range of output variability. And fourth, it does all of these when there is little information, resources, or time to use more sophisticated techniques.

Major disadvantages of sensitivity analysis are that it gives no explicit probabilistic measure of risk exposure and it includes no explicit treatment of risk attitude. The findings of sensitivity analysis are ambiguous. How likely is a pessimistic or expected or optimistic value, for example, and how likely is the corresponding outcome value? Hillier maintains that sensitivity analysis can in fact be misleading if all pessimistic assumptions or all optimistic assumptions are combined in calculating economic measures. ${ }^{32}$ Such combinations of inputs would be most unlikely in the real world. Furthermore, he emphasizes that no conclusions can be reached about the impact of combinations of errors in the input estimates. $33^{\mathrm{p}}$

Sensitivity results can be presented in text, tables, or graphs. One type of graph that is useful in showing the sensitivity of project worth to a critical variable is illustrated in figure 4-1. Net benefits (NB) for

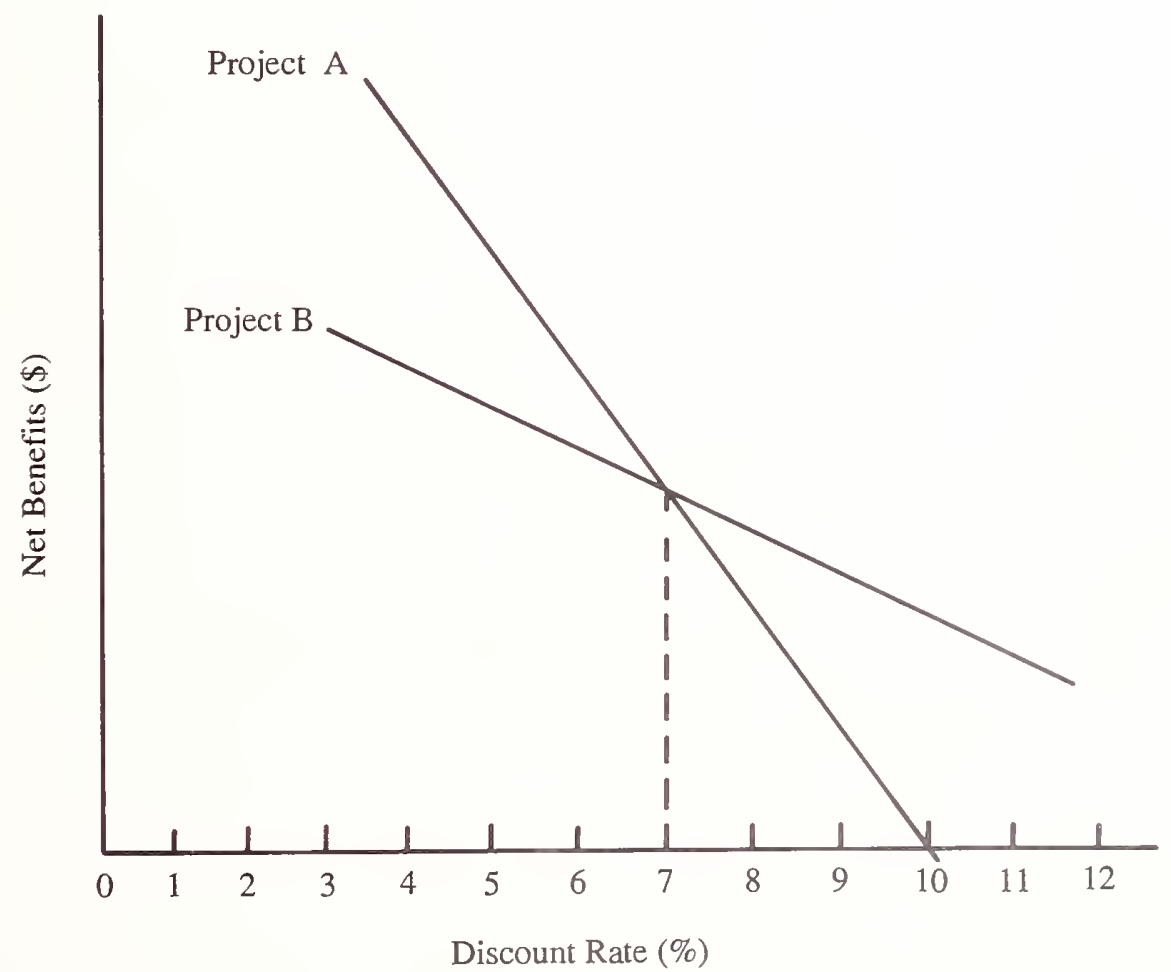

Figure 4-1. Sensitivity of net benefits of projects A and B to discount rate.

${ }^{32}$ F. Hillier, "The Derivation of Probabilistic Information for the Evaluation of Risky Investments," Management Science, 1969, p. 444.

${ }^{33}$ For additional information on sensitivity analysis, see Robert G. Hendrickson, A Survey of Sensitivity Analysis Methodology, National Bureau of Standards Interagency Report 84-2814, February 1984. 
projects $\mathrm{A}$ and $\mathrm{B}$ decrease as the discount rate increases. The slopes of the functions show that NB is more sensitive to the discount rate changes for project $\mathrm{A}$ than for project $\mathrm{B}$, assuming other variables remain unchanged. These functions also help in making comparisons as to which project is more cost elfective. At a discount rate below 7 percent, for example, A has the greater NB. At a rate above 7 percent, B yields the greater NB. And at 7 percent, the two projects provide identical NB. ${ }^{34}$

Note that the functions indicate the potential values of NB if different values of the discount rate occur. If decision makers have some idea as to the likelihood of specific discount rates, the graph will help them evaluate the NB implications for these two projects. The sensitivity graph in this sense contributes to an implicit description of risk exposure. Yet the graph fails to provide a quantitative measure of the probability of any given NB occurring.

\subsubsection{Spider Diagram}

Another special graph for sensitivity analysis that presents a snapshot of the potential impact of uncertain input variables on project outcomes is the spider diagram. ${ }^{35}$ The one illustrated in figure 4-2 shows for a prospective commercial building investment the sensitivity of the adjusted internal rate of return (AIRR) to three variables: operation, maintenance, and replacement costs (OM\&R); project life (PL); and the reinvestment rate (RR). ${ }^{36}$ Each variable is represented by a labeled function that shows what AIRR values would result from different values of the uncertain variable. ${ }^{37}$ For example, the downward-sloping OM\&R function indicates that the AIRR is inversely proportional to $O M \& R$ costs. By design, the $O M \& R$ function (as well as the other two functions) passes through the horizontal axis at the "best-guess" estimate of the AIRR (15 percent in this case), based on the "best-guess" estimates of the three uncertain variables. ${ }^{38}$ Since each of the variables is measured by different units (money, years, and percentage), the vertical axis is denominated in positive and negative percent changes from the best-guess values fixed at the horizontal axis. The AIRR value corresponding to any given percent variation indicated by a point on the function is found by extending a line perpendicular to the horizontal axis and reading directly the AIRR value. Thus a 30 percent increase in the best-guess reinvestment rate would yield a 25 percent AIRR, assuming other values remain unchanged. 39

The contribution of the spider diagram is its picture of the relative importance of the different uncertain variables. It shows immediately that the lesser the slope of a function, the more sensitive is the AIRR to that variable. For example, any given percentage change in OM\&R will have a greater impact on the AIRR than will an equal percentage change in RR or PL.

${ }^{34}$ Note that the graph also shows the breakeven discount rate (i.e., 10 percent) for project A.

${ }^{35}$ For descriptions of spider diagrams used in the analysis of construction and building projects, see $\mathrm{J}$. G. Perry and R. W. Hayes, "Risk and Its Management in Construction Projects," Proceedings Institution of Civil Engineers, Vol. 78, pp. 499-521, and Roger Flanagan, Adrian Kendell, George Norman, and Graham Robinson, "Life-Cycle Costing and Risk Management," CIB Proceedings of the Fourth International Symposium on Building Economics, Danish Building Research Institute, Copenhagen, 1987.

${ }^{36}$ See chapter 2 for an explanation of the AIRR.

37 The functions are linear here to simplify exposition. In practice they may not be linear.

${ }^{38}$ Other variables, for example occupancy rate, will impact the AIRR, but these are assumed to be known for purpose of this analysis.

${ }^{39}$ Note that if the measure of AIRR were also given in percent differences, then the best-guess AIRR would be at the origin. 


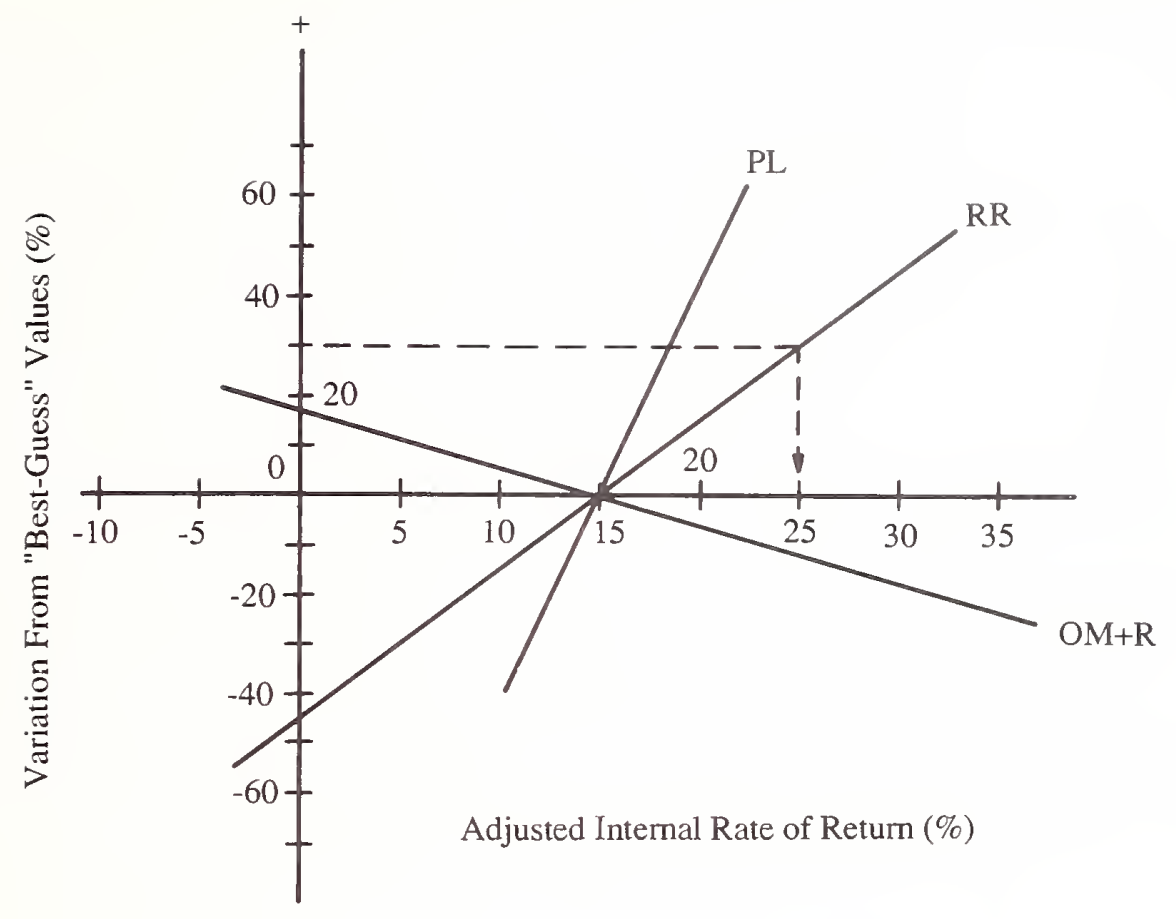

Figure 4-2. Spider diagram showing sensitivity of the adjusted internal rate of return to variations in uncertain variables.

$\mathrm{PL} \quad=$ project life,

$\mathrm{RR} \quad=$ reinvestment rate, and

$\mathrm{OM} \& \mathrm{R}=$ operation, maintenance, and replacement costs

\subsubsection{Contour Lines 40}

Wrapping contour lines around the variable functions in a spider diagram has been recommended by Perry and Hayes ${ }^{41}$ and by Flanagan et al. ${ }^{42}$ to overcome the perceived limitation in sensitivity analysis of failing to describe uncertain input variables with probabilities. However, it is shown here that wrapping contours around spider diagrams adds no additional information and may actually mislead analysts. To evaluate this approach, let us describe how to wrap a contour around the spider diagram shown in figure 4-3. (This is the same spider diagram shown in figure 4-2, except now it has a contour.) Assume that the uncertain variables are normally distributed and that we know their means and standard deviations. A probability is selected on which to base the contour. In this case 68 percent was used because it represents about one standard deviation from the mean in a normal distribution. Thus the range of values within which each

${ }^{40}$ This section on contour lines includes a discussion of probability distributions. Contour lines are described here rather than in the next chapter, however, because contour lines go with sensitivity analysis. And sensitivity analysis generally does not require the use of probability distributions.

\footnotetext{
${ }^{41}$ Perry and Hayes, "Risk and Its Management in Construction Projects."

${ }^{42}$ Flanagan et al., "Life-Cycle Costing and Risk Management."
} 


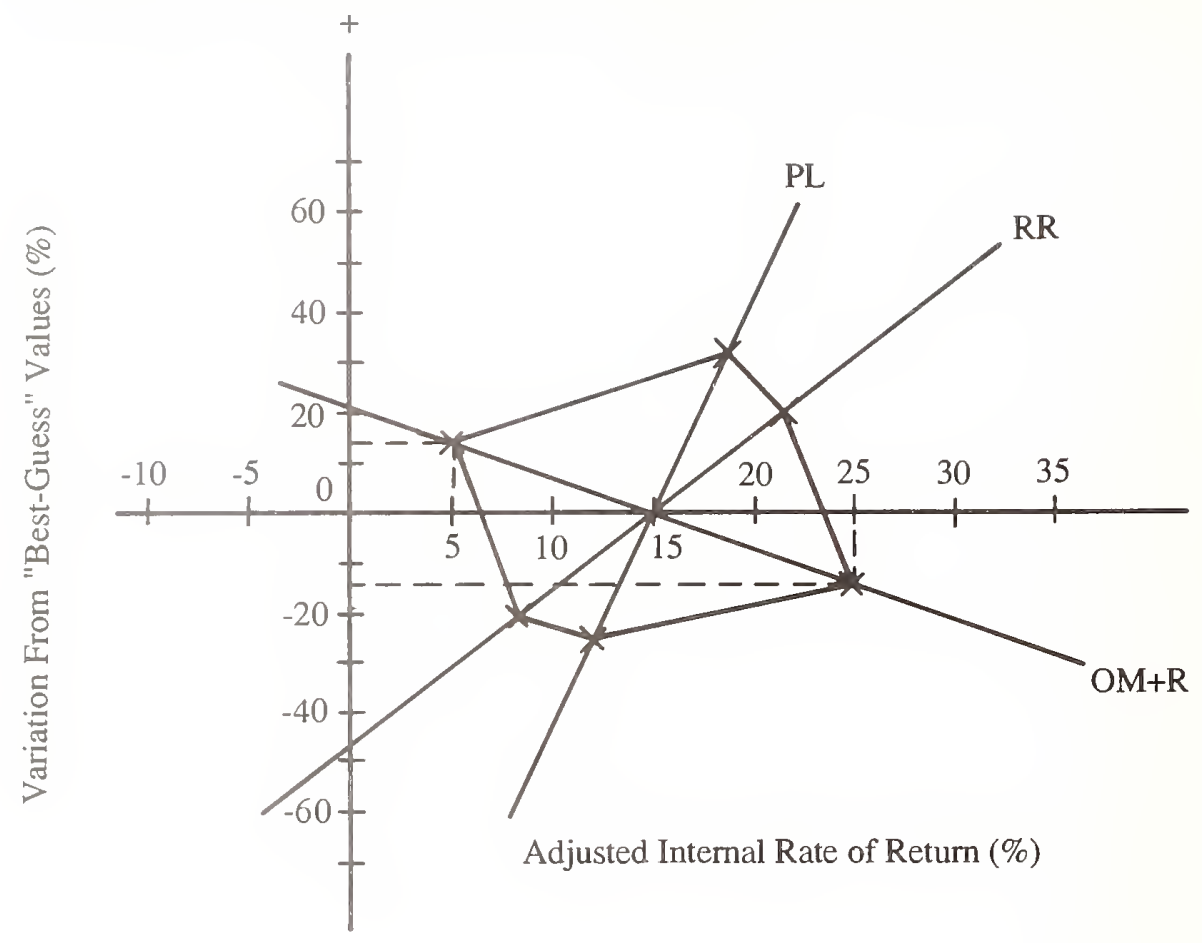

Figure 4-3. Spider diagram with a contour.

$$
\begin{aligned}
& \mathrm{PL}=\text { project life, } \\
& \mathrm{RR} \quad=\text { reinvestment rate, and } \\
& \mathrm{OM \& R}=\text { operation, maintenance, and replacement costs }
\end{aligned}
$$

uncertain variable is expected to be found 68 percent of the time can be calculated (i.e., a high of $\mu+\sigma$ to a low of $\mu-\sigma)$. This range is indicated in figure $4-3$ by the segment of the vertical axis that corresponds to the vertical distance between the two "x's" on each function. Joining these "x's" with a continuous line forms the 68 percent contour.

According to Perry and Hayes, ${ }^{43}$ this contour implies that 68 percent of the possible outcomes fall inside this contour and " ... is then a subjective opinion by the estimator of the likelihood of occurrence." This might be true for values of each of the input variables, but it is not true of the measure of worth, i.e., the AIRR. The contour reveals nothing about the likelihood of obtaining any single AIRR value or range of possible AIRR values, because it applies only to the maximum variation in an individual variable where all other variables are held constant at their "best-guess" values.

The most that can be inferred from figure 4-3 is the range in AIRR values that might be expected 68 percent of the time for variation in any one of the three variables while the other two are held constant. This can best be seen, however, by ignoring the contour and simply finding the corresponding AIRR values for the " $\mathrm{x}$ " marks on each variable function. For example, in figure 4-3 there is a 68 percent probability that OM\&R will be in the range bounded by the two " $\mathrm{x}$ ' $\mathrm{s}$ " of 14 percent above to 14 percent below the best-guess estimate. Assuming all other variables are at their best-guess values, this translates into a range in the AIRR of 5 percent to $\angle 5$ percent, as shown by the dotted lines to the horizontal axis.

${ }^{43}$ Perry and Hayes, "Risk in Construction Projects," p. 504. 


\subsubsection{Spider Diagrams for Competing Projects}

Spider diagrams can be helpful when comparing competing projects as long as the decision maker keeps in mind that extreme values of the measure of worth reflect variations in one variable only. For example, look at the spider diagram for projects $A$ and $B$ in figure 4-4. The NB of project $A$ is a function of variables $\mathrm{A} 1$ and $\mathrm{A} 2$, and the $\mathrm{NB}$ of project $\mathrm{B}$ is a function of variables $\mathrm{B} 1$ and $\mathrm{B} 2$. The horizontal axis suggests that project $\mathrm{B}$ has a higher present value net benefits $(\$ 90,000)$ than project $\mathrm{A}(\$ 50,000)$. That is, if only best-guess values were used in a single-value, deterministic approach, B would be the preferred project. However, if we assign, say, a 50 percent confidence interval about the uncertain variables A1, A2, $\mathrm{B} 1$, and B2, as shown by " $\mathrm{x}$ 's" on the functions, there appears the possibility that A could yield a higher NB than B. That is, within that confidence interval, if the extreme B1 value to the left were to occur, project B would yield a lesser NB than would project A for A1 or A2 extreme values to the left. Furthermore, if $\mathrm{A} 1$ and $\mathrm{B} 1$ were the same input variable, we would know that project $\mathrm{A}$ would be preferred at values of $\mathrm{A} 1$ and $\mathrm{B} 1$ above 10 percent over the best-guess value, and project $\mathrm{B}$ would be preferred at values of $\mathrm{A} 1$ and B1 below 10 percent.

Once again, however, sensitivity analysis gives no indication of the probability of any given value of NB. Furthermore, because only one variable is allowed to change at a time, and NB is a function of more than one variable, sensitivity analysis gives an incomplete description of the possible outcomes.

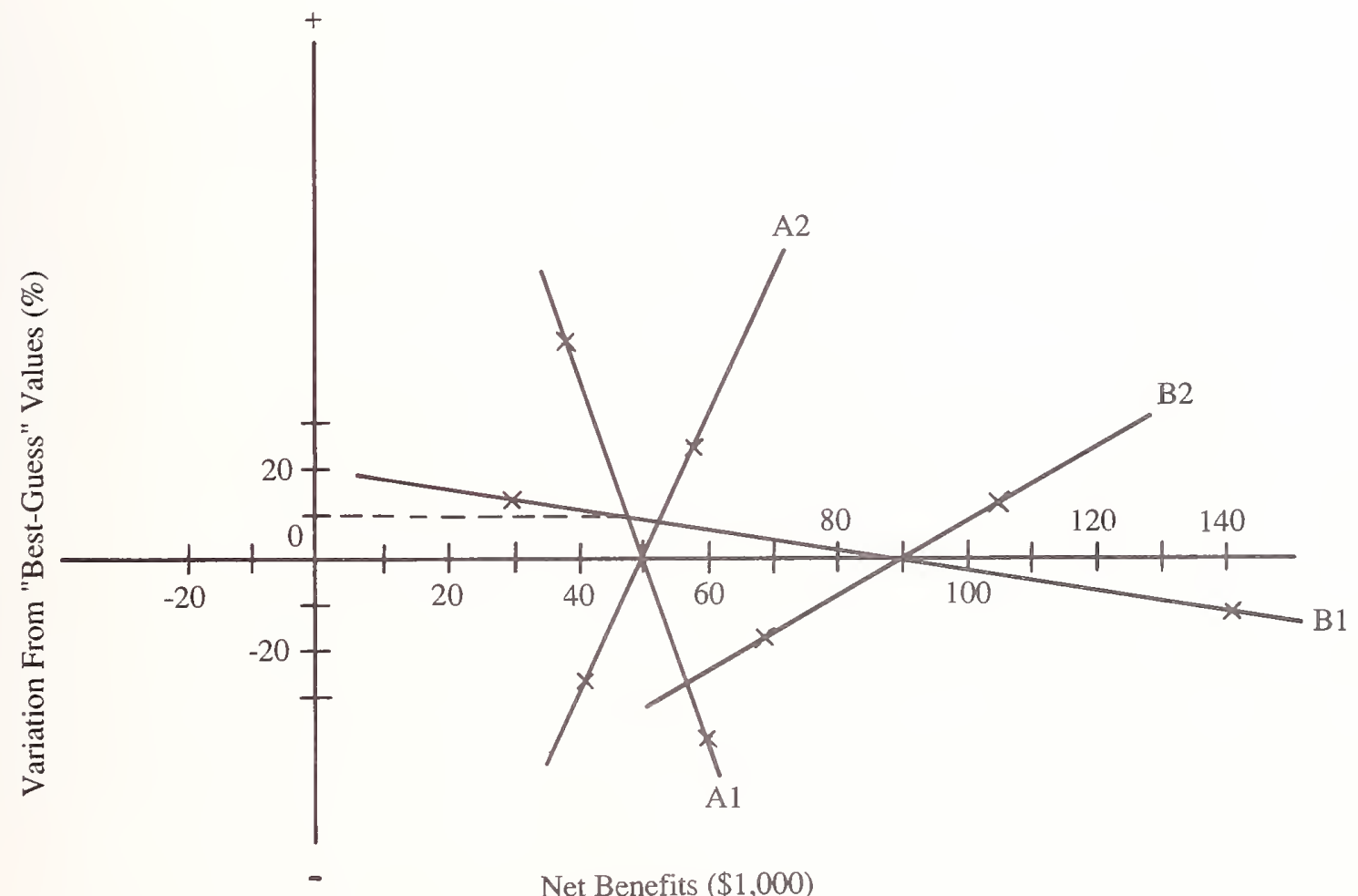

Figure 4-4. Spider diagrams for competing projects. 


\subsection{Risk-Adjusted Discount Rate}

One technique used by the business community to account for risk is the risk-adjusted discount rate (RADR). The objective of using the RADR technique is to raise the likelihood that the investor will earn a return over time sufficient to compensate for extra risk associated with specific projects.

Projects with anticipated high variability in distributions of project worth have their net benefits or returns discounted at higher rates than projects with low variability. Thus in computing net benefits or the benefit-to-cost ratio, the discount rate is higher for benefit streams of risky projects than for those with certain outcomes. Or, when applying rate-of-return methods, the MARR is raised above the risk-free rate to compensate for the higher variability of returns in risky projects.

The RADR can be found by eq (4.1):

$$
\mathrm{RADR}=\mathrm{RF}+\mathrm{AR} 1+\mathrm{AR} 2
$$

where $\mathrm{RF}=$ risk-free rate,

$\mathrm{AR} 1=$ adjustment for normal risk encountered in the firm's operations,

AR2 = adjustment for extra risk above or below normal risk, and all terms are expressed as percents. ${ }^{44}$

The risk-free rate (RF) component is required to account for the time value of money. It is what might be earned, for example, on government treasury bills, the closest thing to a riskless investment available to most investors. The adjustment for normal risk (AR1) is the risk premium that a firm might impose to cover the average riskiness of the firm's normal operations. The sum of RF and AR1 should equal the MARR the firm requires on typical investments.

The AR2 component adjusts for projects with more or less risk than what is normally associated with the firm. The adjustment can be positive or negative.

For discounting benefit streams, AR2 is an increasing function of the (1) perceived variability in project outcomes (risk exposure) and the (2) degree to which the decision maker is risk averse (risk attitude). For cost streams, AR2 is a decreasing function of those same risk factors.

There are two approaches one might follow in applying the RADR technique. The first, and one recommended, is to discount each benefit and cost stream with a unique RADR that includes AR1 and AR2 values that describe that stream's uncertainty. For benefit or savings streams, AR1 and AR2 are adjusted upwards as perceived risk increases. That is, as future benefits become more uncertain, the RADR technique requires raising the discount rate to make the project look less cost effective. For cost streams, AR1 and AR2 are adjusted downwards as perceived risk increases. That is, as future costs become more uncertain, the correct application of the RADR technique requires lowering the discount rate to make the project look less cost effective. This point is rarely made in the literature. ${ }^{45}$ It follows then that the

${ }^{44}$ For additional information on the RADR, see Clark et al., Capital Budgeting, pp. 180-189, and William Baumol, Economic Theory and Operations Analysis (Prentice Hall, Inc.: Englewood Cliffs, New Jersey, 1977) Fourth Edition, pp. 620-621.

${ }^{45}$ The only statement in the literature the author has found that recommends lowering discount rates when evaluating uncertain cost streams is in Kenneth J. Arrow and Robert C. Lind, "Uncertainty and the Evaluation of Public Investment Decisions," The American Economic Review, Vol. LX, No. 3, June 1970, pp. 364-378. They say (p. 378) "... if net benefits to an individual are negative, this requires discounting expected returns at a rate lower than the certainty rate. Raising the rate of discount only reduces the present value of net benefits when they are positive." 
appropriate adjustment for risk when using LCC analysis is a decrease in the discount rate for each cost stream to make project costs appear higher. Otherwise LCC analysis will be biased in favor of projects with a greater risk of higher-than-anticipated costs.

The second approach is to use a single discount rate with a constant risk adjustment to evaluate the net cash flows (positive or negative). The constant risk adjustment for AR1 and AR2 are in effect a composite of the risk adjustments that might be made individually on benefit and cost elements about which there is uncertainty in a given project. Instead of discounting each benefit and cost stream with a unique discount rate, an implicit weighted average of the uncertainty is incorporated in the RADR value assigned a given project. This approach, albeit common, is not recommended because it distorts the risk adjustment mechanism.

Let us look once again at the BCR of the time clock for an illustration of the RADR when making an accept/reject decision. If no unusual risk is associated with the time clock, the discount rate is equal to the sum of RF and AR1 as shown under eq (4.1). Let us suppose that the BCR for the time clock is 1.1 in this case. Thus it appears to be a cost effective investment. Now let us assume instead that the economic performance of the time clock is more risky than average. This might arise, for example, from the impact of uncertain kWh reductions or uncertain future energy prices. Furthermore, let us assume that the decision maker is risk averse. Using the RADR technique, we raise the discount rate for evaluating energy cost savings by some positive value of AR2. If the resulting BCR falls below 1.0, the project no longer appears economically acceptable.

The RADR technique as described so far generates a single measure of project worth. The decision maker incorporates implicitly the probabilities of uncertain inputs and risk preference attitudes in the determination of a value for the RADR. However, the RADR technique can be coupled with the mathematical/analytical approach to generate probability density functions and/or cumulative distribution functions of measures of project worth. ${ }^{46}$ In this coupling of techniques, risk exposure is indicated explicitly by the distributions of project worth, and risk attitude is treated explicitly in the adjustment component to the RADR.

Advantages of the RADR technique are that it is relatively simple to understand; it is easy to compute; and it accounts to some extent for the uncertainty of inputs, risk exposure, and risk attitude.

A major limitation in using the RADR is the lack of any accepted procedure for establishing the RADR value. It is typically estimated based on the decision maker's best judgment. One common approach is to simply lump projects into "risk categories," each of which has an assigned RADR. There is little fine tuning. Furthermore, there is no distinction between adjustments for handling risk exposure and risk attitude.

Another shortcoming is that a constant AR2 is typically applied over the entire study period, even when there are periods for which no special adjustment is necessary for risk above or below what is considered normal risk. Furthermore, discounting with a RADR that includes a constant AR2 over the whole study period implies in effect that returns become exponentially more uncertain over time. ${ }^{47}$ Thus a discount rate that includes a constant AR2 severely reduces the weight of net benefits accrued in later years, regardless of the certainty of their occurrence. This biases selection towards projects with early payoffs. ${ }^{48}$

\section{${ }^{46}$ See section 5.5.3.}

${ }^{47}$ In many cases it may be reasonable to assume that estimates for distant years are of lower quality than those for near years.

${ }^{48}$ For an explanation and illustration of how perceived risk is implicitly assumed to increase over time with a constant RADR, see Weston and Brigham, Managerial Finance, pp. 479-480 and pp. 482-484. 


\subsection{Certainty Equivalent Technique}

With the certainty equivalent technique, the decision maker determines a certainty equivalent factor (CEF) by which project returns are adjusted to reflect risk exposure and risk attitude. Adjusting estimated returns of an investment by a CEF yields a "certainty equivalent" amount a decision maker finds equally acceptable to making that same investment with its uncertain outcome.

Let us examine how the certainty equivalent technique is applied in a net benefits analysis. The net benefits computation is based on Formula 2 in appendix A, with the addition of a CEF term multiplied times net benefits to account for risk. The certainty equivalent version of net benefits is found with eq (4.2).

$$
\mathrm{NB}_{\mathrm{Ce}}=\sum_{\mathrm{t}=0}^{\mathrm{N}}\left(\mathrm{CEF}_{\mathrm{t}}\left(\mathrm{B}_{\mathrm{t}}-\mathrm{C}_{\mathrm{t}}\right)\right) /(1+\mathrm{RF})^{\mathrm{t}}
$$

where $\quad \mathrm{NB}_{\mathrm{ce}}=$ certainty equivalent net benefits,

$\mathrm{CEF}_{\mathrm{t}}=$ certainty equivalent adjustment factor in time period $\mathrm{t}$, and

$\mathrm{RF}=$ risk-free discount rate.

The discount rate is "risk-free" since risk is now handled through the CEF. As perceived risk exposure increases, $\mathrm{CEF}$ becomes smaller, making $\mathrm{NB}_{\mathrm{c}}$ smaller. And as aversion to risk increases, $\mathrm{CEF}_{\mathrm{t}}$ becomes smaller, likewise making $\mathrm{NB}_{c e}$ smaller. Any $\mathrm{CEF}_{\mathrm{t}}$ less than 1.0 implies that an investment will be worth less than the estimated net benefits because of the decision maker's assessment of risk. ${ }^{49}$

Given this background on how the certainty equivalent technique is used, let us examine two approaches for deriving a CEF. First, consider the derivation of a CEF based on risk attitude. Suppose a decision maker specifies a certain payment (the certainty equivalent) that must be received to make him or her indifferent between that certain payment and the expected value of a return that is uncertain. For example, assume a person is given a choice between a certain payment of money and a lottery with a 50 percent probability of winning $\$ 1,000$ and a 50 percent probability of winning nothing. For some amount of certain payment, the decision maker will be indifferent between the lottery and that certain payment. Once this tradeoff is specified, the CEF can be derived using eq (4.3).

$$
\mathrm{CEF}=\text { Certain Payment/Expected Value of Uncertain Return }
$$

If a decision maker accepts a certain payment of $\$ 500$ in lieu of the lottery described above, then the CEF $=1.0$, and the decision maker is risk neutral. If the decision maker is indifferent between the lottery or a sure payment of $\$ 550$, then, according to eq (4.3), the CEF $=1.1$ (i.e., $\$ 550 / \$ 500$ ), and the decision maker is a risk taker. On the other hand, if the decision maker is indifferent between the lottery or a sure payment of $\$ 400$, then the CEF $=0.8$ (i.e., $\$ 400 / \$ 500$ ), and the decision maker is risk averse.

Although the decision maker might have some vague notion of the level of investment risk using this approach, risk exposure is not included explicitly in the derivation of CEF.

${ }^{49}$ For a LCC analysis, the $\mathrm{CEF}_{\mathrm{t}}$ adjustment would be in the opposite direction. That is, as risk aversion and exposure increase, $\mathrm{CEF}_{\mathrm{t}}$ becomes larger, making $\mathrm{LCC}_{\mathrm{ce}}$ larger. 
Now consider the second approach to the derivation of the CEF, where the derivation is based on risk exposure. This approach seems particularly appropriate for private firms. They often have a historical record of business performance for different types of investments. The record can be used to establish $\mathrm{CEF}$ values for evaluating proposed investments that are similar. The first step in deriving a CEF table is to divide the firm's investments into categories such as "new plant" and "equipment replacement" as shown in table 4-1. The next step is to divide these general categories into subcategories based on their historical risk-return records as indicated by their coefficient of variation. ${ }^{50}$ The final step is to assign CEFs by year according to the coefficients of variation. ${ }^{51}$

Table 4-1. A firm's certainty equivalent factor table for use in adjusting net cash flows from uncertain investments

Investment Categories

Coefficient

of Variation
Certainty Equivalent Factor

Year 1 Year 2 Year 3

$\begin{array}{lcccc}\text { New Plant A } & \mathrm{v} \leq 0.15 & 0.94 & 0.90 & 0.84 \\ \text { New Plant B } & \mathrm{v}>0.15 & 0.90 & 0.86 & 0.79 \\ \text { Equipment Replacement A } & \mathrm{V} \leq 0.15 & 0.98 & 0.94 & 0.89 \\ \text { Equipment Replacement B } & \mathrm{V}>0.15 & 0.94 & 0.88 & 0.81\end{array}$

The greater the coefficient of variation of cash flows for a given investment subcategory, the greater is the risk exposure associated with that subcategory, and therefore the smaller is the subjectively determined $\mathrm{CEF}$ to be assigned to each year for that subcategory. Looking at table 4-1 again, for each year, the $\mathrm{CEF}_{\mathrm{t}}$ for "new plant B," for example, would be smaller than for "new plant A". Note also that, since the performance of replacement equipment is likely to be more certain than that of new equipment, the CEFs would typically be larger for the replacement equipment.

The procedure for using the CEFs established in table 4-1 in an $\mathrm{NB}_{\text {ce }}$ evaluation is as follows: determine for the proposed investment the appropriate investment category and its coefficient of variation; find the $\mathrm{CEF}_{\mathrm{t}}$ for each year for that investment category and coefficient of variation; and use eq (4.2) to determine the $\mathrm{NB}_{\mathrm{ce}}$.

${ }^{50}$ The coefficient of variation is the standard deviation divided by the mean. See section 5.2 for a discussion of the coefficient of variation.

${ }^{51}$ Determining CEFs with the help of probability functions puts the certainty equivalent technique in the category of risk analysis techniques that are to be examined in chapter 5. However, since the CEF is also derived without the use of probability functions, as shown in eq (4.2), the technique is discussed here. 
To illustrate the impact on project choice of handling risk with the CEF, consider once again the time clock. Three decision makers are individually examining the same time clock investment. Assume that one views the weighted average of $\mathrm{CEF}_{\mathrm{t}}$ as equal to 1.0 for the time clock. Assume further that, for this case, $\mathrm{NB}$ and, therefore, $\mathrm{NB}_{\mathrm{ce}}$ are positive. Thus the decision maker finds the time clock cost effective. Let us assume that the second person assigns a weighted average value to CEF greater than 1.0. Using the same $\mathrm{NB}$ value, $\mathrm{NB}_{\mathrm{ce}}$ for the second person will be higher than for the previous case. Finally, if we assume for the third person that the weighted average value of CEF is less than 1.0, then the project yields lower $\mathrm{NB}_{\mathrm{ce}}$ than it did for the other two persons, and $\mathrm{NB}_{\text {ce }}$ could even be negative.

One advantage of the CEF technique is that it accounts for risk by a factor that can include both the decision makers's risk attitude and assessment of risk exposure. If the CEF is based on risk attitude (eq (4.3)), a subjective adjustment can be made to account for risk exposure. If, on the other hand, the CEF is based on risk exposure (historical risk-return records), a subjective adjustment can be made to account for risk attitude.

Another advantage of the CEF technique is that it separates the discounting procedure that accounts for the time value of money from adjustments for risk, both of which are combined in the RADR technique. By so doing, it allows for differential risk "weighting" over time, which might be more appropriate than the increasingly heavy discounting for risk over time implicit in the RADR technique. Finally the CEF can be used with probabilistic data (sec. 5.5.3) and formal utility models (ch. 3).

A limitation of the CEF application is that it is "data hungry," and the procedure for "feeding" it is to a large extent subjective.

Another limitation of the CEF technique is the lack of a rigorous, theoretically defensible, mathematical expression for establishing a CEF that combines risk attitude and risk exposure. While it is an advantage of the CEF that risk attitude and risk exposure can be treated in one factor, combining the two types of risk adjustment subjectively is not acceptable to many decision makers. The first approach using eq (4.3) fails to measure explicitly risk exposure. The second approach, based on historical experience, treats risk exposure explicitly, but attitude only implicitly. A CEF that explicitly treats exposure and attitude would assure a more comprehensive, consistent, and objective treatment of risk in project evaluation. 


\section{TECHNIQUES THAT USE PROBABILITY}

The five techniques described in this section use probability or cumulative distribution functions to describe input values, measures of worth, or both. The techniques are presented generally in order of increasing complexity.

\subsection{Input Estimation Using Expected Values 52}

A frequently used technique is to apply expected value analysis (also known as probability analysis) to the estimation of uncertain input data. An "expected value" of an input is found by summing the products of possible input values and their respective probabilities of occurrence. The values of any number of inputs can be estimated by this technique. The "expected" input values are ultimately used to compute a singlevalue measure of project worth. Again the time clock is used in illustration. To calculate the BCR for the time clock, let us examine uncertainty regarding the $\mathrm{kWh}$ critical input. The $\mathrm{kWh}$ savings resulting from the time clock determine in part its BCR. Taking, for example, an annual after-hours energy consumption of $230,000 \mathrm{kWh}$, we might expect one of the following three levels of $\mathrm{kWh}$ reductions in consumption: $184,000,138,000$, or $92,000 \mathrm{kWh}$. Table 5-1 shows how the expected value of the energy reduction input value is obtained from the potential $\mathrm{kWh}$ reductions and their estimated probability weights.

Table 5-1. Expected value of reduction in kilowatt hours

\begin{tabular}{ccc}
\hline $\begin{array}{c}\text { Reduction in Energy } \\
(1,000 \mathrm{kWh})\end{array}$ & $\begin{array}{c}\text { Expected Value } \\
\text { of Reduction } \\
(1,000 \mathrm{kWh}) \\
(3)=(2) \cdot(1)\end{array}$ & 74 \\
184 & 0.4 & 69 \\
92 & 0.5 & 9 \\
& 0.1 & 152 \\
\hline
\end{tabular}

The expected reduction of $152,000 \mathrm{kWh}$ is unlikely to be the exact reduction achieved. However, if expected values were used over repeated applications, the differences between actual values and predicted values would tend to be less than if point estimates were used. This is the primary contribution of using expected value analysis to estimate input values.

52 Note that expected values might be computed in using any of the techniques in this section, and can be computed for measures of project worth as well as for inputs. However, the expected-value technique, as used here, refers specifically to the weighted average of an input value, and is described in this subsection solely as a way of handling the uncertainty associated with input variables. 
To compute the monetary benefits of the time clock, the expected value of energy reductions is combined with estimates of values (point estimates or expected values) for the energy escalation rate and initial energy price. Uncertainty has been treated regarding $\mathrm{kWh}$ to the extent that several possible values were considered for $\mathrm{kWh}$ reductions.

A major shortcoming of this technique is that a single BCR value provides no measure of risk exposure. Also, there is no treatment of risk attitude. Finally, applications are limited to problems where input distributions can be developed.

\subsection{Mean-Variance Criterion and Coefficient of Variation}

Comparing the mean values and standard deviations of the measure of project worth can help decision makers evaluate returns and risk exposure of one project versus another and determine stochastic dominance. ${ }^{53}$ If two projects competing for limited funds are being compared on the basis of BCRs, for example, the mean-variance criterion dictates that the one with the higher mean (i.e., expected value) and lower standard deviation be chosen. This presumes that decision makers prefer higher BCRs to lower BCRs and less risk to more risk. ${ }^{54}$

If one project has a higher mean and higher standard deviation of the measure of project worth, then the choice is not clear with the mean-variance criterion. In this case, the coefficient of variation can be computed to determine the relative risk of the two projects. The coefficient of variation is found by dividing the standard deviation by the mean as shown in eq (5.1):

$$
\mathrm{CV}=\sigma / \mu
$$

where $C V=$ coefficient of variation,

$\sigma=$ standard deviation, and

$\mu=$ mean or expected value.

The project with the lower coefficient of variation has the lesser risk per unit of return or project worth. It will be preferred by risk averse decision makers. Risk taking decision makers, on the other hand, will prefer the project with the higher coefficient. ${ }^{55}$

An advantage of the coefficient of variation is that it provides an explicit measure of risk exposure. Another is that risk attitude is considered when the decision maker evaluates the coefficients of variation to choose among alternative projects. The major limitation is in acquiring the $\sigma$ and $\mu$ values for the measure of project worth.

53 See chapter 3 for a discussion of the mean, standard deviation, and stochastic dominance.

${ }^{54}$ Both the mean-variance criterion and coefficient of variation are typically applied under the assumption that the decision maker is risk averse.

55 Another technique sometimes used for evaluating alternatives with just $\sigma$ and $\mu$ is the "gambler's indifference map." Indifference curves, each of which connect equally attractive combinations of $\sigma$ and $\mu$, are constructed to help select the preferred alternative. For a description and case example of this technique, see Tung Au, Richard M. Shane, and Lester A. Hoel, Fundamentals of Systems Engineering: Probability Models (Reading, Massachusetts: Addison-Wesley Publishing Company, 1972), pp. 185-187. 


\subsection{Decision Analysis}

Decision analysis is one of the few techniques for making economic decisions in an uncertain environment that treats formally both risk exposure and risk attitude. It provides a methodology that allows a decision maker to include alternative outcomes, risk attitudes, and subjective impressions about uncertain events in an evaluation of investments. 56

Decision analysis typically uses decision trees to represent all possible outcomes, costs, and probabilities associated with a given decision problem. A decision tree is a decision-flow diagram that serves as a road map to clarify possible alternatives and outcomes of sequential decisions. A decision tree is used in this section to illustrate how it helps bring order to complex decisions about risky investments.

Procedures for using decision analysis are documented extensively in the literature. ${ }^{57}$ In general, the decision analysis approach has three steps. The first is to structure the problem. This includes defining variables, describing with models their relationships, assigning values to possible outcomes, and measuring the importance of the variables through sensitivity analysis. The second step is to assign probabilities to important variables and possible outcomes, and to find the "best" alternative. This includes describing uncertainty with probability distributions, describing risk attitude with a utility function, and finding the alternative that is expected to yield the greatest economic return (or utility if the decision maker is not risk neutral). The third step is to determine whether obtaining additional information is worth the cost. If it is, then the information is collected, and steps 1 and 2 are repeated.

This three-step procedure is not required for every decision analysis. In fact, several of the operations described will not be included in the illustration to be given in this chapter. However, the procedure is useful as a reference when deciding which operations are necessary for applying decision analysis to a specific problem.

\subsubsection{Decision Analysis of Energy Conservation Investment}

This illustration examines an energy investment problem facing a state energy office. The office has been directed to make a choice regarding an energy conservation project from among six possibilities for retrofitting two public buildings. The purpose of the conservation project is to demonstrate to private companies that energy conservation is profitable. The objective of the decision analysis exercise is to choose the retrofit package that yields the maximum net benefits (NB), i.e., shows the greatest profit potential. If none of the packages yields a positive NB, the choice will be not to invest at all.

Two types of retrofit costs are considered. The first is a fixed retrofit investment cost that is incurred for energy conservation work in each building regardless of which retrofit package is chosen. The second is the cost of implementing the individual retrofits in each package. The present value fixed investment (F1 and F2) costs and retrofit package (R1-R6) costs are shown in table 5-2. All costs are assumed to be certain.

${ }^{56}$ Decision analysis as defined here is based on Bayesian analysis; that is, uncertainty regarding input variables and outcomes is quantified probabilistically, and statistical conclusions are interpreted in the direct probability sense. For a comprehensive argument that supports Bayesian decision theory, see James $O$. Berger, Statistical Decision Theory and Bayesian Analysis, 2nd Ed. (New York, New York: Springer-Verlag, 1985) pp. 119-286.

${ }^{57}$ See, for examples, Berger, Statistical Decision Theory and Bayesian Analysis; Matheson and Howard, "An Introduction to Decision Analysis," pp. 9-43; C. S. Stael von Holstein, "A Tutorial in Decision Analysis," Readings in Decision Analysis, pp. 119-145; and Raiffa, Decision Analysis. 
Table 5-2. Fixed investment and retrofit package cost for buildings I and II (cost in millions of \$)

\begin{tabular}{|c|c|c|c|c|c|c|c|}
\hline \multicolumn{4}{|c|}{ Building I } & \multicolumn{4}{|c|}{ Building II } \\
\hline F1 & R1 & $\mathrm{R} 2$ & R3 & $\mathrm{F} 2$ & $\mathrm{R} 4$ & R5 & R6 \\
\hline 0.5 & 2.0 & 3.0 & 4.0 & 0.8 & 3.0 & 4.0 & 4.5 \\
\hline
\end{tabular}

The predicted benefit outcomes (dollar energy savings in present value terms) are uncertain for the different retrofit packages. Table 5-3 shows estimates of these possible benefit outcomes with their respective probabilities of occurrence. Since the state is assumed to be risk neutral and act so as to maximize the expected monetary value of its investments, we need not concern ourselves with risk attitude and the corresponding utility measures of outcomes.

A helpful aid in carrying out a decision analysis is a decision tree. The decision tree in figure 5-1 clarifies the possible alternatives and outcomes listed in tables 5-2 and 5-3. The following explanation describes the potential paths of the decision tree starting from the left side. 58

The basic alternative of not investing is indicated by the top line segment coming out of the box on the left side of figure 5-1. The fixed investment of $\$ 500,000$ in building $I$ is shown by the next line, and the investment of $\$ 800,000$ in building II is shown by the bottom line. Each box in a decision tree represents a "decision juncture" or "node," and the line segments represent "alternative branches" on the decision tree. The state energy office will select that branch sequence that they expect will maximize the present value of net benefits from conservation.

Associated with each building is another decision node, requiring a decision regarding a specific set of retrofit choices, R1-R3 or R4-R6. The known costs of each retrofit package are shown under each alternative branch.

The benefit outcomes (dollar energy savings) are uncertain for the different retrofit packages. Thus at the end of each retrofit package branch is a "chance node" or "juncture" followed by "alternative outcomes." Retrofit package R1, for example, is followed by a chance node, indicated by a circle, with two potential outcomes. The probability of each alternative outcome is indicated on top of its line and the value of each alternative outcome at the tip of its line.

One way to establish the probability and outcome values is for the analyst to discuss with engineers, architects, building managers, equipment manufacturers, and other knowledgeable people the implications of alternative retrofit packages in buildings $\mathrm{I}$ and II.59 The outcome values at the branch tips will be based on anticipated potential impacts of changes in uncertain input variables, including energy prices, length of system life, performance of the conservation retrofits, and the quantity of energy saved.

${ }^{58}$ The procedure for finding the package that yields maximum net benefits requires starting from the right side of the tree, as will be shown later. It is easier to explain the tree structure, however by starting from the left.

${ }^{59}$ For an example of how to obtain a judgmental probability distribution, see Raiffa, Decision Analysis, pp. 161-168. 
Table 5-3. Possible benefit outcomes and their estimated probabilities of occurrence for the six retrofit packages

\begin{tabular}{|c|c|c|}
\hline $\begin{array}{l}\text { Retrofit } \\
\text { Packages }\end{array}$ & $\begin{array}{c}\text { Possible } \\
\text { Benefit } \\
\text { Outcomes } \\
\text { (millions of } \$ \text { ) }\end{array}$ & $\begin{array}{c}\text { Estimated } \\
\text { Probabilities }\end{array}$ \\
\hline R1 & $\begin{array}{l}3.0 \\
2.0\end{array}$ & $\begin{array}{l}0.9 \\
0.1\end{array}$ \\
\hline R2 & $\begin{array}{r}4.5 \\
3.0 \\
-1.0\end{array}$ & $\begin{array}{l}0.6 \\
0.3 \\
0.1\end{array}$ \\
\hline R3 & $\begin{array}{l}6.0 \\
4.0 \\
2.0\end{array}$ & $\begin{array}{l}0.7 \\
0.2 \\
0.1\end{array}$ \\
\hline R4 & $\begin{array}{l}4.0 \\
3.0 \\
2.5\end{array}$ & $\begin{array}{l}0.8 \\
0.1 \\
0.1\end{array}$ \\
\hline R5 & $\begin{array}{l}7.0 \\
4.5 \\
4.0\end{array}$ & $\begin{array}{l}0.5 \\
0.4 \\
0.1\end{array}$ \\
\hline R6 & $\begin{array}{l}7.0 \\
4.5 \\
1.0\end{array}$ & $\begin{array}{l}0.5 \\
0.3 \\
0.2\end{array}$ \\
\hline
\end{tabular}

Looking again at the first decision node, starting at the left of the decision tree, let us trace out one set of decisions with its possible outcomes. If the state energy office invests in building I for $\$ 500,000$ and chooses the R1 package of retrofits for an additional $\$ 2,000,000$, there is a 90 percent probability that the outcome (payoff) will be $\$ 3,000,000$ and a 10 percent chance it will be only $\$ 2,000,000$.

Let us also examine how some of the outcome and probability values might have been derived. The 90 percent probability associated with $\mathrm{R} 1$ for a $\$ 3,000,000$ payoff might be due to the $\mathrm{R} 1$ conservation package being a well-tested one with predictable results. On the other hand, R2 might contain conservation options that are new and untried, thereby explaining the spread of possible outcomes and the lower probabilities. And since there is no record of performance, and there is some chance of the conservation options not working, a 10 percent probability of a loss of $\$ 1,000,000$ is included in $\mathrm{R} 2$, as shown on the bottom outcome branch.

The outcome values at the tips of the outcome branches, the probabilities on the outcome branches, and the retrofit and fixed building costs on the alternative branches have been estimated (tables 5-2 and 5-3). The values shown at each decision node and chance node, on the other hand, must be calculated. The following 


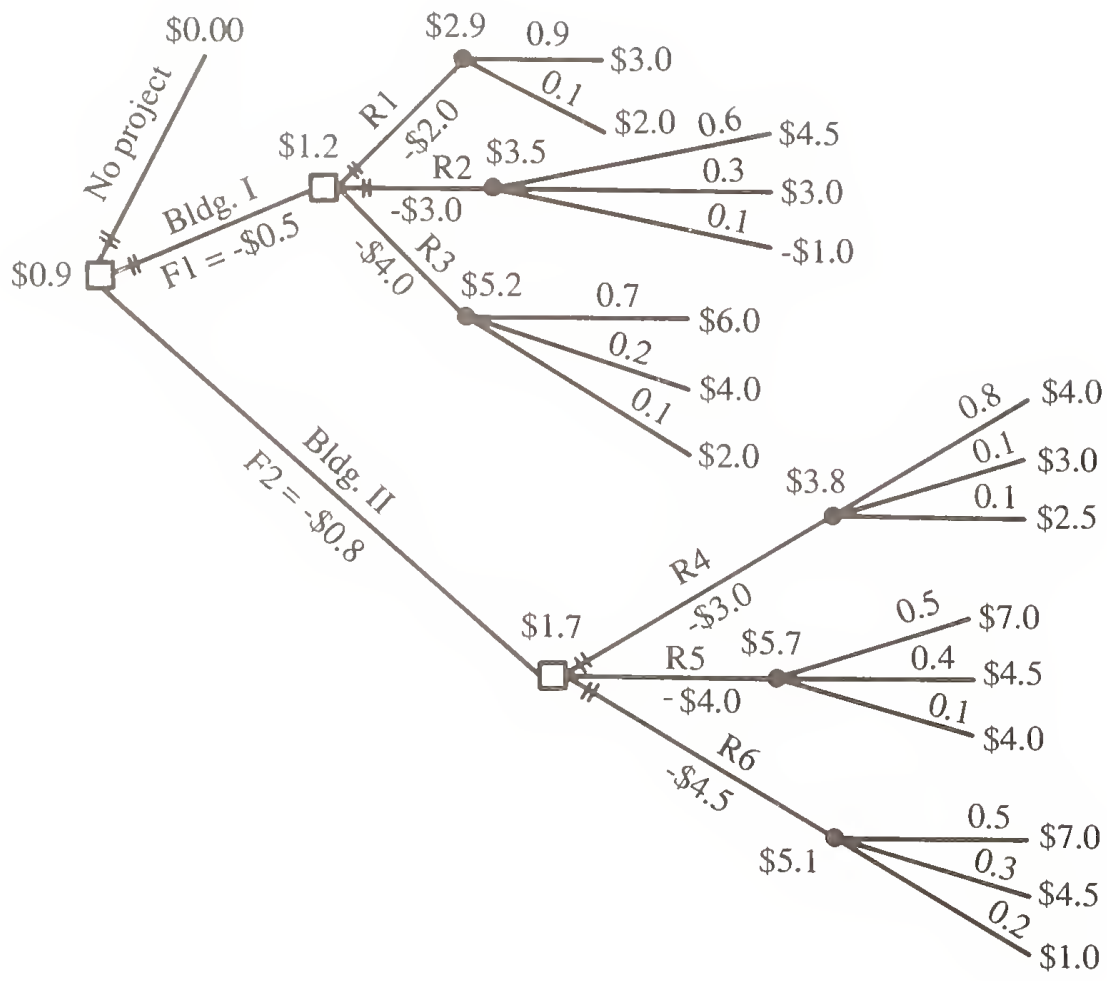

Figure 5-1. Decision tree for conservation investment (\$ values are in millions). $\square=$ Decision Node

$-=$ Chance Node

$\mathrm{R}=$ Retrofit Package

steps describe the calculation process for the node values and how to determine the retrofit choice that maximizes net benefits. Note that the calculation process starts from the right side of the tree and works backwards to the left side.

First, starting from the right-hand side of the tree, the expected value is averaged out for each chance node; that is, a weighted average is calculated for each probability fan by summing the products of the possible outcomes weighted by their respective probabilities. For example, the expected value of the probability fan of $\mathrm{R} 1$ ( $\mathrm{R} 1 \mathrm{EV}$ ) is computed as follows:

$$
\mathrm{R}_{\mathrm{EV}}=0.9(\$ 3,000,000)+0.1(\$ 2,000,000)=\$ 2,900,000 .
$$

The expected value is written atop each chance node, as shown in figure 5-1.

The second $s_{2} \Rightarrow$ is to fold or roll back to the preceding stage. That is, at each decision node the alternative branches are evaluated for their expected benefits and costs, and the one with the highest net benefits (all benefits and costs are assumed to be in present value terms) is selected. The net benefits calculated for the most efficient alternative branch is written atop the decision node box. For example, if 
we fold back the decision node values on the building II path sequence, we find expected NB values (before subtracting the $\$ 800,000$ building II fixed cost) for R4-R6 as follows:

$$
\begin{aligned}
& \mathrm{R}_{\mathrm{NB}}=\$ 3,800,000-\$ 3,000,000=\$ 800,000, \\
& \mathrm{R} 5_{\mathrm{NB}}=\$ 5,700,000-\$ 4,000,000=\$ 1,700,000, \text { and } \\
& \mathrm{R}_{\mathrm{NB}}=\$ 5,100,000-\$ 4,500,000=\$ 600,000 .
\end{aligned}
$$

The preferred (i.e., maximum NB) branch is $\mathrm{R5}$. Its value, $\$ 1,700,000$, is written atop the decision node box. The other two paths are truncated by parallel slash marks to indicate they are less cost-effective choices.

The final step is to fold back one more time. Retrofit package R5 in Building II is the most efficient choice because its expected value of net benefits is $\$ 900,000$ (i.e., $\$ 1,700,000$ - $\$ 800,000$ ) compared to $\$ 700,000$ (i.e., $\$ 1,200,000$ - \$500,000) for retrofit package R3 in Building I and zero dollars for having no project. The maximum expected value is entered at the initial decision node box at the far left of the decision tree. Parallel slash marks are used to truncate the "no project" and Building I paths. Thus the decision tree, when all values are written in, can be examined directly to determine the economically efficient path sequence (Building II/R5 in this case) and the expected value of net benefits $(\$ 900,000)$ for that path sequence.

Note that risk attitude was not addressed explicitly with utility values in this example because the state is assumed to be risk neutral (i.e., an EMV'er). If the decision maker were risk averse or a risk taker, however, the projected earnings and costs associated with each decision branch could be converted to utility values. A utility function (see sec. 3.2 and appendix B) is used to find the utility value corresponding to these benefits and costs. The averaging out to find expected values (now expected utility values) and the rolling back process are the same as described earlier. Once the alternative that maximizes utility is identified, the certain equivalent dollar value corresponding to that alternative's utility is found on the utility function. The certain equivalent value shows what the risky investment is worth, taking into consideration the decision maker's risk attitude.

\subsubsection{Advantages and Disadvantages of Decision Analysis}

An advantage of decision analysis is that it describes multiple investment alternatives in one series of calculations. For example, if each decision path sequence in figure 5-1 were evaluated as a separate project, there would be six different NB calculations to make. This could be done. The decision tree, however, provides a structure for solving directly and efficiently for the specific alternative that is likely to yield the greatest net benefits. Inefficient alternative branches are truncated in the decision analysis so that fewer calculations are required with the decision tree to arrive at the single NB value for the most efficient path sequence.

Another advantage of the decision tree structure is that it provides perspective in defining investment alternatives. It forces decision analysts to examine how the different alternatives and chance events relate to one another. And it helps them iteratively embellish, prune, and refine alternative branches before beginning the process of calculating the most efficient investment.

A disadvantage of decision analysis as shown here is that the NB values of truncated investment paths are customarily not shown. Thus the relative economic worth of alternative designs may not be apparent to the decision maker presented only with evaluation results. Lack of information could be important when other considerations might make the preferred investment an alternative that is not the most cost-effective choice. The tree structure, however, contains all the information required to generate a measure of project worth for each path sequence if a comprehensive picture is desired. 
Another possible problem with the decision tree analysis as shown in figure 5-1 is that there is no explicit measure of the risk of choosing an uneconomic project. The probability fans are for benefits only instead of NB measures of worth. Thus it is not obvious as to what the NB distributions look like. This should not make any difference to decision makers who are confident in their statements of probability and risk, because risk exposure and attitude are both handled in finding the preferred alternative. ${ }^{60}$ However, if desired, the data presented in the decision tree can be used to generate probability distributions and cumulative distribution functions of $\mathrm{NB}$ for each design. 61 If these functions are generated, then the decision tree analysis provides a profile of risk exposure.

To illustrate the generation of these functions, let us use package R2 in figure 5-1. The first step is to find the net benefits (costs) associated with each of the three probabilities associated with R2. This is done by subtracting the fixed and retrofit costs associated with the R2 path sequence from the value of each of the three possible outcomes. Thus the probability distribution values would be determined as follows:

For probability of $0.6, \$ 4,500,000-\$ 3,000,000-\$ 500,000=\$ 1,000,000$,

For probability of $0.3, \$ 3,000,000-\$ 3,000,000-\$ 500,000=-\$ 500,000$,

For probability of $0.1,-\$ 1,000,000-\$ 3,000,000-\$ 500,000=-\$ 4,500,000$.

These can be plotted as shown in the discrete probability distribution of figure 5-2. By cumulating the probabilities, the cumulative distribution function of figure 5-3 can be derived. Note that these graphs give

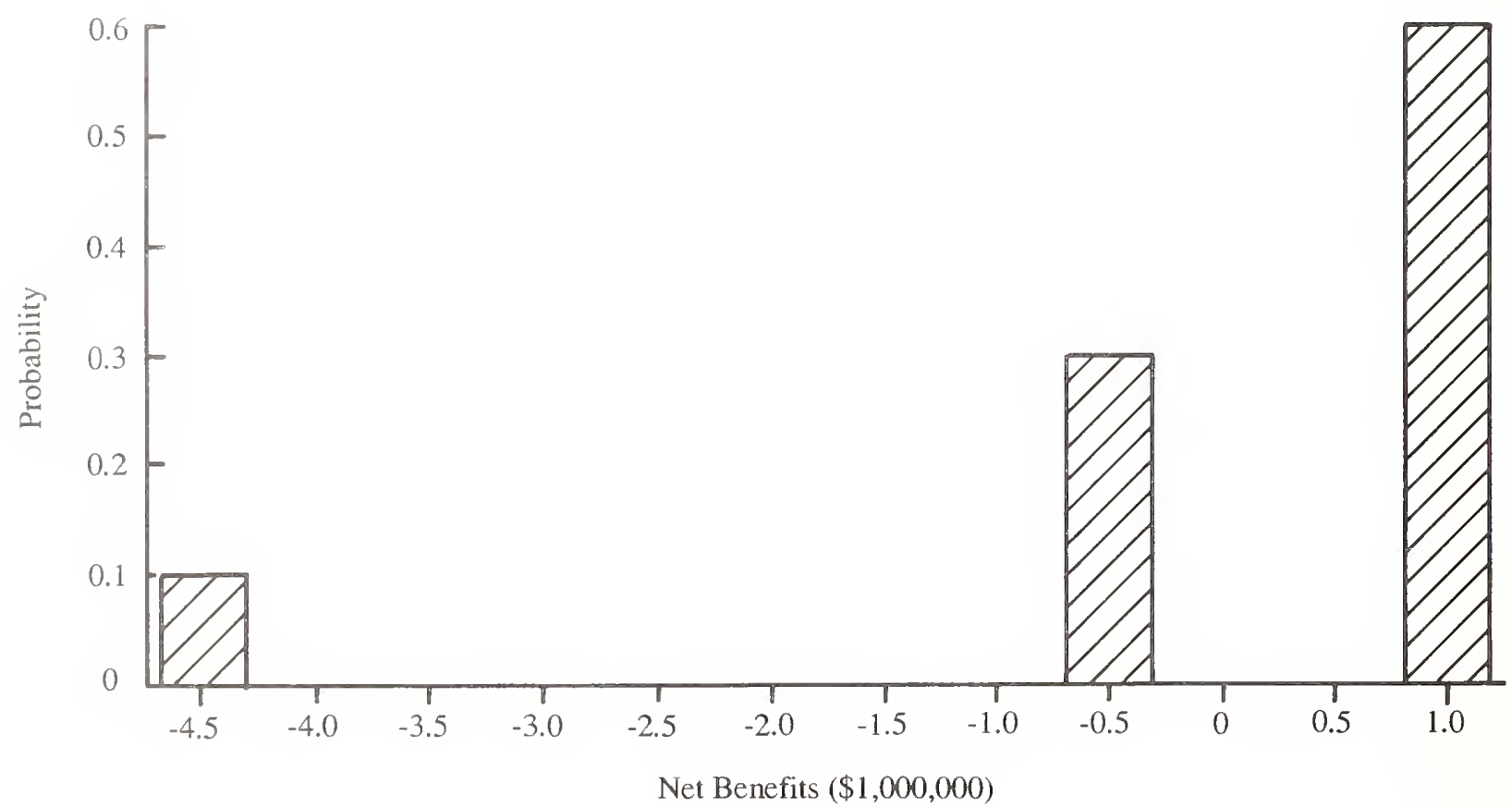

Figure 5-2. Probability distribution of net benefits for alternative outcomes from R2.

\footnotetext{
${ }^{60}$ Risk attitude is handled in decision analysis by substituting utility values for dollar values, as described in section 5.3.1. However, since the state is risk neutral, maximizing expected monetary value is the same as maximizing utility.

${ }^{61}$ See chapter 3 for a detailed discussion of probability distributions and cumulative distribution functions.
} 


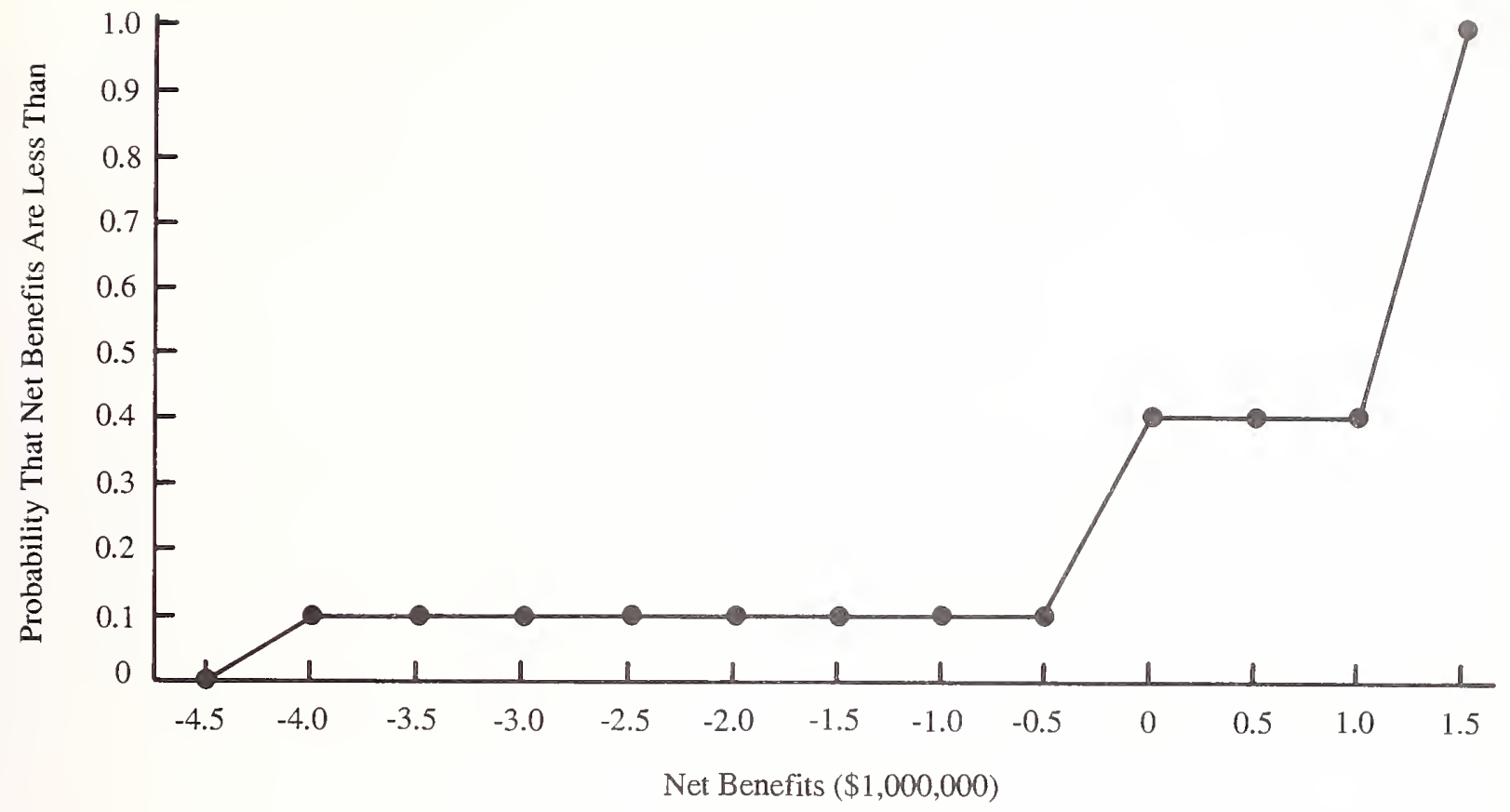

Figure 5-3. Cumulative distribution function of net benefits for alternative outcomes from R2.

additional information to that provided by the decision tree; namely, that there is a 40 percent probability that R2 will not have positive net benefits. Whereas the perceptive reader might readily intuit such probability implications from the decision tree of figure 5-1, it would be less obvious for more complex problems with complex trees. Thus providing explicit information regarding risk exposure may be helpful.

\subsection{Simulation}

Simulation is a common technique used to determine risk exposure from an investment decision. To perform a simulation, probability functions of the input variables are required. The simulation process for building a probability density function ( $\mathrm{pdf}$ ) and cumulative distribution function (cdf) of the measure of project worth is as follows: a value for each input variable is drawn randomly from its probability function; the set of input values for that round of draws is substituted into the formula for computing the measure of economic worth; and the process is repeated over and over until a pdf and cdf can be constructed for the measure of worth.

For example, in analyzing the time clock, the initial energy price, the rate of energy price escalation, and the $\mathrm{kWh}$ savings are uncertain input variables. If each of these inputs could be described by a probability distribution, a simulation could be used to arrive at a probability distribution of the time clock's BCR (or some other measure of worth). Specifically, a random combination of each of the three variables would be selected and combined with constant inputs to compute a BCR. By repeating this random sampling over and over, typically 500 to 1,000 times, and computing the BCR for each combination, a pdf and cdf can be generated for evaluating the cost effectiveness of the time clock. 
Newnan ${ }^{62}$, Pouliquen ${ }^{63}$, and $\mathrm{Hertz}^{64}$ have discussed in detail the application of simulation in measuring the risk of capital investments. Two illustrations of the concept in building economics are given here. The first is for a private investor who is evaluating the economic merits of constructing small-scale warehouse storage facilities for rent. The second is for an engineering firm that is trying to determine the appropriate bid to make on a construction project.

\subsubsection{Storage Facility Simulation Example}

A private investor wants to compute $\mathrm{NB}, \mathrm{BCR}$, and $\mathrm{AIRR}$ measures of worth to evaluate the economic merits of constructing small-scale warehouse storage facilities for rent. (Any one measure would be adequate, but all three are used to illustrate the flexibility of the simulation technique.) Examples of uncertain inputs that might affect the profitability of a warehouse are rental receipts, operating costs, resale value of the facility at the end of its holding period, and building costs. These uncertain inputs can be described by probability distributions. Random combinations of each of the variable inputs are selected and combined with constant inputs to compute a single measure of worth for each of the three methods listed earlier. This simulation process is repeated a total of 50 times. ${ }^{65}$ From each of the three sets of 50 measures of worth generated by the simulation, a pdf and cdf are constructed for evaluating the likely economic performance and risk exposure of investing in the warehouse facility.

Tax effects are included to illustrate the net effect on the investor after taxes. ${ }^{66}$ It is assumed that the investment is owner financed, so borrowing costs are not pertinent to the analysis. It is also assumed that the probability distributions are independent, so that a selection from one distribution does not affect the selections from others. Table 5-4 lists input data which are held fixed (i.e., assumed certain) in the analysis. 67

An option has been obtained to purchase 9 acres at $\$ 20,000 /$ acre for a total of $\$ 180,000.68$ The $\$ 1200 /$ unit annual rent projection is based on comparable space currently being rented. It is assumed that the real dollar value of the rent will remain the same over the 10 years; i.e., annual rents will be escalating in

${ }^{62}$ D. Newnan, Engineering Economic Analysis (San Jose, California: Engineering Press, Inc., 1980).

${ }^{63}$ L. Y. Pouliquen, Risk Analysis in Project Appraisal (Baltimore, Maryland: Johns Hopkins University Press, 1970).

${ }^{64}$ Hertz, "Risk Analysis in Capital Investment," pp. 95-106.

${ }^{65}$ The special sampling scheme used here to select values from the input distributions requires only 50 draws to characterize the distribution of project worth. This will be demonstrated later.

${ }^{66}$ The effects of personal income and capital gains taxes are computed in the case illustration. Property taxes do not enter into the calculation in this case because the local government is assumed to be granting a 10-year exemption on property taxes to attract new business to a designated area for industrial development. If property taxes were being levied, they would be accounted for in operating costs.

${ }^{67}$ The case illustration is based on estimated costs and revenues of building and operating the described facility in a lightly urbanized area of Virginia. Thanks are due Mr. David Rosoff for providing realistic figures for the analysis. He helped in identifying cost items, establishing the costs of fixed-value inputs, and in defining the shapes of pdfs describing inputs of uncertain value. Note, however, that this illustration is not intended to provide economic advice about any particular investment opportunity in storage facilities.

${ }^{68}$ The cost of the option is not pertinent to the analysis because it is a sunk cost whether or not the investment is made in the warehouse. 


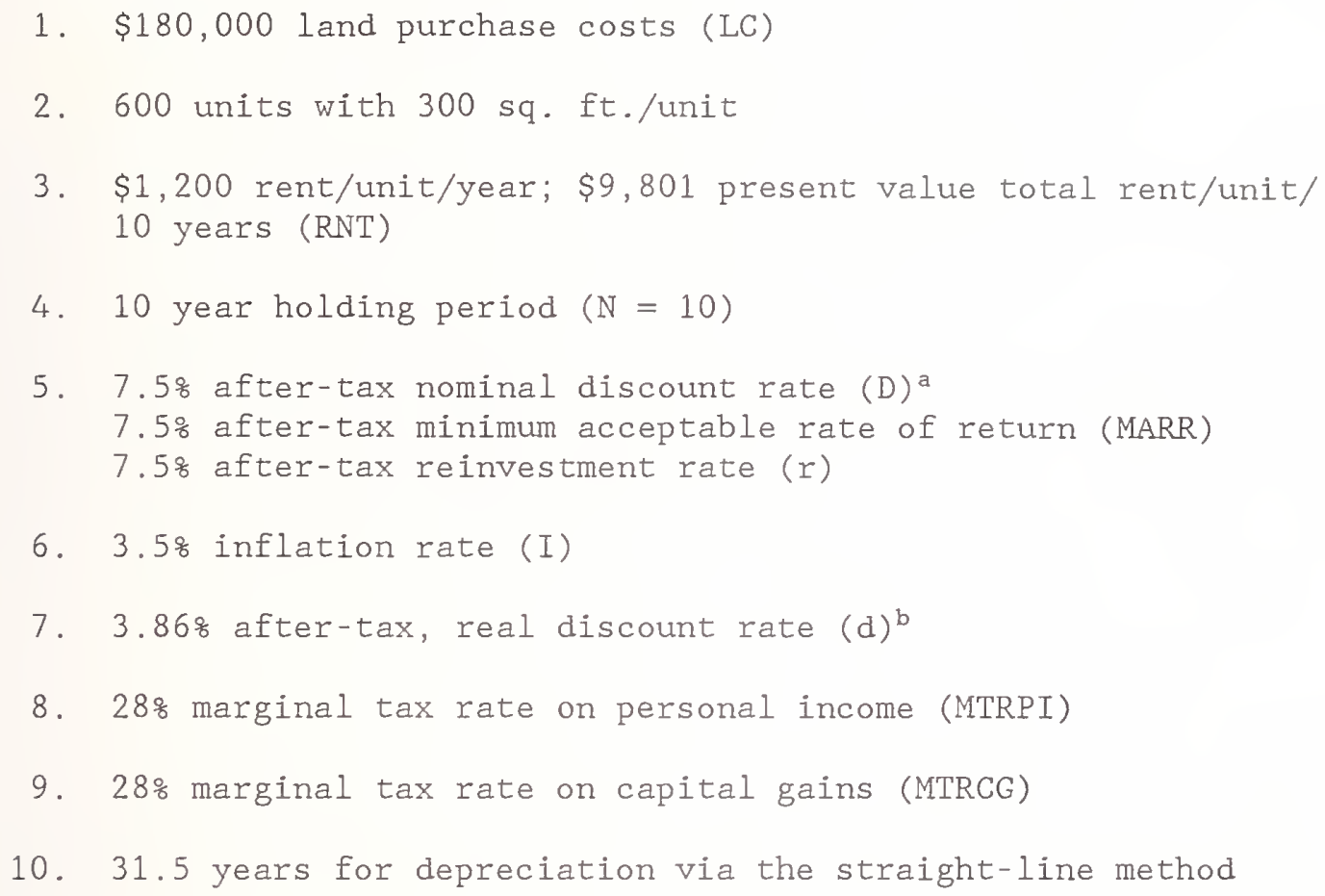

${ }^{a} D$ was selected as follows: The best available return ( $7.5 \%$ ) on a lowrisk, tax exempt bond was compared against the after-tax equivalent return $(7.37 \%)$ on the best available taxable investment of similar risk. The after-tax, equivalent rate was computed for the taxable investment by multiplying the before-tax opportunity rate by the factor 1 -ctr, where ctr is the composite Federal/State tax rate at the margin. In this case, $D=11 \%(1-0.33)=7.37 \%$. The better opportunity was the tax-exempt bond $(7.5 \%>7.37 \%)$; therefore $7.5 \%$ is the after-tax discount rate used in the analysis.

${ }^{\mathrm{b}} \mathrm{d}=((1+\mathrm{D}) /(1+\mathrm{I}))-1$, or $(1.075 / 1.035)-1$, or $\left.3.86 \%\right)$.

current dollars at the rate of general price inflation. Thus the $\$ 1,200$ figure is multiplied by the UPV factor for 10 years at 3.86 percent (i.e., UPV $=8.1677$ ) to find the present value of total rents/unit/10 years $(\$ 9,801) .69$

The input data about which there is uncertainty in this problem are revenues (rental rate multiplied times the number of units occupied), operating costs, resale value (the projected warehouse selling price in 10 years), and building costs (including both preparation costs and construction costs). The pdfs shown in figures 5-4 through 5-7 represent the uncertainty associated with each of these input factors. In each iteration of the simulation, a draw is made from the possible values in each pdf and entered into formulas for computing measures of project worth.

${ }^{69}$ The time period, t, used throughout the analysis is one year; rates of discount and inflation are quoted per annum; and the convention of end-of-year discounting is followed. The derivation of the aftertax, real discount rate of 3.86 percent is shown in a footnote to table 5-4. 


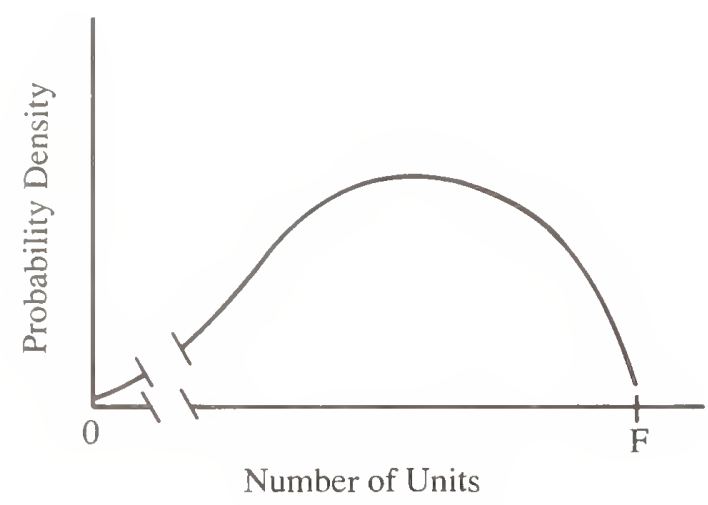

Figure 5-4. Probability density function of number of units rented.

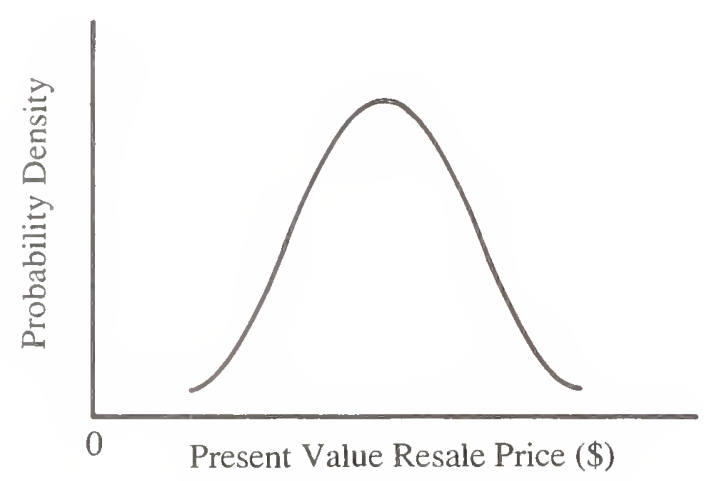

Figure 5-6. Probability density function of present value resale price.

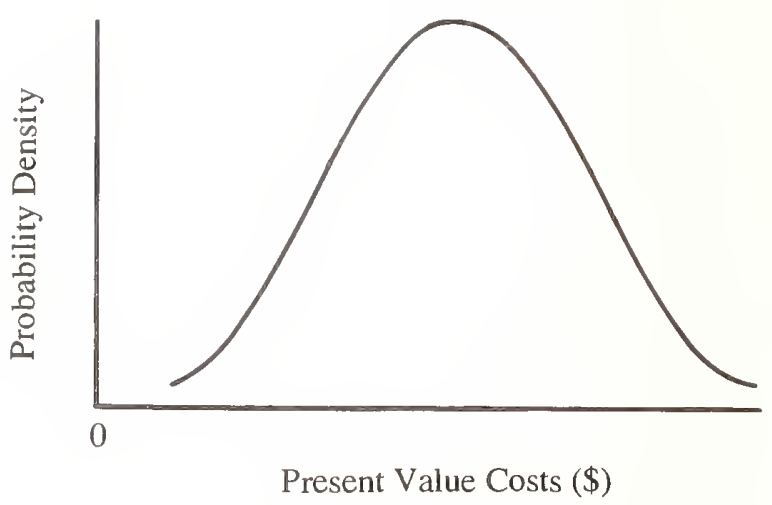

Figure 5-5. Probability density function of present value operating costs.

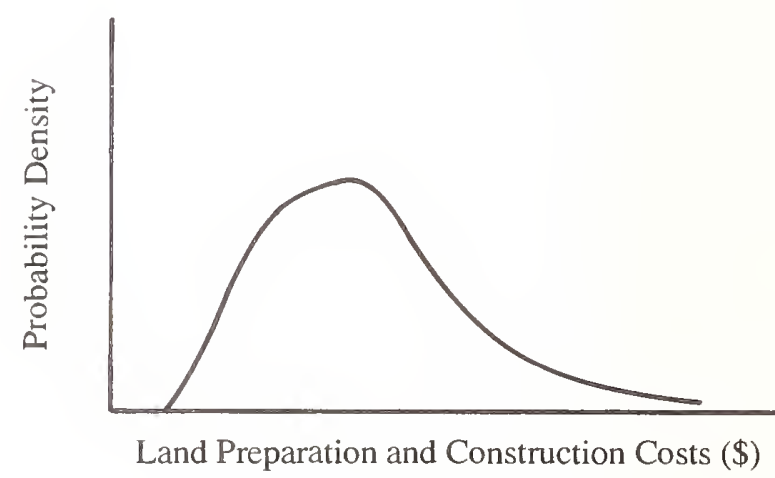

Figure 5-7. Probability density function of present value of land preparation and construction costs.

The pdf in figure 5-4 depicts the number of units expected to be rented in any given year. A gamma distribution seems best to describe anticipated rentals. The distribution has a mean of 564 units (94 percent occupancy) with a standard deviation of 12 units ( 2 percent). The left-hand tail lies close to the horizontal axis up to an occupancy level of about 520. This is the point at which the function in figure 5-4 begins to rise significantly. (Gaps in the function and on the horizontal axis occur for a range of occupancy values less than 520. These segments are not shown because the occupancy values are relatively low-probability events and the tail would be very long.) The right-hand tail does not touch the horizontal axis because there is some likelihood that all 600 units (indicated by point $F$ on the axis) could be rented. The facility is expected to fill up rapidly due to a shortage of storage in that location. Over the holding period for the facility, new renters are anticipated to quickly replace those that terminate their lease. Thus the pdf is assumed to be about the same for each year, and figure 5-4 therefore is assumed to represent the average occupancy for every year in the 10-year period. In the simulation procedure, a value is drawn from this distribution on each iteration and multiplied times the present value rental rate $(\$ 9,801)$ for the 10 years to arrive at rental revenues in the measure of economic worth. 
Annual operating costs are thought to be distributed normally, with a mean of $\$ 156,000$ (base year dollars) and standard deviation of $\$ 16,000$ (about 10 percent variation from the mean). ${ }^{70}$ Figure 5-5 shows the normal distribution of annual costs converted to a normal distribution of present value operating costs over the 10 -year holding period. The mean of the distribution is $\$ 1,274,161$. $^{71}$

The normal pdf in figure 5-6 depicts the present value resale price of the warehouse facility at the end of 10 years. It has a mean of $\$ 1,355,758$ (in present value terms) and a standard deviation of $\$ 230,479$ (about 17 percent variation from the mean). The resale price in constant dollars at the end of 10 years was projected to be $\$ 1,980,000 .^{72}$ This amount discounted at the after-tax, real rate of 3.86 percent over 10 years yields a present value of $\$ 1,355,758$. This seemingly optimistic, mean resale figure is based on the investor's perception that the property will likely hold its value as a storage facility. The higher values depicted by the right-hand tail might arise if the land were converted to a "higher and better use," thereby reflecting substantial "real" appreciation. Resale enters into the economic evaluation both as a direct benefit in terms of sale proceeds and as a component of capital gains on which taxes are levied.

Building costs are depicted by figure 5-7 as a lognormal distribution. The mean is thought to be $\$ 1,800,000$ with a standard deviation of $\$ 180,000$ (about 10 percent variation from the mean). ${ }^{73}$ The right-hand tail stretches out because unforeseen land preparation and construction problems always create the possibility of much higher costs than anticipated. Building costs will be incurred in what is expected to be a relatively short construction period and are given in present value dollars.

Three formulas (eqs (5.2) - (5.4)) based on those in table A-1 in appendix A are used to compute the economic measures of worth. ${ }^{74}$ All dollar values are in present value terms unless defined otherwise. Bars over parameters signify that they are constants. The values of these parameters are found in table 5-4. Parameters without bars are uncertain variables represented by the distributions in figures 5-4 to 5-7 or uncertain variables dependent on one of the distributions.

${ }^{70}$ Operating costs include the costs of gate attendants, liability insurance, administration, advertising, lighting, water and sewer service, and routine maintenance.

${ }^{71}$ Real annual costs of operating the facility are expected to remain unchanged over the 10 years as measured in constant dollars; i.e., current dollar annual costs are assumed to increase at the same rate as general price inflation. Therefore the conversion of annual operating costs to present values can be made by multiplying any given uniform annual cost by the UPV factor for 10 years and 3.86 percent. Thus the present value equivalent of the mean annual operating costs of $\$ 156,000$ would be $\$ 156,000$ times the UPV factor 8.1677 , or $\$ 1,274,161$.

${ }^{72}$ The projection is based on the supposition that the property might likely sell for about $\$ 1,980,000$ in constant dollars (i.e., the equivalent of its total costs of land $(\$ 180,000)$, site preparation $(\$ 900,000)$, and construction $(\$ 900,000)$.

${ }^{73}$ The estimated building costs are based on a projected $\$ 900,000$ in land preparation costs (concrete slab, paving, underground utilities, fence, lights, etc.) and $\$ 900,000$ (\$1,500/unit) in building construction costs.

${ }^{74}$ Note that substantial calculations are required to include tax effects. This is complicated by having to use current dollar amounts for tax effects and having to reconcile them with constant dollar amounts for non-tax items. 
NET BENEFITS (NB)

$$
\mathrm{NB}=\mathrm{RS}+(\overline{\mathrm{RNT}} \cdot \mathrm{UN})-\overline{\mathrm{LC}}-\mathrm{LPCC}-\mathrm{OC}-\mathrm{TX},
$$

where $\mathrm{RS}=$ resale proceeds,

$$
\begin{aligned}
& \overline{\mathrm{RNT}}=\text { rent rate/unit/10 years }=\$ 9,801, \\
& \mathrm{UN}=\text { number of units rented/year, on average, over } 10 \text { years, } \\
& \overline{\mathrm{LC}}=\text { land purchase costs }=\$ 180,000, \\
& \text { LPCC }=\text { land preparation and building construction costs, } \\
& \mathrm{OC}=\text { operating costs, and } \\
& \mathrm{TX}=\text { change in tax liability due to investment }=\text { change in personal income tax liability }(\mathrm{PTX})+ \\
& \bar{N} \\
& \text { where } \quad \text { PTX }=\overline{\operatorname{MTRPI}}\left(\left(\Sigma\left(\mathrm{RNT}^{\mathrm{CD}} \mathrm{t}\right)(\mathrm{UN})-\mathrm{OC}^{\mathrm{CD}} \mathrm{t}-\mathrm{DEPCD}\right) /(1+\overline{\mathrm{D}})^{\mathrm{t}}\right) \text {, } \\
& \mathrm{t}=1 \\
& \text { CGTX }=\overline{\text { MTRCG }}\left(\left(\operatorname{RS} \mathrm{CD}_{-}((\mathrm{LPCC}+\overline{\mathrm{LC}})-\overline{\mathrm{N}}(\mathrm{DEPCD}))\right) /(1+\overline{\mathrm{D}})^{\overline{\mathrm{N}}}\right) \text {, and }
\end{aligned}
$$

where $\mathrm{RNT}^{\mathrm{CD}} \mathrm{t}=$ rent rate/unit/year $\mathrm{t}$ in current dollars,

$$
=\$ 1,200(1+\overline{\mathrm{I}})^{\mathrm{t}}, \text { or }\left(\$ 1,200 \cdot 1.035^{\mathrm{t}}\right),
$$

$\mathrm{OC}^{\mathrm{CD}} \mathrm{t}=$ operating costs/year $\mathrm{t}$ in current dollars,

$=$ constant dollar operating costs times $1.035^{\mathrm{t}}$,

$\mathrm{DEPCD}=$ depreciation/year in current dollars,

$=\mathrm{LPCC} / 31.5$,

$\mathrm{RS}^{\mathrm{CD}}=$ resale price in current dollars,

$=$ resale price in constant dollars times $1.035^{\bar{N}}$.

BENEFIT-COST RATIO (BCR) ${ }^{75}$

$$
\mathrm{BCR}=((\mathrm{RS}+\overline{\mathrm{RNT}} \cdot \mathrm{UN})-\mathrm{OC}-\mathrm{TX}) /(\overline{\mathrm{LC}}+\mathrm{LPCC}) .
$$

${ }^{75}$ The choice of placing an item of cost or benefit in the numerator or denominator can affect the relative ranking of projects. The convention followed here is to place first or initial costs only in the denominator in order to measure returns solely on initial investment. 


$$
\mathrm{AIRR}=-1.0+(1.0+\overline{\mathrm{r}})(\mathrm{BCR})^{1 / \overline{\mathrm{N}}}
$$

where $\quad r=$ reinvestment rate, and $\vec{r}=\bar{D}$ in this problem.

Figures 5-8 through 5-10 give the cdfs for NB, BCR, and AlRR respectively. ${ }^{76}$ Looking first at figure 5-8, we see approximately, for example, a probability of 5 percent that NB will be less than $\$ 2$ million, 50 percent that NB will be less than $\$ 2.33$ million, and about 98 percent that NB will be less than $\$ 3$ million. This cdf gives a strong indication that the storage facility is cost effective with a high likelihood of a NB between $\$ 2$ million and $\$ 3$ million.

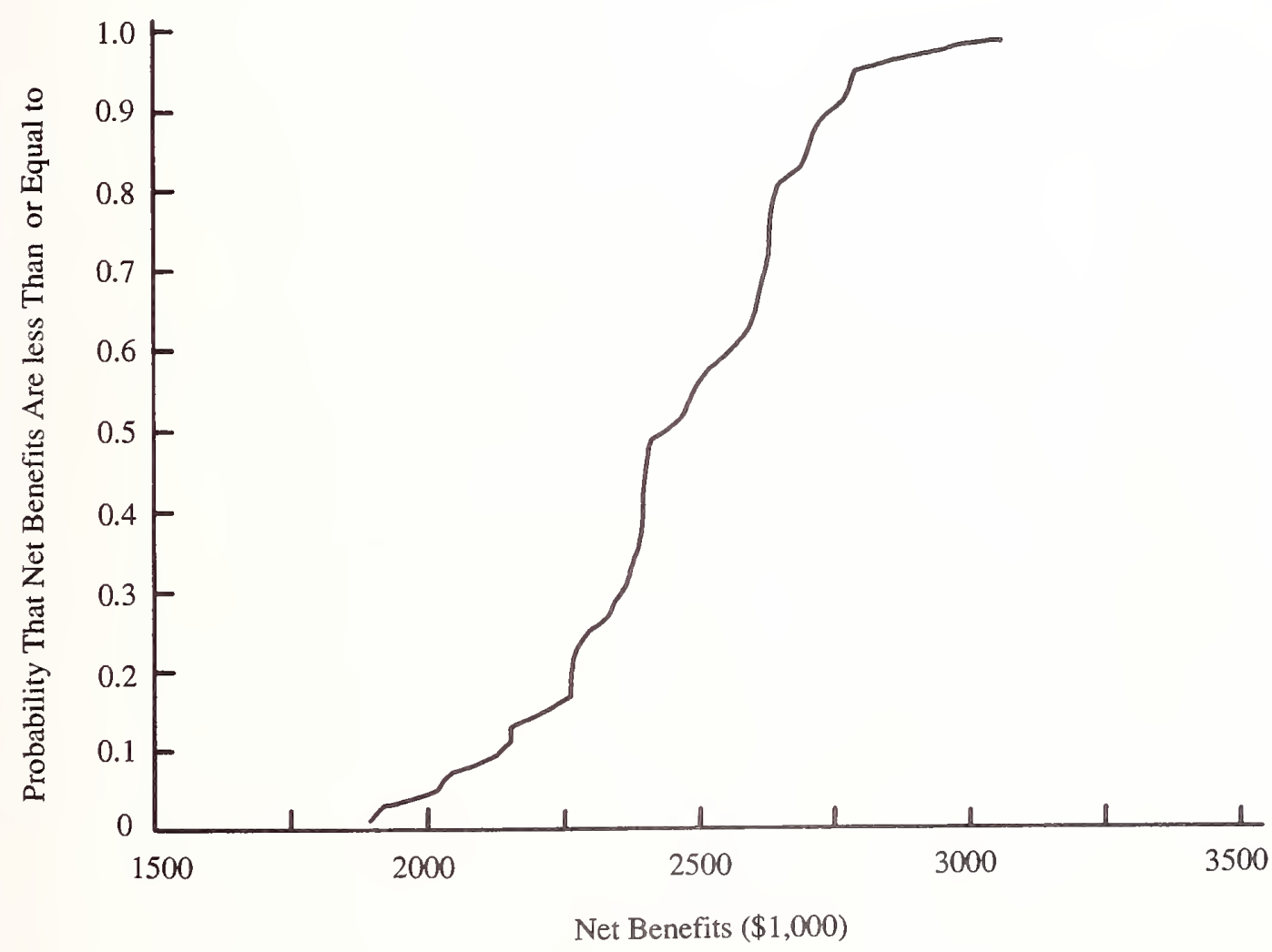

Figure 5-8. Cumulative distribution function of net benefits for the storage facility.

${ }^{76}$ The computer program to perform these simulations and plot the distributions was written and executed by Robert E. Chapman at the National Institute of Standards and Technology. 
Figure 5-9 also gives strong evidence of a cost-effective project, showing approximately a 5 percent probability that the $\mathrm{BCR}$ will be less than $1.97,50$ percent probability that the $\mathrm{BCR}$ will be less than 2.22 , and 98 percent probability that the BCR will be less than 2.5 .

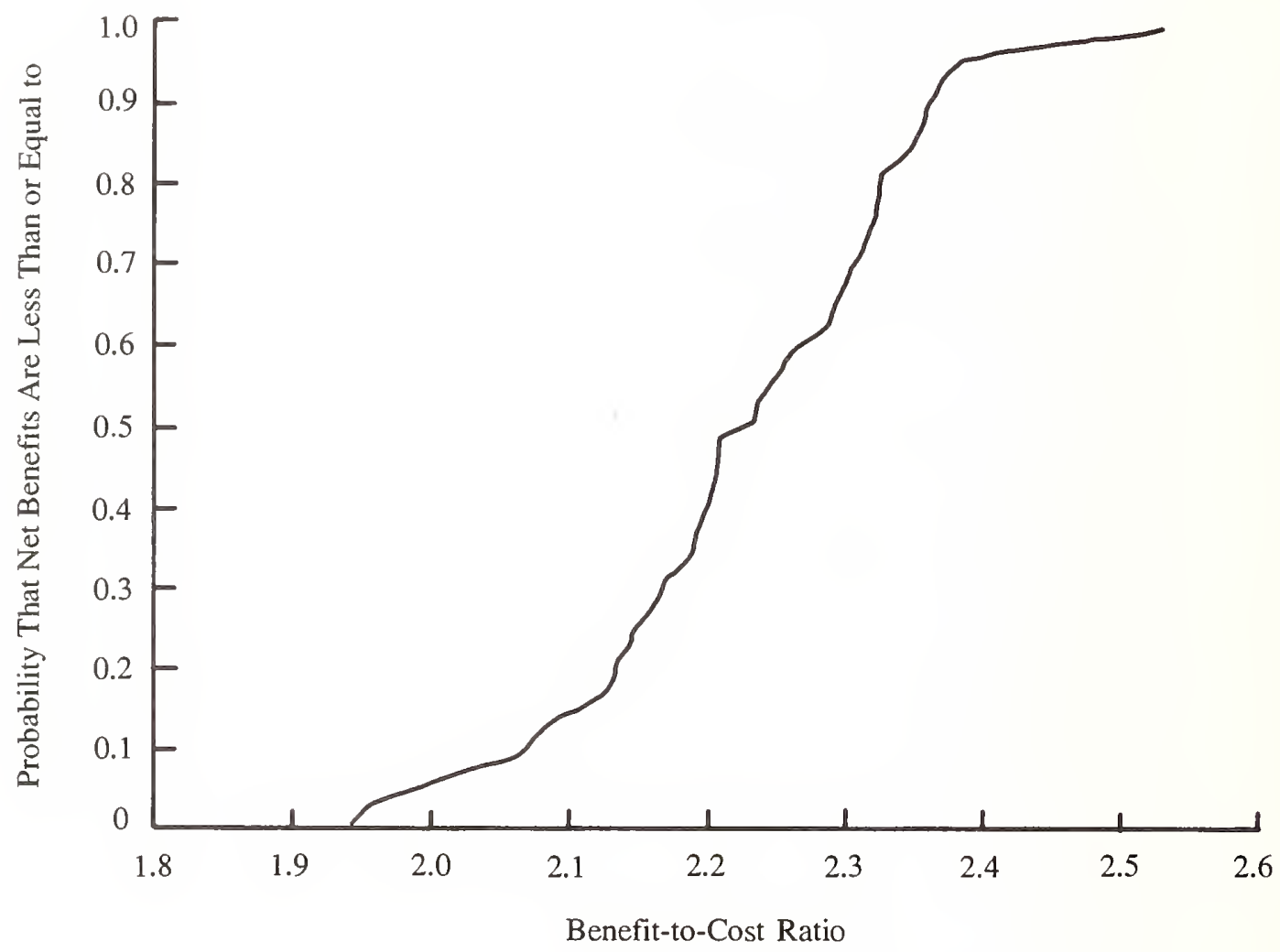

Figure 5-9. Cumulative distribution function of benefit-to-cost ratio for the storage facility.

Figure 5-10 gives similar results with the AIRR--a 5 percent probability that it will be less than 15.2 percent, 50 percent probability that it will be less than 16.4 percent, and 98 percent probability that it will be less than 17.55 percent. Recall that the MARR shown in table 5-4 is only 7.5 percent.

The Latin Hypercube sampling scheme was used to select values from the input distributions. ${ }^{77}$ With this scheme, 50 simulations are sufficient to characterize the distributions of project worth. To confirm this, two replications of the simulation, of 50 draws each, were performed for measuring net benefits. Figure 511 plots the cdfs for these two replications. The closeness of the two functions indicates that a single replication gives a relatively accurate picture of the distribution of worth.

77 The name "Latin Hypercube" comes from a class of experimental designs known by statisticians as Latin squares. This sampling scheme was selected because it requires fewer simulations than other schemes based on random sampling. For a more complete description of the sampling scheme, see Robert E. Chapman, "The Efficiency Implications of Safety Standards," Dissertation for the George Washington University, Washington, DC, 1988, pp. 360-371. 


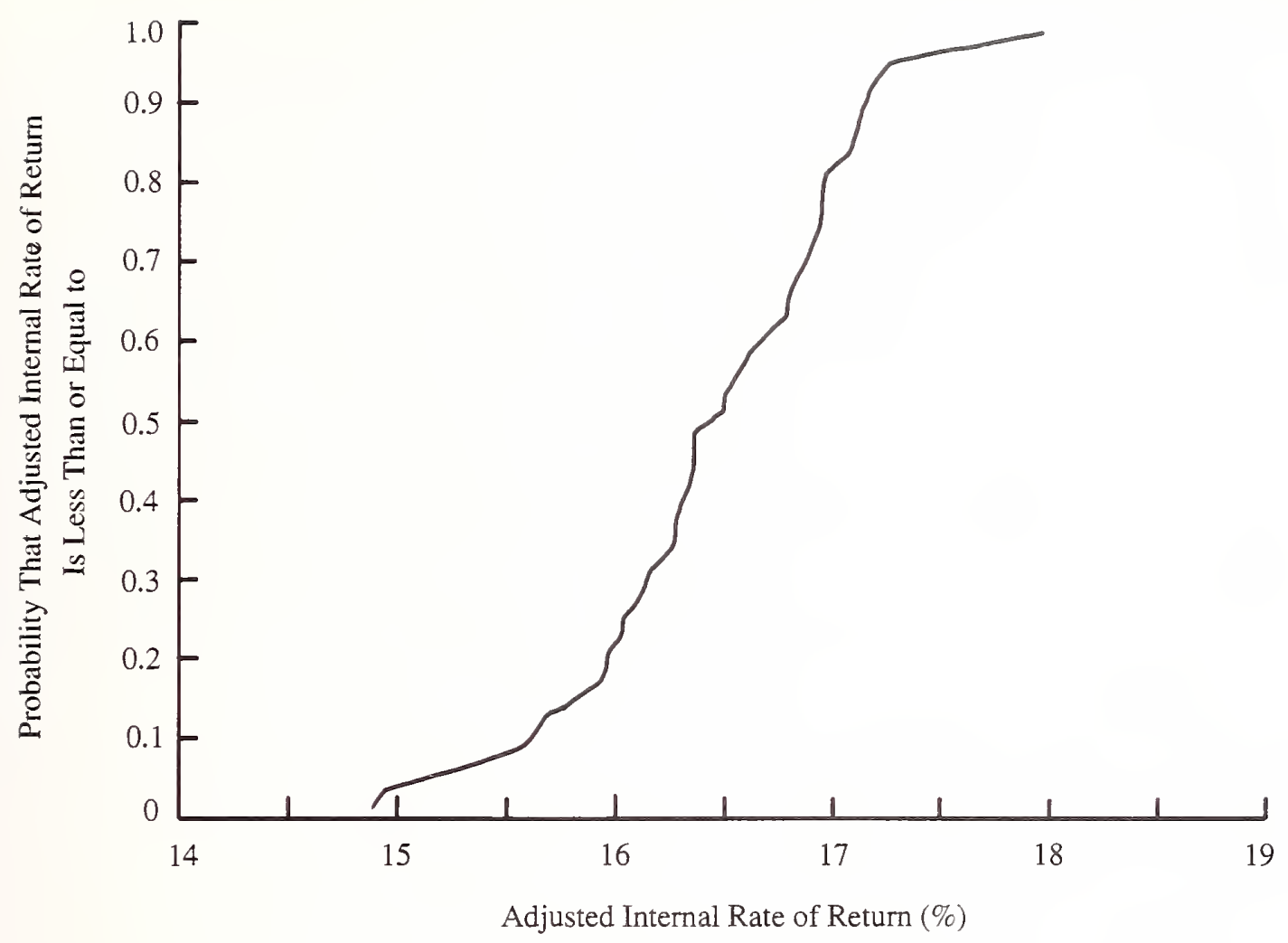

Figure 5-10. Cumulative distribution function of adjusted internal rate of return for the storage facilty. 


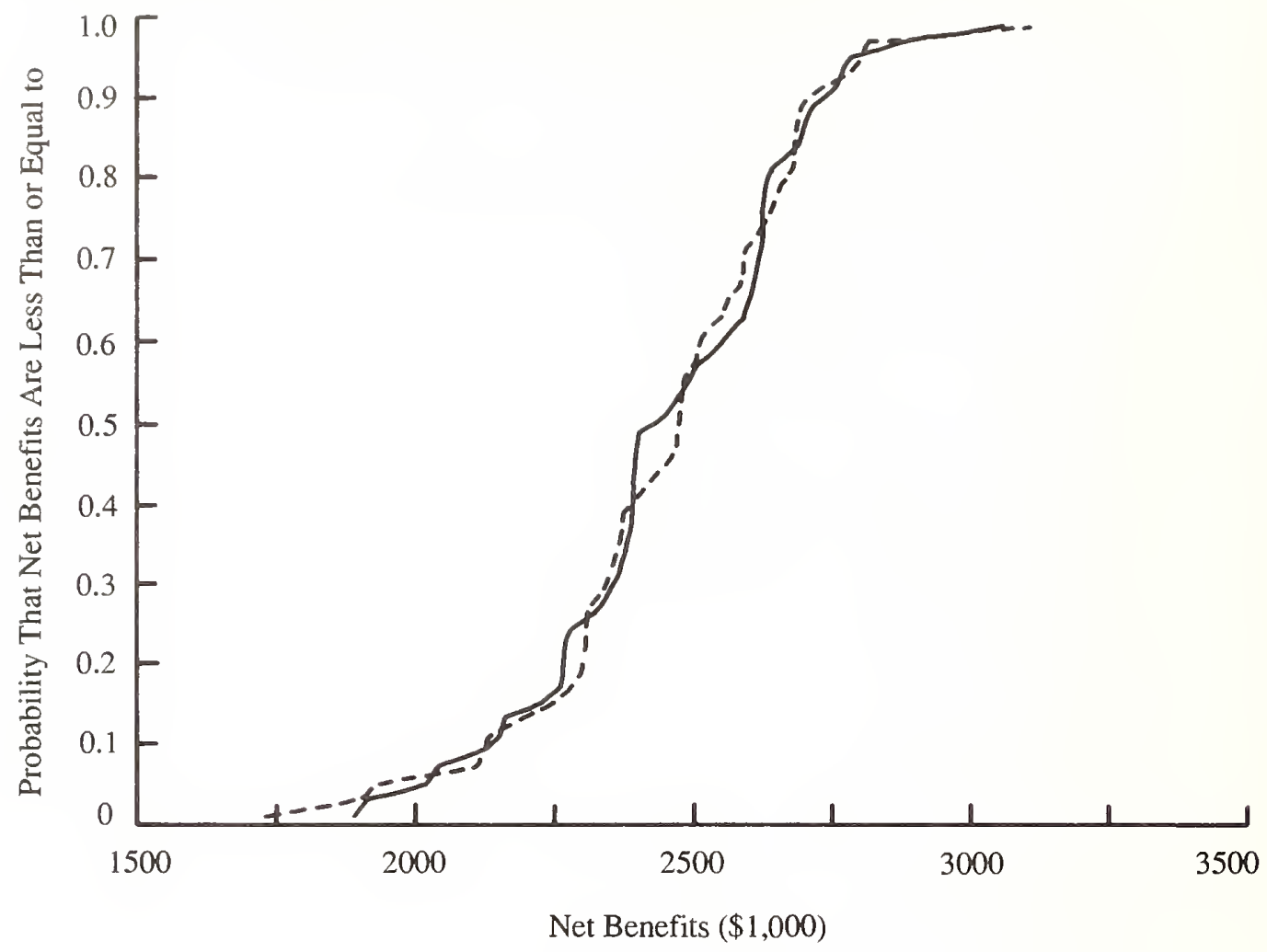

Figure 5-11. Two cumulative distribution functions of net benefits for the storage facility. Replication $1=$ solid line Replication $2=$ dotted line

\subsubsection{Construction Contingency Simulation Example}

Contingency analysis is routinely used by cost engineers in estimating the costs of construction projects. A contingency is a cost element included in project cost estimation to cover costs that have some likelihood of occurrence, but whose amounts cannot be predicated with certainty. By adding the contingency to the line-item estimate of project cost, the cost engineer hopes to project the "most likely" final cost. Typical uses of contingencies are to cover possible increases in material or labor costs beyond normal escalation, unanticipated developments in applying a first-time technology, changes in project scope due to omission or error, or unforeseen work disruptions from operating in a volatile foreign country. ${ }^{78}$

Contingencies are often estimated simply as a percentage of the base estimate of project cost. Historical data on the differences between actual and estimated costs for similar projects can be used to determine an average percentage of underestimation (or overestimation). The percentage can apply to the overall project or to specific elements of the project which are estimated separately. This simple approach is typical in estimating costs of small projects. There is no distinction, however, between accounting for risk exposure and risk attitude in the contingency estimate.

${ }^{78}$ For a more complete listing of possible types of contingencies, see James J. Stevenson, Jr., "Determining Meaningful Estimate Contingency," Cost Engineering, Vol. 26, No. 1, February 1984, pp. 35-41. 
For large construction projects, a sophisticated risk-analysis technique based on simulations is often employed in estimating contingencies. It provides decision makers with the probabilities of cost overruns (i.e., risk exposure) associated with every possible contingency markup in the relevant range. The following example from the Cost Engineers' Notebook illustrates how to use simulation to measure risk exposure when making a cost estimate for a specific construction project. ${ }^{79}$

Construction cost is being estimated for project $X$. It is expected to cost $\$ 140$ million exclusive of contingencies. Of the $\$ 140$ million, $\$ 60$ million are spent dollars or firm commitments. Being relatively certain, they require no consideration for contingency. The other $\$ 80$ million are uncertain and make up the base on which the contingency is calculated.

The process for carrying out a "contingency/risk analysis" is as follows. Probability distributions are generated for every activity that is deemed particularly uncertain. The distributions describe the percent of estimated costs of these activities, where the midpoint is 100 percent of the estimated value. These data, along with the estimated dollar costs of both certain and uncertain activities, are entered into a computer simulation package. It generates a probability distribution of the contingency percent of total project cost and a graph that plots probability of cost overrun against contingency percent and amount.

Figure 5-12 shows how the probability of a cost overrun (i.e., risk exposure) varies with the contingency adjustment for this construction project. To use this contingency/risk analysis to select a single cost

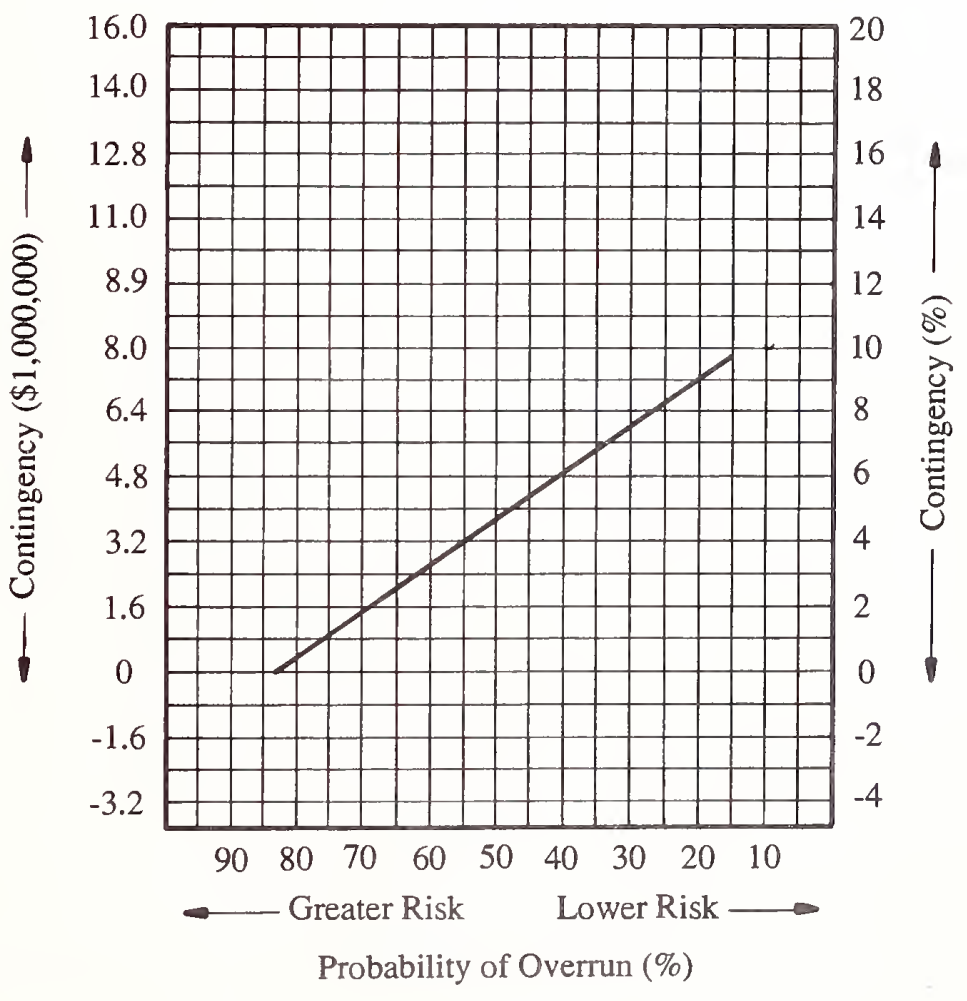

Figure 5-12*. Contingency/risk graph for construction project $\mathrm{X}$.

*S. H. Zaheer, "Contingency and Capital Cost Estimates," Cost Engineers Notebook, American Association of Cost Engineers, Morgantown, WV, March 1983, p. 13.

${ }^{79}$ S. H. Zaheer, "Contingency and Capital Cost Estimates," Cost Engineers' Notebook, A-1.200, March 1983, American Association of Cost Engineers, pp. 1-14. 
estimate, the decision maker considers risk exposure and risk attitude. Risk exposure, as indicated by the rising probability of cost overrun, increases as the percent contingency markup goes down. Risk exposure decreases as the percent contingency markup increases. Risk attitude enters when the decision maker chooses a contingency amount, thereby establishing a probability of overrun that will be acceptable.

The risk neutral decision maker would choose the most likely cost estimate of $\$ 144$ million, which includes the $\$ 140$ million without contingency plus a contingency of $\$ 4$ million $(0.05 \cdot \$ 80$ million of uncertain costs). That is, the vertical axis on the right side of the graph shows the most likely contingency percent (where the probability of overrun is 50 percent) to be about 5 percent. This assumes an underlying probability distribution which is symmetric.

A more risk averse decision maker might opt for a lower risk of overrun by choosing a larger contingency. For example, if an overrun probability of only 20 percent were acceptable, the contingency would be $\$ 7.2$ million (0.09 - \$80 million), and the total cost estimate would be $\$ 147.2$ million ( $\$ 140$ million plus $\$ 7.2$ million contingency).

On the other hand, a risk taker might choose a relatively low contingency. For example, if an overrun probability of 70 percent were acceptable, the contingency would be $\$ 1.6$ million (0.02 $\$ 80$ million), and the total cost estimate would be $\$ 141.6$ million ( $\$ 140$ million plus $\$ 1.6$ million contingency). Note that figure 5-12 is really a cdf similar to that described in figure 3-2 with two exceptions. First, figure 5-12 has the axes reversed. The item whose distribution is being measured (contingency percent and amount) is on the vertical axis instead of the horizontal axis, and the cumulative distribution measure (probability of overrun) is on the horizontal axis. Second, the cdf in figure 5-12 measures cumulative probabilities of a value being "greater than" instead of "less than," as in figure 3-2. Thus, for example, there would be about a 35 percent probability of a cost overrun with a contingency of 7 percent. That is, there is a 35 percent probability that the necessary contingency to avoid an overrun would be "greater than" 7 percent. 80

\subsubsection{Advantages and Disadvantages of Simulation}

There are several advantages of the simulation technique applied to risk analysis. First, simulation works with any kind of distribution of input variables, so it is not limited to certain classes of well-behaved distributions.

Second, it can handle interdependencies between inputs. That is, where one input is related to another, the two can be tied together. For example, if operating costs for the storage facility described earlier were dependent on occupancy rates, then we would draw first a value for number of units occupied and then go to the pdf on operating costs that includes the value of the occupancy rate that was already drawn. Thus there would be several pdfs of operating costs that would map to every possible occupancy rate.

Third, simulation can be used in generating pdfs and cdfs for any of the economic measures described in table 2-1.

Fourth, while it is true that the cdf describes only risk exposure, it also facilitates incorporation of risk attitude by the decision maker in the decision process. That is, when the decision maker selects projects on the basis of cdfs, inherent in that selection is an implicit assessment of risk attitude.

The disadvantage of simulation is that it requires many calculations, and is therefore practical only when used with a computer.

${ }^{80}$ For additional information on contingency analysis, see Zaheer, "Contingency and Capital Cost Estimates;" p. 13; J. R. Healy, "Contingency Funds Evaluation," American Association of Cost Engineers Transactions, B-3, 1982; and M. W. Graf, "An Overview of Contingency Consideration," Cost Engineering, Vol. 26, No. 1, February 1984. 


\subsection{Mathematical/Analytical Technique}

The mathematical/analytical (M/A) technique was developed by Hillier as a means of obtaining probability functions for economic measures of worth without the repeated trials of simulation. ${ }^{81}$ The M/A technique allows one to generate pdfs and cdfs of life-cycle costs, net benefits, and unadjusted internal rate-of-return measures. 82

Equations (5.5) and (5.6) show how to compute the aggregated, discounted mean and variance for the net benefits measure of project worth. The input data are the mean and variance of net cash flows for each year of the investment's study period.

$$
\begin{gathered}
\mu_{N B}=\sum_{t=0}^{N} \mathrm{E}\left(B_{t}-C_{t}\right) /(1+i)^{t}, \text { and } \\
\sigma^{2} N B=\sum_{t=0}^{N} \operatorname{Var}\left(B_{t}-C_{t}\right) /(1+i)^{2 t}
\end{gathered}
$$

$$
\begin{aligned}
& \text { where } \mu_{\mathrm{NB}}=\text { the mean of net benefits, } \\
& \sigma^{2} \mathrm{NB}=\text { the variance of net benefits, } \\
& \mathrm{E}\left(\mathrm{B}_{\mathrm{t}}-\mathrm{C}_{\mathrm{t}}\right)=\text { the expected value (mean) of net benefits in time period } t, \\
& \operatorname{VAR}\left(\mathrm{B}_{\mathrm{t}}-\mathrm{C}_{\mathrm{t}}\right)=\text { the variance of net benefits in time period t. } 83
\end{aligned}
$$

By using the mean and variance of net benefits earned on the investment and the probability tables for the normal distribution, pdfs and cdfs can be derived for net benefits of the investment. Also, the probability of the investment yielding net benefits less than, equal to, or greater than zero (or some other specified target value) can be computed directly.

The M/A technique requires that input values be normally distributed to generate pdfs and cdfs of the measures of worth. Even without normal input distributions, however, the technique produces means and variances of economic measures of worth. And these statistics by themselves can be highly useful.

The technique as applied here presumes independence in a single project's profitability over time. Approaches to handling interdependence are treated in section 5.5.2.

${ }^{81}$ Hillier, "The Derivation of Probabilistic Information," p. 444.

${ }^{82}$ Park extended Hillier's model to develop a method for computing probability distributions of benefitcost ratios. See "Probabilistic Benefit-Cost Analysis," The Engineering Economist, Vol. 29, No. 2., 1983, pp. 83-100.

${ }^{83}$ The notation for benefits and costs used in these equations is consistent with that of the formulas in table A-1 in appendix A. 


\subsubsection{Shopping Centers Example of M/A Technique}

To illustrate the technique, a cdf is derived for net cash flows from an investment in a limited partnership that is buying shopping centers. ${ }^{84}$ The minimum investment in the partnership is $\$ 5,000$, so that is the amount on which net cash flow returns will be estimated for making the economic evaluation. A 6-year holding period is projected. Although fewer, or more, than 6 years may pass before the shopping centers are sold and the proceeds distributed to investors, the brokerage house selling the partnerships will make a market for the shares in the over-the-counter market. So we know with certainty that the investment can be cashed in at the end of 6 years. Table 5-5 lists these and additional assumptions on which the case illustration is based.

Note that net cash flows are not net of initial investment cost in this example. That is why we use the term net cash flows here instead of net benefits. The approach followed in this case illustration is to (1) apply Hillier's approach to the uncertain net cash flows and then (2) compare the final cdf of net cash flows against the certain $\$ 5,000$ investment cost to see how cost effective the shopping centers are likely to be.

Table 5-5. Assumptions for the economic evaluation of the limited-partnership shopping centers

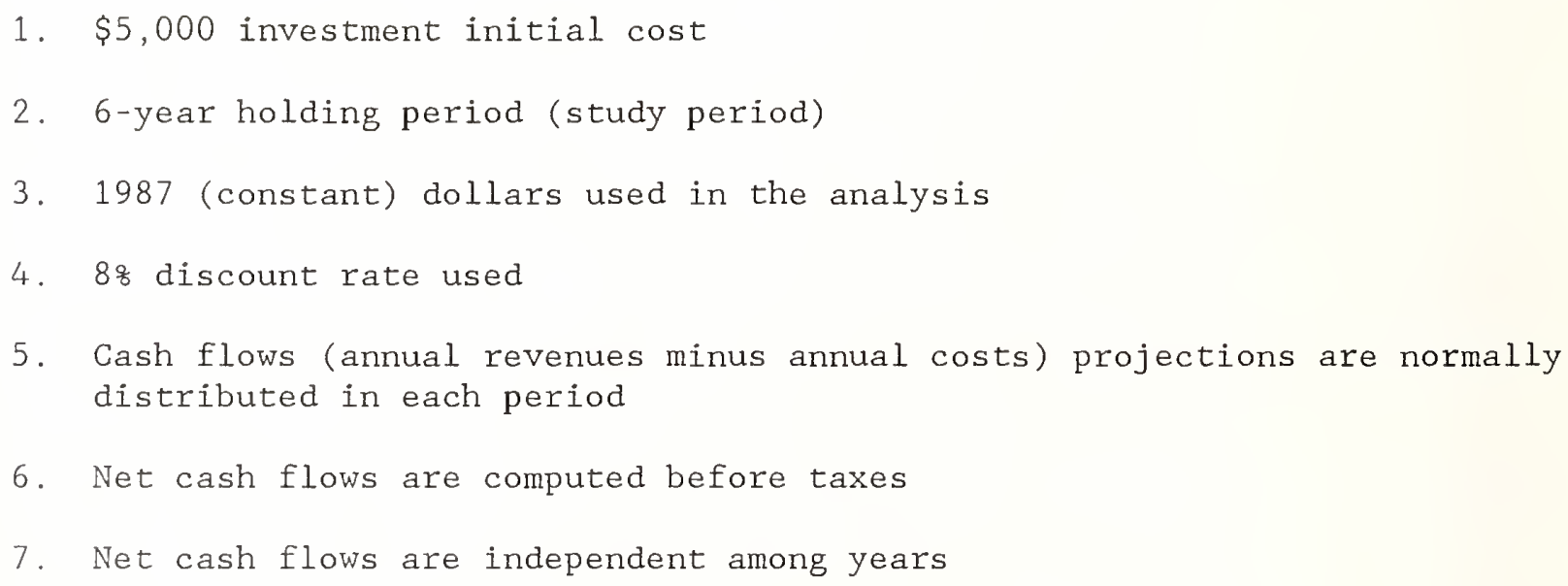

${ }^{84}$ This case illustration is based on data in part from a 1987 prospectus issued by a brokerage house sponsoring a limited partnership for buying shopping centers. The prospectus is used only for the purpose of helping to generate a realistic problem. The illustration is not intended to provide economic advice about any particular investment opportunity in shopping centers. 
Equations (5.7) and (5.8) are used to calculate the mean and standard deviation of present value net cash flows from the shopping centers over the 6-year study period. These equations differ slightly from eqs (5.5) and (5.6) in two ways. First $\mu_{t}$ and $\sigma_{t}{ }^{2}$ do not incorporate investment costs, whereas $E\left(B_{t}-C_{t}\right)$ and $\operatorname{Var}\left(\mathrm{B}_{\mathrm{t}}-\mathrm{C}_{\mathrm{t}}\right)$ would. Second, the $\sigma_{\mathrm{PVC}}$ is computed directly by eq (5.8) rather than computing the variance as in eq (5.6). Equations (5.9) and (5.10) are used to calculate the mean and standard deviations of net cash flows in each of the 6 years of the project study period.

$$
\begin{aligned}
& \mu \text { PVC }=\sum_{t=1}^{N}\left(\mu_{t} /(1+i)^{t}\right), \\
& \left.\sigma_{\mathrm{PVC}}=\underset{\mathrm{t}=1}{\mathrm{~N}}\left(\sigma_{\mathrm{t}}^{2} /(1+\mathrm{i})^{2 \mathrm{t}}\right)\right)^{1 / 2} \\
& \text { where } \mu_{\mathrm{t}}=\underset{s=1}{\mathrm{~K}}\left(\mathrm{C}_{\mathrm{ts}} \mathrm{P}_{\mathrm{ts}}\right) \text {, } \\
& \left.\sigma_{\mathrm{t}}=\underset{\mathrm{s}=1}{\mathrm{~K}}\left(\mathrm{C}_{\mathrm{ts}}-\mu_{\mathrm{t}}\right)^{2} \mathrm{P}_{\mathrm{ts}}\right)^{1 / 2} \text {, and }
\end{aligned}
$$

where $\quad \mu_{\mathrm{PVC}}=$ the expected value of present value net cash flows over the project holding period,

$\mu_{\mathrm{t}}=$ the expected value of net cash flows in period $\mathrm{t}$,

${ }^{\circ} \mathrm{PVC}=$ the standard deviation of the present value of net cash flows over the project holding period,

$\sigma_{\mathrm{t}}^{2}=$ the variance of net cash flows in period $\mathrm{t}$,

$\mathrm{K}=$ number of possible states of business success,

$\mathrm{C}_{\mathrm{ts}}=$ net cash flow associated with state $\mathrm{s}$ in period $\mathrm{t}$, and

$\mathrm{P}_{\mathrm{ts}}=$ probability of state $\mathrm{s}$ in period $\mathrm{t}$, and

$\sigma_{\mathrm{t}}=$ the standard deviation of net cash flows in period $\mathrm{t}$.

Four steps are described for deriving the pdf and cdf of the shopping centers. The first is to construct on the basis of perceived uncertainty the net cash flow distributions for a $\$ 5,000$ investment in the shopping centers. Techniques for assigning probability to uncertain events have been developed elsewhere, so they are not discussed here. ${ }^{85}$ Table 5-6 provides the probability distributions and means that describe potential earnings of the shopping centers. Five states (s) of business success are hypothesized for the

${ }^{85}$ C. S. Spetzler and C. S. Stael von Holstein, "Probability Encoding in Decision Analysis," Readings in Decision Analysis, pp. 403-427; A. Wilson, "Risk Analysis in Retail Store Design: A Case Study," Quality and Profit in Building Design, edited by P. S. Brandon and J. A. Powell (London, England: E. \& F. N., Spon, 1984); and Capen, "The Difficulty of Assessing Uncertainty," pp. 843-850. 


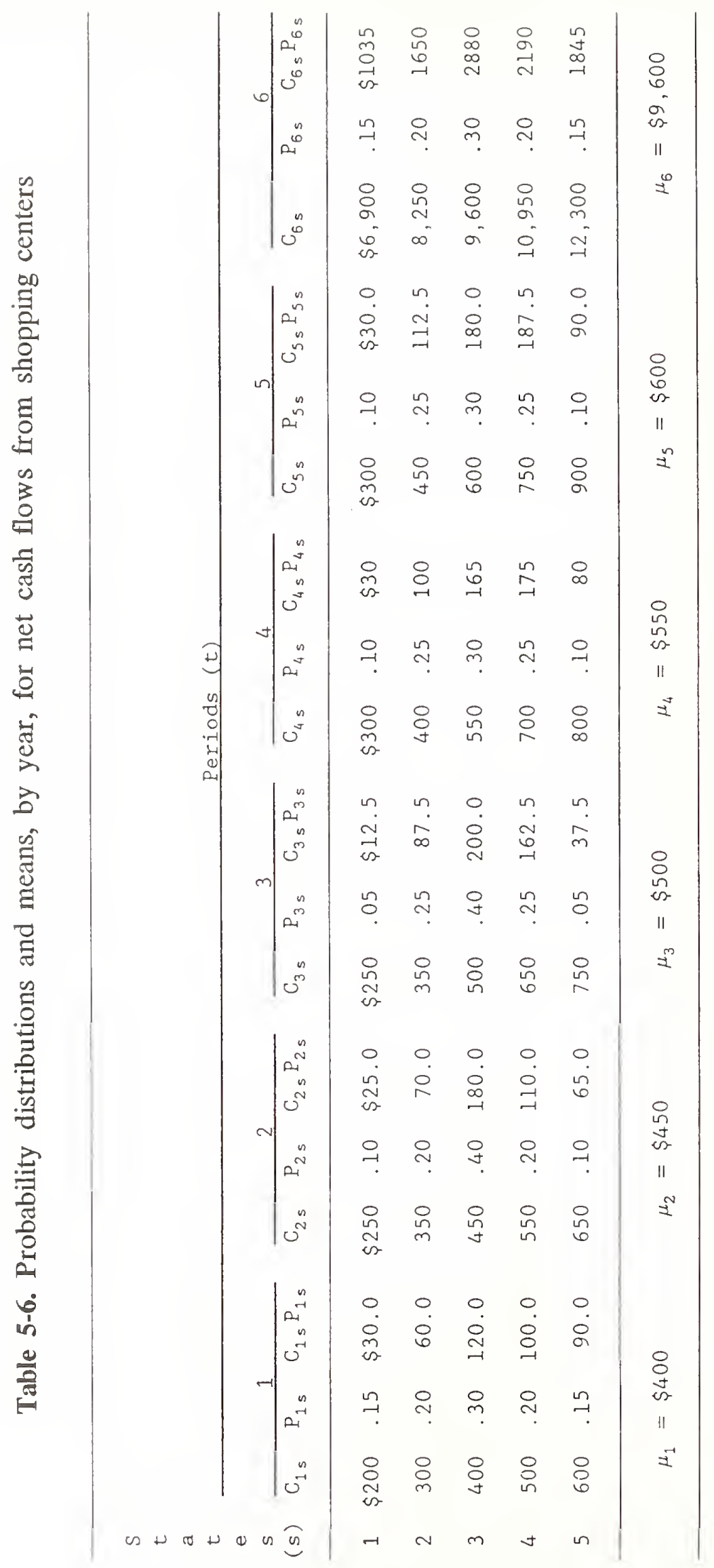


group of shopping centers ranging from the least profitable state, $s=1$, to the most profitable, $s=5$. Potential net cash flows (current earnings minus current expenses) are estimated for each of the 6 years $(\mathrm{t}=1$ through 6$)$ for all five states of success. The net cash flow $\left(\mathrm{c}_{\mathrm{ts}}\right)$ values are weighted by the probabilities $\left(\mathrm{P}_{\mathrm{ts}}\right)$ that those respective business conditions might occur. The $\mathrm{C}_{\mathrm{ts}}$ and $\mathrm{P}_{\mathrm{ts}}$ values define the cash flow distributions for each year.

The following rationale was used in deriving the distributions for this case illustration. Based on current shopping center earnings, the prospectus predicted an 8 percent return ( $\$ 400$ on the $\$ 5,000$ investment) in the first period (i.e., year). The dispersion of earnings about the mean (table 5-7) is based on uncertainty about finding renters right away for shopping centers under new management. In the second period there is a higher probability associated with a larger mean and a smaller variance than in the first period. It is more likely that all of the space will be rented in the second year. Furthermore, two years are a short enough time that the general partners feel confident in predicting high rental rates with greater certainty. For periods $t_{3}$ through $t_{5}$, the mean continues to rise because rent escalation contracts call for increasing rents (in constant dollar terms), while mortgage payments are fixed in current dollars (probably dropping in constant dollar terms). The variance about the mean increases, however, because estimates become less certain as the time horizon is extended. Resale proceeds have been coupled with annual net cash flows to make all the values in the probability distribution for period 6 (col. $\mathrm{C}_{6 \mathrm{~s}}$ in table 5-6) larger than those in earlier periods. Resale (in constant dollar terms) is estimated at 1.2 to 2.4 times the $\$ 5,000$ purchase price.

The second step is to calculate the mean, variance, and standard deviation of net cash flows for each of the 6 years. The mean, shown as $\mu_{\mathrm{t}}$ on the bottom line of table 5-6, is computed with eq (5.9). The standard deviation, shown as $\sigma_{\mathrm{t}}$ in table 5-7, is computed with eq (5.10).

The third step is to use eqs (5.7) and (5.8) to calculate the mean and standard deviation of the pdf of the present value net cash flows over the 6 years. Substituting into the equations, we find for the pdf a mean present value net cash flow of $\$ 8,015$ and a standard deviation of $\$ 1,104$, as shown below.

$$
\begin{aligned}
\mu_{\mathrm{PVC}}= & \frac{\$ 400}{(1.08)^{1}}+\frac{\$ 450}{(1.08)^{2}}+\frac{\$ 500}{(1.08)^{3}}+\frac{\$ 550}{(1.08)^{4}}+\frac{\$ 600}{(1.08)^{5}}+\frac{\$ 9,600}{(1.08)^{6}} \\
= & \$ 370.37+\$ 385.80+\$ 396.92+\$ 404.27+\$ 408.35+\$ 6,049.63 \\
= & \$ 8,015, \text { and } \\
\sigma_{\mathrm{PVC}}= & {\left.\left.\left[\frac{\$ 16,000}{(1.08)^{2}}+\frac{\$ 12,000}{(1.08)^{4}}+\frac{\$ 17,500}{(1.08)^{6}}+\frac{\$ 23,750}{(1.08)^{8}}+\frac{\$ 29,250}{(1.08)^{10}}+\frac{\$ 2,916,000}{(1.08)^{12}}\right]\right]^{1 / 2}\right] } \\
= & {[\$ 13,717.42+\$ 8,820.36+\$ 11,027.97+\$ 12,831.39} \\
& +\$ 13,548.41+\$ 1,157,983.70] \\
= & {[\$ 1,217,929.30]^{1 / 2} } \\
= & \$ 1,104 .
\end{aligned}
$$




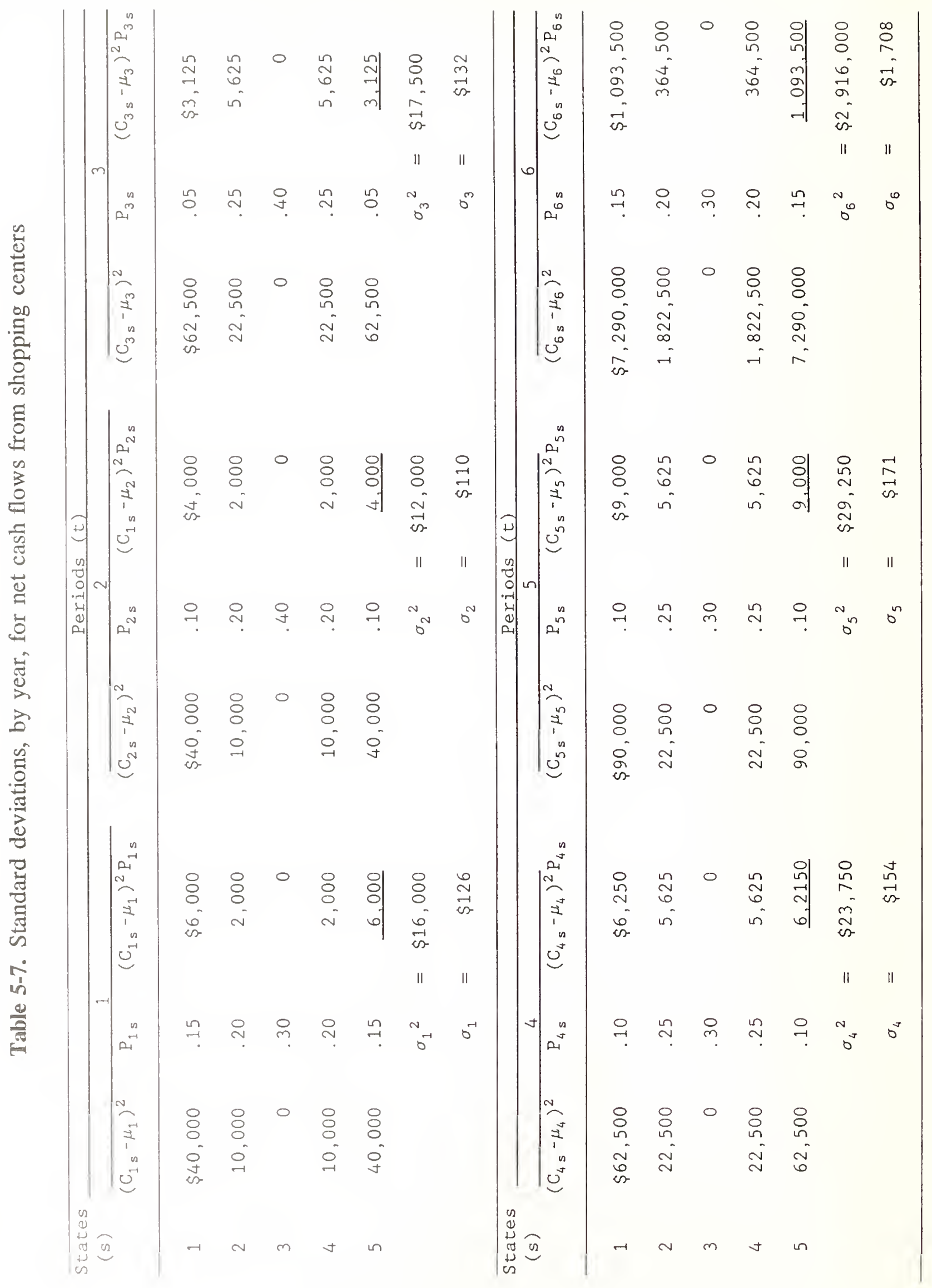


The fourth and final step is to construct a pdf and cdf for the present value of net cash flows from the shopping centers, and evaluate them in light of the $\$ 5,000$ investment. To construct a pdf, ordinates from a statistical table on normal curves are used to derive relative heights on the $y$ axis for corresponding present value net cash flows. However, ordinal values in statistical tables are given only for standardized z values. Thus $\mathrm{z}$ values that correspond to specific dollar amounts must be available before corresponding ordinates on the $\mathrm{y}$ axis can be found. Equation (5.11) shows the relationship between $\mathrm{z}$ and $\mathrm{x}$, where $\mathrm{x}$ represents net cash flow. Each $\mathrm{z}$ value measures the number of standard deviations that any given net cash flow lies above or below the mean $(\$ 8,015)$.

$$
\mathrm{z}=(\mathrm{x}-\mu) / \sigma .
$$

Table 5-8 illustrates the derivation of the pdf with ordinate values. Arbitrary z values are selected (col. 1) to establish the range of the distribution. Since 99.73 percent of all values in a normal distribution lie within 3 standard deviations of the distribution mean, $\mathrm{z}$ values from 0 to 3.0 are chosen. The present value net cash flow ( $\mathrm{x}$ value) corresponding to each $\mathrm{z}$ value is computed for the range 3 standard deviations below (col. 2) to 3 standard deviations above (col. 3) the mean. The ordinates (col. 4) for the corresponding $\mathrm{z}$ values are taken from a statistical table. ${ }^{86}$ Values for $\mathrm{y}$ are plotted in the same proportion to one another as the ordinates in column 4. Figure 5-13 shows a smooth function drawn through these y plots to construct the pdf.

Table 5-8. Data for constructing probability density function of present value net cash flows for shopping centers

\begin{tabular}{lccc}
\hline & Net Cash Flow Values (\$) & \\
\cline { 2 - 3 }$z$ & $\mathrm{x}=\mu-z \sigma$ & $\mathrm{x}=\mu+z \sigma$ & \\
$(1)$ & $(2)$ & $(3)$ & Ordinate at $z$ \\
& & & \\
\hline & & & .3989 \\
0.0 & 8,015 & 8,015 & .3521 \\
0.5 & 7,463 & 8,567 & .2420 \\
1.0 & 6,911 & 9,119 & .1295 \\
1.5 & 6,359 & 9,671 & .0540 \\
2.0 & 5,807 & 10,223 & .0175 \\
2.5 & 5,255 & 10,775 & \\
3.0 & 4,703 & 11,327 & \\
& & & \\
\hline
\end{tabular}

86"The Normal Probability Function and Related Functions," Standard Mathematical Tables, 14th ed., edited by Samuel M. Selby, the Chemical Rubber Co.; Cleveland, Ohio, 1965, pp. 260-265. Note that x and $\mathrm{f}(\mathrm{x})$ values in the Chemical Rubber Co. tables correspond respectively to $\mathrm{z}$ and ordinate values in this report. 


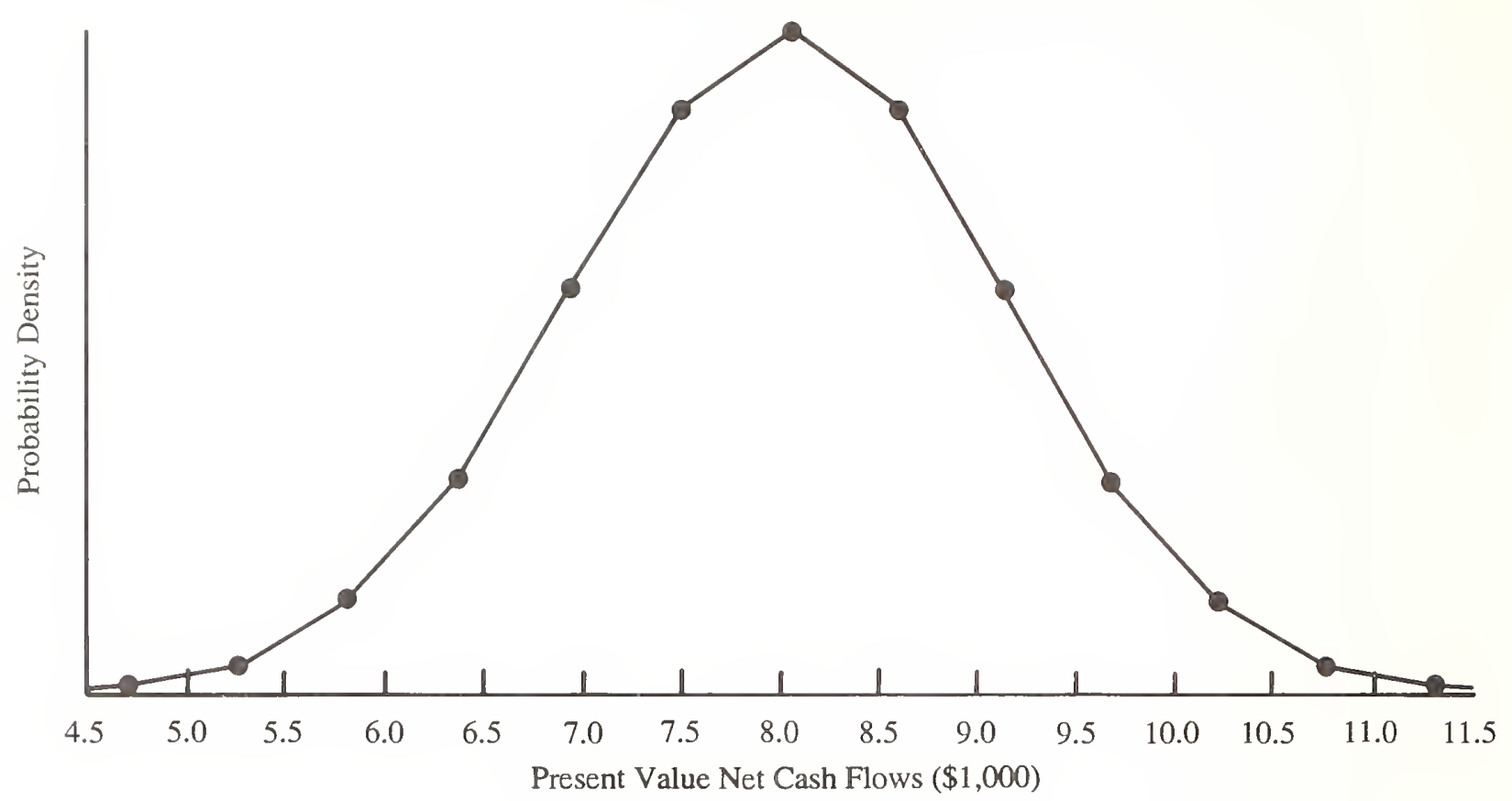

Figure 5-13. Probability density function of present value net cash flows for shopping centers.

Note that the pdf by itself gives considerable information about the cost effectiveness of the shopping centers. For example, visual inspection indicates that there is little area under the left tail of the pdf for present value net cash flows less than $\$ 5,000$, the amount that must be recovered to at least break even with the initial investment. Thus we know immediately there is a low probability that the investment will not at least break even. Furthermore, we can see directly that the most likely value of the net cash flows is about $\$ 8,000$.

The cdf in figure 5-14 is even more helpful, because it indicates the probability of being less than or just equal to target levels of present value net cash flows over the entire range of possible outcomes. Conversely, it can be used to determine the probability of exceeding target levels of present value net cash flows.

Table 5-9 shows how the numbers are obtained for plotting the cdf. First we establish an arbitrary range of present value net cash flows (col. 1) over which to plot the cdf. Since 99.73 percent of all values lie within 3 standard deviations of the mean, we can feel comfortable selecting a range of net cash flows between $\mu-3 \sigma$ and $\mu+3 \sigma$. Looking back to table 5-8, columns 2 and 3 show a corresponding range of net cash flow values from $\$ 4,703$ to $\$ 11,327$. For convenience we round to $\$ 4,000$ and $\$ 12,000$ with $\$ 1,000$ intervals. Column 1 in table 5-9 shows the present value net cash flow amounts for which the cdf is constructed.

A $z$ value is computed in table 5.9 (col. 2) for every net cash flow value (col. 1) using eq (5.11). This is necessary because curve areas in statistical tables are given only for standardized $\mathrm{z}$ values. The associated normal curve areas for $z$ values in column 2 are listed in column 3 of table 5-9.87 The area value

${ }^{87}$ The normal curve areas were found in table 10, "Table of Areas of the Normal Curve," Tables for Statisticians, by Herbert Arkin and Raymond R. Colton (New York, New York: Barnes and Noble, 1950), p. 114. 


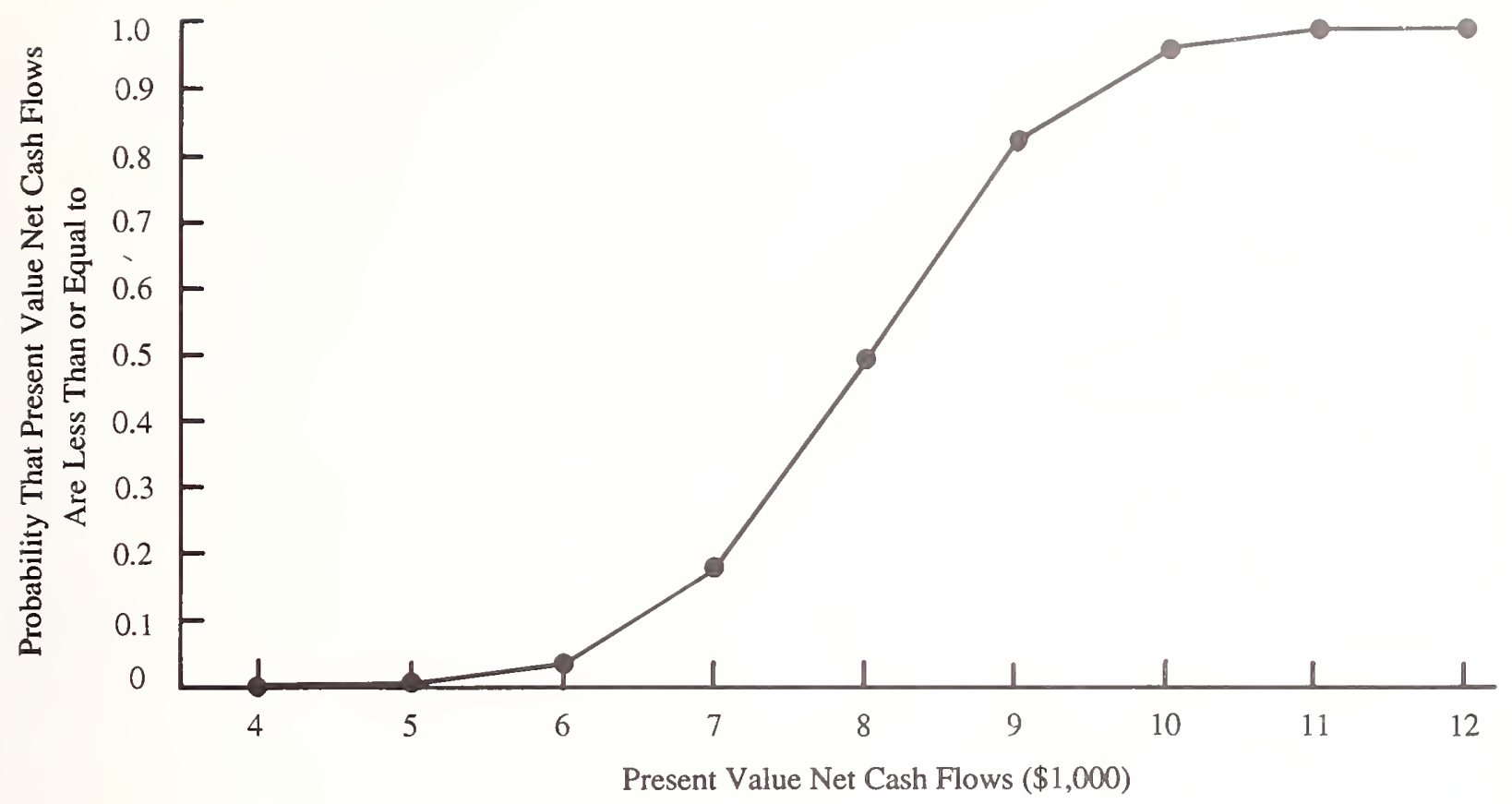

Figure 5-14. Cumulative distribution function of present value net cash flows for shopping centers.

Table 5-9. Data for constructing cumulative distribution function of present value net cash flows for shopping centers

\section{Net Cash Flows}

$(\$ 1,000)$

(1)

4.0

5.0

6.0

7.0

8.0

9.0

10.0

11.0

12.0 z Value

(2)

\section{$-3.64$}

$-2.73$

$-1.83$

$-0.92$

$-0.01$

$+0.89$

$+1.80$

$+2.70$

$+3.61$
Area

(3)
Cumulative Probability

$(4)=(3)+.5000$
$-.4998$

$-.4968$

$-.4664$

$-.3212$

-. 0040

.3233

.4641

.4965

.4998
.0002

.0032

.0336

.1788

.4960

.8233

.9641

.9965

.9998 
describes what percent of total area under the pdf lies between the mean and some specified number of standard deviations ( $\mathrm{z}$ value) to the right (positive area value) or left (negative area value). The probability that net cash flows will be less than or equal to any given target value of PVC in column 1 is the area under the pdf to the left of the target value. To find the cumulative probability (col. 4) at any given present value net cash flow, the area of the corresponding $z$ value is added to 0.5000 .

Let us first use table 5-9 to evaluate the likelihood that our $\$ 5,000$ investment will at least break even. The area under the normal curve to the left of $\$ 5,000$ is found as follows: The value of $z=-2.73$ (i.e., $(\$ 5,000-\$ 8,015) / \$ 1,104)$. The area under the normal curve between the mean and the $z$ value of -2.73 is 0.4968. The difference between this area and the total area to the left of the mean is 0.0032 (i.e., 0.5000 0.4968). Thus, given the data used in the analysis, there is less than a 1 percent chance that the shopping centers would not at least break even. Given the extremely low probability of a loss, all but the most risk-averse decision makers would likely accept this investment unless other higher-return alternatives with similar or less risk were competing for limited budget funds.

We can also examine the cdf to determine probabilities that the investment will achieve various degrees of profitability or loss. For example, we find about a 50 percent probability that returns would be less than $\$ 8,000$ ( $\$ 3,000$ profit) and about a 97 percent probability that returns would be less than $\$ 10,000(\$ 5,000)$ profit.

\subsubsection{Advantages and Disadvantages of M/A Technique}

A major advantage of the M/A technique is that means and variances (and therefore pdfs and cdfs) of project worth can be generated directly by hand calculations without repeated simulations on a computer. Thus risk exposure can be determined without the use of a computer.

Another advantage is that implicit incorporation of risk attitude into the selection process is facilitated when the decision maker selects a project based on cdfs.

A disadvantage of the M/A technique is that it presumes that the underlying probability distributions associated with the inputs are normally distributed. This condition is necessary to generate precise probability statements about the measure of worth. However, Hillier has suggested that the subjective probability distributions analysts tend to generate in describing uncertain events are often symmetrical and resemble normal distributions. Furthermore, even where the distributions are not normal, the mean and variance of the measure of worth, as computed by egs (5.5) and (5.6), will still be accurate and provide helpful information in evaluating alternative investments. ${ }^{88}$

A possible disadvantage with the M/A technique is in specifying and calculating the impacts of interdependence among a single project's measures of worth over time. For example, the level of interdependence among NB in, let us say, years 1,2, and 3 might range from total independence (zero correlation among NB in different years) to total interdependence (perfect correlation among NB in different years).

One approach to handling interdependence is to use sensitivity analysis--calculate the variance first with the assumption of zero correlation and then with the assumption of perfect correlation. A more accurate approach is to assume that net benefits in some years are related and in other years they are not. Hillier presents a mathematical model for calculating the mean and standard deviation under conditions of varying interdependence. ${ }^{89}$

${ }^{88}$ Hillier, "The Derivation of Probabilistic Information," p. 446.

${ }^{89} \mathrm{~F}$. Hillier, "The Evaluation of Risky Interrelated Investments," Studies in Mathematical and Managerial Economics, ed. by Henri Theil, North-Holland, Amsterdam, 1969. 
A second interdependence issue arises when evaluating interrelated projects. The economic worth of one project may vary as a function of the worth of competing or complementary projects. For example, the returns from a given investment may be correlated to returns on other investments in a group of projects because all of the projects are affected by common factors. Hillier has developed techniques for evaluating large, risky, interrelated investments. ${ }^{90}$

Another disadvantage of the M/A technique is that the input distributions in each period must be of the measure of economic worth. That is, the uncertainty expressed in the input distributions pertains only to the final measure of project worth for that period. Thus for the NB measure, for example, the distribution in each period would be of NB. This means that the analyst would already have had to determine how all of the uncertain factors that affect benefits and costs combined in a given period to make that period's NB distribution. The simulation method, on the other hand, accommodates separate distributions for each of the uncertain inputs and provides for their systematic combining to form a final distribution of the measure of project worth. It should be noted, however, that in the simulation approach, the input variables are all discounted to present or annual values, whereas in the M/A approach, there is a separate distribution for each period in the project's time horizon. Thus the latter has more opportunity for fine tuning the estimated project performance from period to period.

\subsubsection{M/A Technique Used with the CEF and RADR Techniques}

The M/A technique can be used in conjunction with the risk-adjusted discount rate or certainty equivalent technique in computing NB. The uncertainty associated with the variables used to compute NB period-byperiod is captured in the probability distributions of net cash flows. Thus risk exposure is indicated by the mean and variance of $\mathrm{NB}$ and by the pdf and cdf generated from those statistics. Risk attitude, on the other hand, is incorporated exclusively in the CEF or RADR adjustment to NB.

When using the RADR technique, the RADR value, as defined in eq (4.1), substitutes for discount rate " $\mathrm{i}$ " in eq (5.5). Equation (5.6) is used as shown. ${ }^{91}$ The AR2 component of the RADR value should adjust for risk attitude only. Thus the more risk averse is the decision maker, the higher will be the RADR value. ${ }^{92}$ Note that, if the RADR adjusts for risk exposure while using the M/A technique, there will be an overadjustment for risk exposure.

The advantage of a joint M/A and RADR analysis over using the M/A or simulation technique alone is that it treats risk attitude in a formal manner. Typically the mean and standard deviation (and pdf and cdf) reflect only risk exposure, and the decision maker has to make a subjective determination of risk attitude when considering each project alternative. When using the techniques jointly, on the other hand, the distributions already have risk attitude incorporated in them. That is, the NB values have been adjusted by the RADR to reflect, in effect, their certainty equivalent or utility values. Thus the decision maker whose objective function is to maximize the expected value of utility simply chooses the project with the higher expected value of adjusted net benefits.

If decision makers are not comfortable with a choice based on expected values adjusted for risk attitude, additional selection rules might be used in determining which project is preferred after applying eqs (5.5) and (5.6). Where the pdf and cdf show clear stochastic dominance, they can be the guide to project choice. Where stochastic dominance is not obvious, the preferred project might be the one with the lower coefficient of variation (sec. 5.2).

\section{Ibid.}

${ }^{91}$ The RADR and CEF adjustments apply to the mean, but not to the variance, when used with the M/A technique.

${ }^{92}$ This presumes that benefit streams are being discounted. As discussed in section 4.4, if cost streams are being discounted, AR2 is adjusted downwards to compensate for a risk averse attitude. 
When using the certainty equivalent technique (sec. 4.5) with the $\mathrm{M} / \mathrm{A}$ technique, the $\mathrm{CEF}_{\mathrm{t}}$ would be inserted into eq (5.5) as a multiplicative factor times $\mathrm{E}\left(\mathrm{B}_{\mathrm{t}}-\mathrm{C}_{\mathrm{t}}\right)$. Equation (5.6) is used as shown. A riskfree rate of interest would be used for discounting. ${ }^{93}$ In this case, $\mathrm{CEF}_{\mathrm{t}}$ should adjust for risk attitude only. Thus, the more risk averse is the decision maker, the lower would be the $\mathrm{CEF}_{\mathrm{t}}$ and the lower would be the mean of $\mathrm{NB} .{ }^{94}$ Once again note that, if the certainty equivalent technique also adjusts for risk exposure while using the M/A technique, there will be an overadjustment for risk exposure.

The same selection rules discussed for the RADR determining the preferred project are applicable to the certainty equivalent technique. And, as is the case with the RADR technique, when used with the M/A technique, the certainty equivalent technique provides a formal treatment of risk attitude. Thus the decision maker whose objective function is to maximize the expected value of utility might simply choose the project with the higher expected value of adjusted net benefits.

\subsection{Other Techniques}

Additional techniques for evaluating investments, which are based on distributions and include utility considerations in the decision-making process, are gaining increased attention in the building field. The two techniques described briefly here are used to evaluate the risk and return of combinations or portfolios of projects in which interactions among the projects affect the overall riskiness of the portfolio, and to determine what the expected return of an individual asset should be, given its risk.

\subsubsection{Portfolio Analysis}

Portfolio analysis is a technique used to seek the combination of assets with the maximum return for any given degree of risk (i.e., variance of the return), or the minimum risk for any given rate of return. ${ }^{95}$ By diversifying its assets so that returns are not perfectly positively correlated, a firm's overall investment risk can be reduced. The risk reduction from this diversification of assets is called the portfolio effect.

Portfolio theory was originally developed for the analysis of stocks. The model has been extended, however, to the analysis of other assets. The evaluation of building investments seems a logical application of portfolio theory. Yet few applied efforts have been made. One reason is that it is difficult to get data to measure the correlation of building investments.

Another reason portfolio analysis is not applied frequently to building investments is that they involve large chunks of capital, large and lumpy chunks of real estate, cumbersome markets, lengthy transaction times, and large transaction costs. This is certainly a more complex market environment than the New York Stock Exchange provides, for example, to an investor accumulating and managing a portfolio of stocks.

An academic study of portfolio analysis in construction is available in Vegara's thesis. ${ }^{96}$ It combines probabilistic estimating, portfolio theory, and utility theory in the development of models for helping construction firms select an optimal mix of new projects.

${ }^{93}$ Note that it is appropriate to use risk-free rates of interest for discounting whenever risk is being accounted for by some means other than the RADR.

${ }^{94}$ For a LCC analysis, the more risk averse is the decision maker, the higher would be the $\mathrm{CEF}_{\mathrm{t}}$.

${ }^{95}$ For the landmark treatment of portfolio analysis, see Harry Markowitz, Portfolio Selection: Efficient Diversification of Investment (New York, New York: John Wiley and Sons, 1959).

96J. A. Vegara, "Probabilistic Estimating and Applications of Portfolio Theory in Construction," Ph.D. Thesis, Graduate College of the University of Illinois at Urbana-Champaign, Urbana, Illinois, 1977. 


\subsubsection{Capital Asset Pricing Model}

The Capital Asset Pricing Model (CAPM), the best known model of risk and return among asset pricing models, is an extension of portfolio theory. ${ }^{97}$ It explains how an asset should be priced based on the additional risk it will add to the risk of a market portfolio of assets. Said another way, it indicates what the return on an asset should be, based on that asset's risk.

Two types of risk are attributed to any investment in an asset. One is unsystematic risk; that is, risk associated with random events, such as fires and strikes, that are unique to the investment. The other is systematic risk (also called market risk) resulting from market variations to which all investments are subjected. 98

Unsystematic risk can be eliminated with a diversified portfolio, but systematic risk cannot. The systematic risk of a given asset is a function of how sensitive its return is to changes in market conditions. This sensitivity to market conditions is measured by "beta." The beta coefficient is measured as the covariance of the asset's returns with the market portfolio's returns. According to CAPM, an asset's beta measures the risk that is compensated in the market place. Thus higher returns are not predicated for higher unsystematic risk. An asset with a beta of 1.0 has average market risk and, therefore, one would expect an average return for it. A beta below 1.0 indicates proportionately less-than-average market risk and therefore a lower return. And a beta above 1.0 indicates proportionately more-than-average market risk and therefore a higher return.

Risk and return relationships can be specified using CAPM. Once the risk/return relationship is defined, the expected rate of return on an asset can be estimated based on its systematic risk as defined by beta. The return on an asset should equal the risk-free rate of return plus a risk premium in proportion to the asset's beta. An asset with an estimated return higher than the expected return based on its beta would be a "good buy." Over time, however, increased demand for it will raise its price and lower its relative return in a perfect market until the estimated return is in line with the asset's beta. 99

Portfolio analysis and the CAPM show promise theoretically for the evaluation of building investments. The data needed to apply these techniques, however, are not available. Estimating the beta for a real estate investment, for example, is much more complicated than for a stock. Thus widespread application of these techniques awaits additional research.

${ }^{97}$ For the landmark treatment of the Capital Asset Pricing Model, see W. F. Sharpe, "Capital Asset Prices: A Theory of Market Equilibrium Under Conditions of Risk," Journal of Finance, Vol. 19, No. 4, September 1964.

${ }^{98}$ Examples of events that affect market risk are interest rate changes, war, and economic expansion and contraction.

${ }^{99}$ For a treatment of CAPM and other asset pricing theories, see Russell J. Fuller, Capital Asset Pricing Theories--Evolution and New Frontiers, Monograph No. 12, The Financial Analysts Research Foundation, Charlottesville, Virginia, 1981. 


\section{CONCLUSIONS}

If it can be agreed that better decisions come from more complete information, then accounting for uncertainty and risk will enhance decision making. Yet there is no "best" technique for handling uncertainty and risk in evaluating every investment. What is best will depend on circumstances of the organization. The analyst and decision maker should consider the following items of information before selecting a technique for a given investment problem.

First, the level of resources must be assessed. How much time is available to evaluate the project? How much money is available for staff and computer support? Does the staff have the technical capability to apply all of the techniques? For example, can they derive utility functions from inferred risk attitudes and develop probability distributions for uncertain variables? And finally, are computer software and hardware available for applying all of the techniques? By asking these questions, the set of feasible techniques (where feasibility depends on resource availability) can be defined.

Second, the particular audience that will use the analysis must be identified, and their reactions to the techniques should be considered. Has executive judgment and intuition been successful in the past? Will the management team understand the information generated from applying the techniques? Will they accept the different types of information produced by the techniques? If the chief executive officer has been choosing profitable projects on the basis of personal judgments and deterministic, single-value estimates of project worth, for example, the analyst who presents cumulative distribution functions using the simulation technique will probably have little influence.

Third, the approximate size of the investment relative to the institution's budget or portfolio of other investments should be taken into account. For example, if the investment to be analyzed were small relative to the total portfolio, and would affect total profitability only slightly if it yielded a poor return, then a sophisticated approach to risk analysis such as the mathematical/analytical technique would not be needed. On the other hand, if the investment were relatively large, and a poor return could bankrupt the institution, then a sophisticated technique might be needed.

Fourth, risk attitude should be considered in choosing a technique. If the decision maker were risk neutral, for example, decisions could be made on the basis of maximizing net benefits instead of utility, and the procedure to account for risk attitude would be unnecessary. If the decision maker were very risk averse or a risk taker, on the other hand, it becomes appropriate to use techniques that can adjust for risk attitude, such as decision analysis, the risk adjusted discount rate, and certainty equivalent technique.

Table 6-1 is a quick-reference guide to the 10 techniques described in this report for treating uncertainty and risk. Column 1 indicates the form in which input data are accepted for each technique. The possibilities include single values $(\underline{\mathrm{S}})$, multiple values $(\underline{\mathrm{M}})$, and probability distributions $(\underline{D})$. For example, the technique "conservative benefit and cost estimating" is shown to require single-value data inputs, whereas the simulation technique requires probability distributions. On the other hand, the risk-adjusted discount rate or certainty equivalent technique can be used with either single values or probability distributions.

Column 2 indicates the form in which the measure of project worth is expressed. It can be expressed as a single value (S), multiple values (M), or distribution of values (D). Input estimation using expected values displays the measure of worth as a single value, for example, whereas the mathematical/analytical approach yields a cumulative distribution of worth values.

Column 3 treats risk exposure. Explicit (Ex) consideration means that a numerical adjustment for or graphical measure of risk exposure is provided by the technique. The cumulative distribution of project worth given by the simulation and mathematical/analytical techniques are explicit measures of risk exposure. An implicit (Im) treatment considers risk exposure, but does not treat it quantitatively or graphically. Sensitivity analysis, for example, suggests a possible range of output values, and thereby implies something about risk exposure, but does not quantify that risk exposure. 
Table 6-1. Characteristics of techniques for treating uncertainty and risk

\begin{tabular}{|c|c|c|c|c|c|c|c|c|c|c|}
\hline \multirow[b]{2}{*}{ Technique } & \multicolumn{3}{|c|}{ (1) } & \multicolumn{3}{|c|}{ (2) } & \multicolumn{2}{|c|}{ (3) } & \multicolumn{2}{|c|}{ (4) } \\
\hline & $(\underline{S})$ & $\begin{array}{l}\text { rm o } \\
\text { Enput } \\
\text { Data } \\
\text { (M) }\end{array}$ & $(\underline{D})$ & (S) & $\begin{array}{l}\text { Form } \\
\text { least } \\
\text { E Wor } \\
\text { (M) }\end{array}$ & $\begin{array}{l}\text { f } \\
\text { ce } \\
\text { ch } \\
\text { (D) }\end{array}$ & $\begin{array}{r}\text { Con } \\
R \\
\operatorname{Exp} \\
(\mathrm{Ex})\end{array}$ & $\begin{array}{l}\text { ider } \\
\text { sk } \\
\text { sure } \\
\text { (Im) }\end{array}$ & $\begin{array}{l}\text { Consi } \\
\text { Ris } \\
\text { Attit } \\
\text { (Ex) }\end{array}$ & $\begin{array}{l}\text { der } \\
\text { kde } \\
\text { (Im) }\end{array}$ \\
\hline $\begin{array}{l}\text { Conservative } \\
\text { Benefit and } \\
\text { Cost Estimating }\end{array}$ & $x$ & & & $\dot{x}$ & & & & $\dot{x}$ & & $*$ \\
\hline $\begin{array}{l}\text { Breakeven } \\
\text { Analysis }\end{array}$ & $*$ & & & $*$ & & & & $*$ & & $*$ \\
\hline $\begin{array}{l}\text { Sensitivity } \\
\text { Analysis }\end{array}$ & & $\therefore$ & & & $*$ & & & $*$ & & $*$ \\
\hline $\begin{array}{l}\text { Risk-Adjusted } \\
\text { Discount Rate }\end{array}$ & $*$ & & $*$ & $*$ & & 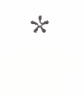 & $*$ & 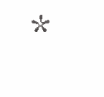 & $*$ & * \\
\hline $\begin{array}{l}\text { Certainty } \\
\quad \text { Equivalent }\end{array}$ & $*$ & & $x$ & $*$ & & $*$ & $*$ & $*$ & $*$ & $\dot{x}$ \\
\hline $\begin{array}{l}\text { Input Estimation } \\
\text { Using Expected } \\
\text { Values }\end{array}$ & & & $*$ & $*$ & & & & & & \\
\hline $\begin{array}{l}\text { Mean-Variance/ } \\
\text { Coefficient of } \\
\text { Variation }\end{array}$ & & & * & & & $*$ & $*$ & & & $*$ \\
\hline $\begin{array}{l}\text { Decision } \\
\text { Analysis }\end{array}$ & & & $*$ & $*$ & & $*$ & $*$ & & $*$ & \\
\hline Simulation & & & $*$ & & & $*$ & $*$ & & & $x$ \\
\hline $\begin{array}{c}\text { Mathematical/ } \\
\text { Analytical }\end{array}$ & & & $*$ & & & $*$ & $*$ & & & * \\
\hline
\end{tabular}


Table 6-1 (continued)

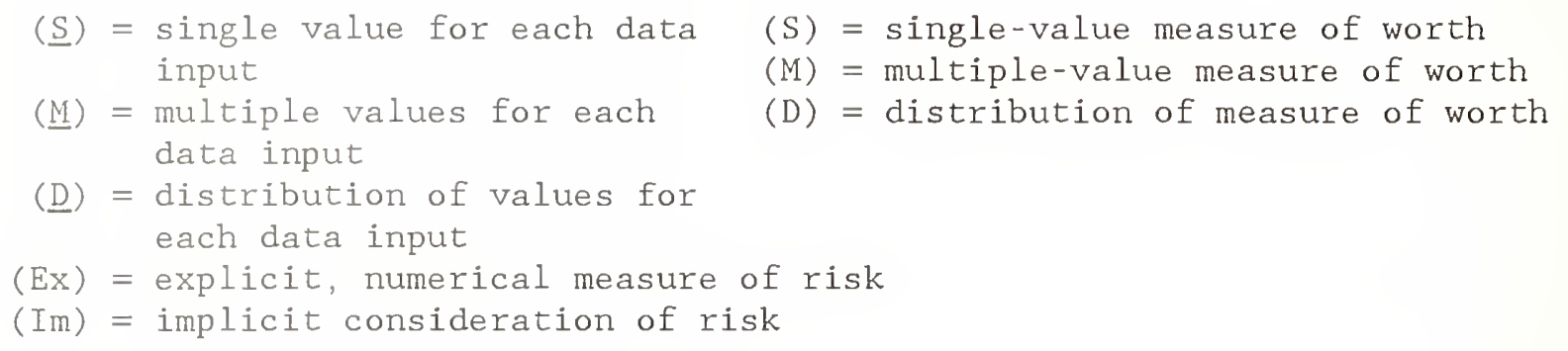

a Breakeven analysis solves for the value of the uncertain input value that will just make the investment break even (e.g., $\mathrm{NB}=0, \mathrm{BCR}=1.0$, or AIRR $=$ MARR $)$. Thus the economic measure of worth would be a single value.

${ }^{b}$ Risk-adjusted discount rate and certainty equivalent techniques have both single values and distributions of values indicated for the form of data input and for the form of measure of worth. Distributions are cited because both techniques can be used with the mathematical/analytical technique.

${ }^{c}$ Input estimation using expected values does not treat risk exposure or risk attitude. Expected values are computed only for inputs, yielding no information in the single-value measure of worth to help the decision maker consider even implicitly risk attitude.

Column 4 treats risk attitude. Explicit consideration occurs when a numerical adjustment is made for risk attitude in project evaluation. Using utility functions with decision analysis is one example. Implicit treatment considers risk attitude, but provides no measure of it in project evaluation. For example, if a cumulative distribution function of project worth is constructed through simulation, implicit in the decision based on that function is the decision maker's attitude towards risk. That is, a risk-averse decision maker might very well make a different decision than a risk taker, given the same profile of risk exposure.

Note that the risk-adjusted discount rate and certainty equivalent techniques can be applied to treat risk exposure and attitude either explicitly or implicitly.

Once the questions asked earlier about resources, management acceptance, and risk attitude have been answered, table 6-1 can help decision makers or analysts select the appropriate technique. Suppose, for example, a decision maker wants to know the range of possible AIRRs an investment might take and at least enough information for the implicit consideration of risk exposure and risk attitude. Furthermore, assume that the decision maker is uncomfortable with the process of generating probability functions of uncertain events and prefers deterministic over non-deterministic answers. Looking at table 6-1, the single technique that satisfies these conditions is sensitivity analysis. Multiple (but deterministic) AIRR values are obtained, and information in the form of an array of possible AIRR values is given that helps the decision maker consider risk exposure and attitude implicitly in making a decision. Any other technique that would meet the criteria for this decision maker would violate the constraint that probability functions not be used. 
Over half of the techniques in table 6-1 use probability distributions in displaying the measure of project worth. Yet these techniques are rarely used in the building community. Why are they not more common? It is not due to lack of research. An early treatment by Hillier 100 demonstrated mathematical/analytical techniques for measuring risk exposure. And Poliquen ${ }^{101}$ and $\mathrm{Hertz}^{102}$ described in detail the application of the simulation technique. More recent works in capital budgeting ${ }^{103}$ and engineering economics ${ }^{104}$ continue to explain the techniques. In addition, commercial software is available to perform these analyses on widely-available microcomputers. 105

One author explains the paradoxical low level of use historically in the following description of the nondeterministic approach in LCC analysis: ${ }^{106}$

"... its variable output is harder to understand, it is more costly to set up and operate, and its answer is often unwelcome. Few managers want to tell their supervisor or their customer that a project is risky or an estimate uncertain. Thus, although it is possible to construct probabilistic models that are intellectually satisfying and mathematically rigorous, most LCC models are deterministic."

Although this explanation is probably correct for the past, new evidence suggests that techniques for risk analysis are of increasing interest to the building community and will become increasingly common in the economic evaluation of buildings and building components. First, increasing education in these techniques will yield practitioners that will understand and want to use them in building evaluations. Second, the increased availability, decreased cost, and better understanding of computers and applied software will make computations much easier. Third, managers are increasingly better educated in advanced analysis techniques and are requesting risk analysis as a routine part of economic evaluations. And fourth, technical societies such as the American Society for Testing and Materials are encouraging the development of standard methods for measuring the risk associated with economic measures applied to building decisions.

${ }^{100}$ Hillier, "The Derivation of Probabilistic Information," 1963.

${ }^{101}$ Poliquen, Risk Analysis in Project Appraisal, 1970.

${ }^{102}$ Hertz, "Risk Analysis in Capital Investments," 1964.

${ }^{103}$ Weston and Brigham, Managerial Finance, 1981.

${ }^{104}$ Newnan, Engineering Economic Analysis, 1980.

${ }^{105}$ One example of software is "Supertree ${ }^{\text {TM }}$ Decision Analysis Software," from SDG Decisions Systems, Menlo Park, California.

106 Robert M. Seldon, Life-Cycle Costing: A Better Method of Government Procurement (Boulder, Colorado: Westview Press, 1979), p. 163. 



\section{APPENDIX A. Formulas for Calculating Economic Measures}

Table A-1. Formulas useful for measuring the economic worth of building investments ${ }^{a}$

\begin{tabular}{|c|c|c|c|}
\hline To Measure & Use This Formula & & \\
\hline Life-Cycle Cost & $\mathrm{LCC}=\sum_{t=0}^{N}\left[\left(\vec{C}_{t}-\vec{B}_{t}\right) /(1+i)^{t}\right]$ & & (1 \\
\hline Net Benefits ${ }^{b}$ & $N B=\sum_{t=0}^{N}\left[\left(B_{t}-C_{t}\right) /(1+i)^{t}\right]$ & & (2 \\
\hline Benefit-to-Cost Ratio & $\mathrm{BCR}=\sum_{\mathrm{t}=1}^{\mathrm{N}}\left[\left(\mathrm{B}_{\mathrm{t}}-\mathrm{C}_{\mathrm{t}}\right) /(1+i)^{\mathrm{t}}\right]$ & & $(3$ \\
\hline $\begin{array}{l}\text { Adjusted Internal Rate } \\
\text { of Return (AIRR) }\end{array}$ & $\begin{array}{l}\text { Find the AIRR Value for which } \\
\sum_{t=1}^{N}\left(B_{t}-C_{t}\right)\left(1+r_{t}\right)^{N-t} /(1+\text { AIRR })^{N} \\
\text { Solve directly } \\
\text { AIRR }=-1+\left(T V / C_{0}\right)^{1 / N} \text {, or } \\
\text { AIRR }=-1+(1+r)(B C R)^{1 / N} \text {, where } \\
r \text { is a constant, and } r=i .\end{array}$ & $-C_{0}=0$, or & $(4$ \\
\hline
\end{tabular}

${ }^{a}$ Only present value formulas are shown in table A-1. Annual value measures could also be used.

${ }^{b}$ When the main effect of a project is to reduce costs, $c_{t}$ in formulas 2-7 will be negative. Thus there will be a cost reduction or savings resulting in a positive value. (The minus sign coupled with a negative value yields a positive value.) These savings are added to any positive benefits the project might have over the alternative. When cost reductions dominate, the net benefits measure is called the net savings measure, and the benefit-to-cost ratio is called the savings-to-investment ratio. 
Table A-1 (continued)

\section{SYMBOLS}

$\mathrm{N}=$ total number of discounting periods in the study period,

$\bar{C}_{t}=$ costs associated with a given investment alternative in time period $t$,

$\bar{B}_{t}=$ benefits (e.g., resale value) associated with a given investment alternative in time period $t$,

$i=$ discount rate for the period considered,

$B_{t}$ = benefits (including resale values) in time period $t$ for the project being evaluated less the benefits in time period $t$ of a mutually exclusive alternative against which it is being compared,

$C_{\mathrm{t}}=$ costs in time period $t$ for the project being evaluated less the costs in time period $t$ of a mutually exclusive alternative against which it is being compared,

$\mathrm{C}_{0}=$ initial project costs, net any initial benefits, for the project being evaluated less initial project costs, net of any initial benefits, for a mutually exclusive alternative against which it is being compared,

$r_{t}=$ reinvestment rate in time period $t$, and

$\mathrm{TV}=$ terminal value $=\sum_{\mathrm{t}=1}^{N}\left(B_{t}-C_{t}\right)\left(1+r_{t}\right)^{N-t}$ 


\section{APPENDIX B. Constructing a Utility Function}

This appendix explains one approach ${ }^{107}$ to the construction of utility functions. The approach derives the utility function directly through questions to a decision maker about willingness to trade guaranteed sums for larger, uncertain sums. The appendix also presents the data on which the three utility functions in figure 3-7 are based. Figure B-1 is used here to explain the derivation of the three functions in figure 3-7. Figure $B-1$ is exactly like figure 3-7, except that the points through which the curves were fitted are shown in figure $B-1$.

The function in figure B-1 that bends over to the right indicates a risk averse (RA) decision maker. The RA function is used to explain the process of constructing a utility function. The steps taken to construct it were as follows:

(1) Two arbitrary incomes were selected. The decision maker chose $\$ 0$ and $\$ 100,000$. Then the decision maker was asked to assign arbitrary utility values (U) to these two incomes. They were as follows:

$$
\mathrm{U}(\$ 100,000)=70 \quad \mathrm{U}(\$ 0)=0
$$

(2) The decision maker was then asked to choose the amount of money (certainty equivalent) which he would be indifferent to receiving when compared to the following lottery:

$$
.50 U(\$ 100,000)+0.50 U(\$ 0)
$$

The decision maker chose $\$ 25,000$, half the $\$ 50,000$ expected value of the lottery. By substitution we solve for the corresponding utility value as follows:

$$
U(\$ 25,000)=0.50(70)+0.50(0)=35
$$

(3) Using the $U(\$ 25,000)$ as a known value, another point is experimentally determined by finding the certainty equivalent which the decision maker would be indifferent to receiving when compared to the following lottery:

$$
0.50 U(\$ 25,000)+0.50 U(\$ 0)
$$

The choice was $\$ 5,000$, considerably less than the $\$ 12,500$ expected value of the lottery. By substitution we find the corresponding utility value of $\$ 5,000$ as follows:

$$
U(\$ 5,000)=0.50(35)+0.50(0)=17.5
$$

${ }^{107}$ Examples of other approaches to constructing utility functions are to base utility measures (1) on observations of individual or firm behavior in practice and (2) on recorded behavior in games of chance designed to test risk attitude. 
(4) To find utility values for levels of income greater than $\$ 25,000$, alternative lotteries are posed that use the known utility values of $\$ 25,000$ and $\$ 100,000$. For example, the decision maker was asked to choose the amount of money which he would be indifferent to receiving when compared to the following lottery:

$$
0.90 U(\$ 100,000)+0.10 U(\$ 25,000)
$$

The decision maker chose $\$ 70,000$, compared to an expected value of $\$ 92,500$. By substitution we solve for the corresponding utility value as follows:

$$
U(\$ 70,000)=0.90(70)+0.10(35)=66.5
$$

(5) When asked to choose a value for the certainty equivalent of this lottery,

$$
0.75 U(\$ 70,000)+0.25 U(\$ 25,000),
$$

the decision maker chose $\$ 50,000$, compared to an expected value of $\$ 58,750$. By substitution we find the corresponding utility value as follows:

$$
U(\$ 50,000)=0.75(66.5)+0.25(35)=58.6
$$

(6) To find a point in the range where the decision maker could lose money, a loss situation was introduced into the lottery. The decision maker was asked to find the probabilities of outcomes which would make him indifferent between the following lottery and the certain equivalent from doing nothing.

$$
P U \cdot(\$ 5,000)+(1-P) \cdot U(-\$ 5,000)=U(\$ 0) \text {, }
$$

where $P$ and $(1-P)$ sum to 1.0 .

The decision maker assigned to $P$ the probability 0.70 and to $(1-P)$ the probability 0.30 . Substituting known values for $U(\$ 5,000)$ and $U(\$ 0)$ yielded the utility of losing $\$ 5,000$; i.e.

$$
\begin{aligned}
0.70(17.5)+(.30) \cdot U(-\$ 5,000) & =0 \\
U(-\$ 5,000) & =-(.70(17.5)) / 0.30 \\
& =-40.8
\end{aligned}
$$

To complete the process of constructing the risk averse utility function, a curve was statistically "fitted" through the combination of points selected arbitrarily $(\$ 0,0 ; \$ 100,000,70)$ and experimentally $(\$ 25,000,35 ; \$ 5,000$, $17.5 ; \$ 70,000,66.5 ; \$ 50,000,58.6$; and $-\$ 5,000,-40.8)$, as shown in function RA in figure B-1.108 A curve-fitting routine from DATAPLOT, a computer program developed at the National Institute of Standards and Technology, was used to establish the utility function. The risk taking (RT) and risk neutral (RN) functions in figure B-1 were constructed with the same routine, using the data shown in table B-1. ${ }^{109}$

${ }^{108}$ For additional information on how to construct utility functions, see Berger, Statistical Decision Theory and Bayesian Analysis, pp. 46-70, and Ronald A. Howard, "Risk Preference," Readings in Decision Analysis, ed. by Ronald Howard et al. (Menlo Park, California: SRI International, 1977, pp. 431-465.

${ }^{109}$ Robert E. Chapman of the National Institute of Standards and Technology ran DATAPLOT to construct the three utility functions. 


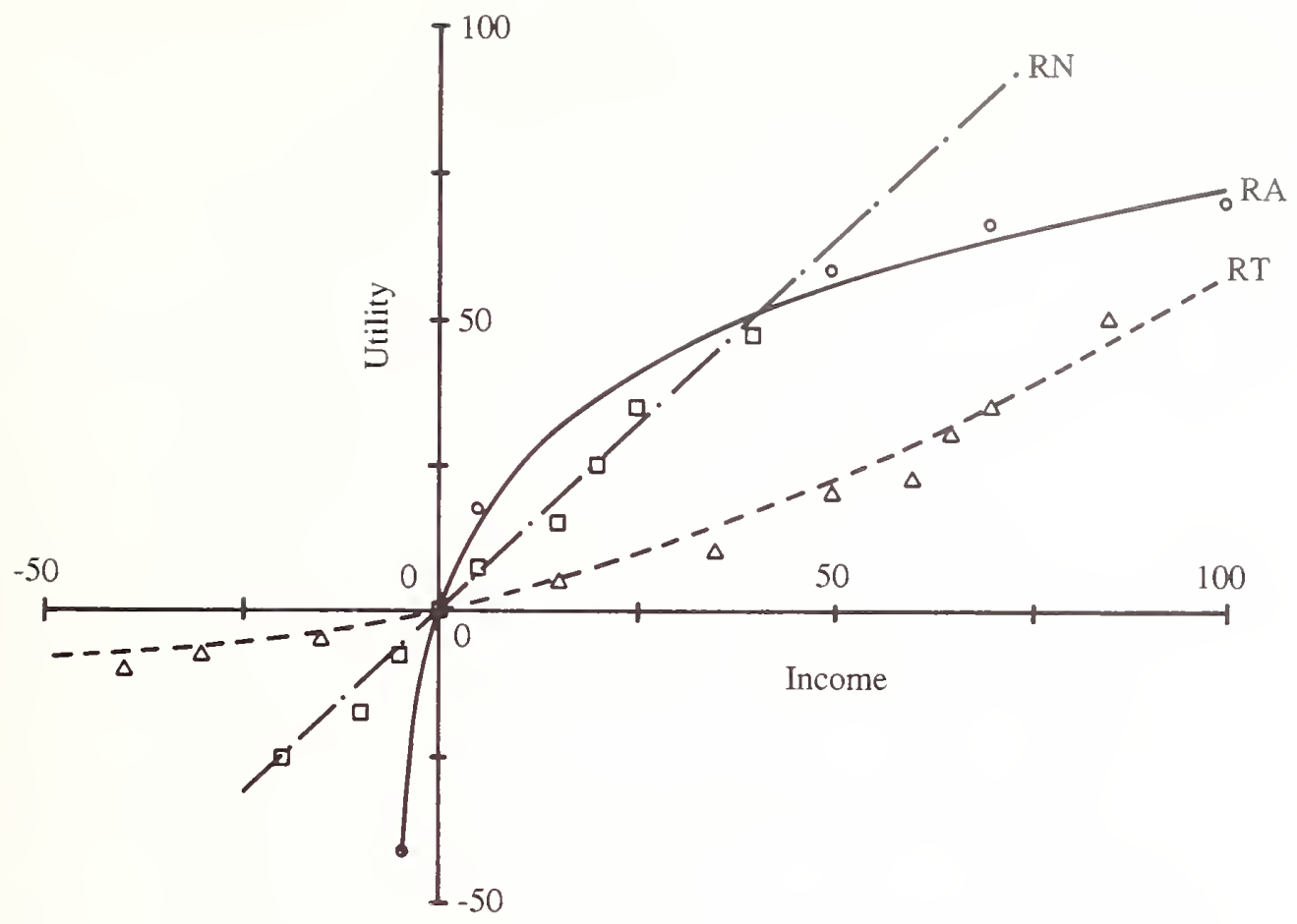

Figure B-1. Three types of risk attitude: Data and fitted functions.

$\mathrm{RN}=$ risk neutral

$\mathrm{RA}=$ risk averse

$\mathrm{RT}=$ risk taking

Table B-1. Data for plotting utility functions

\begin{tabular}{cccc}
\hline \multicolumn{2}{c}{ Risk Taker } & \multicolumn{2}{c}{ Risk Neutral } \\
\cline { 3 - 4 } $\begin{array}{c}\text { Thousands } \\
\text { of } \$\end{array}$ & Utility & & $\begin{array}{c}\text { Thousands Utility } \\
\text { of } \$\end{array}$ \\
\hline & & & \\
-40 & -10.0 & -20 & -25.0 \\
-30 & -7.5 & -10 & -17.5 \\
-15 & -5.0 & -5 & -7.5 \\
0 & 0.0 & 0 & 0.0 \\
15 & 5.0 & 5 & 7.5 \\
35 & 10.0 & 20 & 25.0 \\
50 & 20.0 & 25 & 35.0 \\
60 & 22.5 & 40 & 47.5 \\
65 & 30.0 & & \\
70 & 35.0 & & \\
80 & 42.5 & & \\
85 & 50.0 & & \\
\hline
\end{tabular}




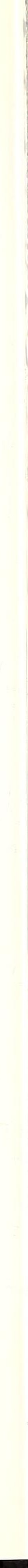




\section{BIBLIOGRAPHY}

American Society for Testing and Materials. Annual Book of Standards, Vol. 04.07 (Philadelphia, Pennsylvania: ASTM, 1987).

American Society of Heating, Refrigerating and Air-Conditioning Engineers, Inc. "Life-Cycle Costing," ASHRAE Handbook, Chapter 42 (Atlanta, Georgia: ASHRAE, 1984).

Arkin, Herbert and Colton, Raymond R. "Table of Areas of the Normal Curve," Tables for Statisticians (New York, New York: Barnes and Noble, 1950).

Arrow, Kenneth J. and Lind, Robert C. "Uncertainty and the Evaluation of Public Investment Decisions," The American Economic Review, Vol. LX, No. 3, June 1970.

$\mathrm{Au}$, Tung and $\mathrm{Au}, \mathrm{T} . \mathrm{P}$. Engineering Economics for Capital Investment Analysis (Boston, Massachusetts: Allyn and Bacon, Inc., 1983).

Au, T., Shane, Richard M., Hoel, Lester A. Fundamentals of Systems Engineering: Probability Models (Reading, Massachusetts: Addison-Wesley Publishing Company, 1972).

Baumol, William. Economic Theory and Operations Analysis, Fourth Edition (Englewood Cliffs, New Jersey: Prentice-Hall, Inc., 1977).

Berger, James O. Statistical Decision Theory and Bayesian Analysis, 2nd Edition (New York, New York: Springer-Verlag, 1985).

Capen, E. C. "The Difficulty of Assessing Uncertainty," Journal of Petroleum Technology, August 1976.

Chapman, Robert E. "The Efficiency Implications of Safety Standards." Dissertation for the George Washington University, Washington, DC, 1988.

Chemical Rubber Company. "The Normal Probability Function and Related Functions," Standard Mathematical Tables, 14 ed., edited by Samuel M. Selby, Cleveland, Ohio, 1965.

Clark, J. J., Hindelang, T. J., and Pritchard, R. E. Capital Budgeting: Planning and Control of Capital Expenditures (Englewood Cliffs, New Jersey: Prentice-Hall, Inc., 1984).

Curran, Michael W. "Range Estimating for Plaudits and Profits," Baltimore Engineer, April 1986.

Dell-Isolla, Alphonse and Kirk, Stephen J. Life-Cycle Costing for Design Professionals (New York, New York: McGraw-Hill, 1981).

Farragher, Edward J. "Capital Budgeting Practices of Non-Industrial Firms, The Engineering Economist, Vol. 31, No. 4, Summer 1986.

Fellner, W. Probability and Profit (Homewood, Illinois: Richard D. Irwin, Inc., 1965).

Flanagan, Roger; Kendell, Adrian; Norman, George; and Robinson, Graham. "Life-Cycle Costing and Risk Management," CIB Proceedings of the Fourth International Symposium on Building Economics, Danish Building Research Institute, Copenhagen, 1987.

Friedman, Milton and Savage, L. J. "The Utility Analysis of Choices Involving Risk," Readings in Price Theory (Homewood, Illinois: Richard D. Irwin, Inc., 1952). 
Fuller, Russell J. Capital Asset Pricing Theories--Evolution and New Frontiers, monograph No. 12, The Financial Analysts Research Foundation, Charlottesville, Virginia, 1981.

Graf, M. W. "An Overview of Contingency Consideration," Cost Engineering, Vol. 26, No. 1, February 1984.

Gurnani, C. "Capital Budgeting: Theory and Practice," The Engineering Economist, Vol. 30, No. 1, Fall 1984.

Healy, J. R. "Contingency Funds Evaluation," American Association of Cost Engineers Transactions, B-3, 1982.

Hendrickson, Robert G. A Survey of Sensitivity Analysis Methodology, National Bureau of Standards Interagency Report 84-2814, February 1984.

Hertz, D. "Risk Analysis in Capital Investment," Harvard Business Review, January 1964.

Hillier, F. "The Derivation of Probabilistic Information for the Evaluation of Risky Investments," Management Science, April 1963.

Hillier, F. "The Evaluation of Risky Interrelated Investments," Studies in Mathematical and Managerial Economics, ed. by Henri Theil, North-Holland, Amsterdam, 1969.

Hirshleifer, Jack and Shapiro, David L. "The Treatment of Risk and Uncertainty," ed. Robert Haveman and Julius Margolis, 2nd ed., Public Expenditure and Policy Analysis, 1977.

Holstein, C. S. von. "A Tutorial in Decision Analysis," Readings in Decision Analysis, ed. by Ronald Howard et al. (Menlo Park, California: SRI International, 1977).

Howard, Ronald A. "Risk Preference," Readings in Decision Analysis, ed. by Ronald Howard et al. (Menlo Park, California: SRI International, 1977).

Kim, Suk H. and Farragher, Edward J. "Current Capital Budgeting Practices," Management Accounting, June 1981.

Knight, Frank H. Risk, Uncertainty, and Profit (New York, New York: Harper and Row, 1965).

Lutz, Raymond P. and Cowles, Harold A. "Estimation Deviations: Their Effect Upon the Benefit-Cost Ratio," The Engineering Economist, Vol. 16, No. 1.

Markowitz, Harry. Portfolio Selection: Efficient Diversification of Investment (New York, New York: John Wiley and Sons, 1959).

Marshall, Harold E. and Ruegg, Rosalie T. Recommended Practice for Measuring Benefit/Cost and Savings-toInvestment Ratios for Buildings and Building Systems, National Bureau of Standards Interagency Report 812397, November 1981.

Marshall, Harold E. and Ruegg, Rosalie T. Simplified Energy Design Economics: Principles of Economics Applied to Energy Conservation and Solar Energy Investments in Buildings, National Bureau of Standards Special Publication 544, Reprinted by American Institute of Architects, January 1980.

Marshall, Harold E. Recommended Practice for Measuring Net Benefits and Internal Rates of Return for Investments in Buildings and Building Systems, National Bureau of Standards Interagency Report 83-2657, October 1983.

Marshall, Harold E. Recommended Practice for Measuring Simple and Discounted Payback for Investments in Buildings and Building Systems, National Bureau of Standards Interagency Report 84-2850, March 1984. 
Matheson, J. E. and Howard, R. A. "An Introduction to Decision Analysis," Readings in Decision Analysis (Menlo Park, California: Stanford Research Institute, 1977).

Neuman, John von and Morgenstern, Oskar. The Theory of Games and Economic Behavior (Princeton, New Jersey: Princeton University Press, 1944).

Newnan, D. Engineering Economic Analysis (San Jose, California: Engineering Press, Inc., 1980).

Park, C. "Probabilistic Benefit-Cost Analysis," The Engineering Economist, Vol. 29, No. 2, 1983.

Perry, J. G. and Hayes, R. W. "Risk and Its Management in Construction Projects," Proceedings Institution of Civil Engineers, Vol. 78.

Pouliquen, L. Y. Risk Analysis in Project Appraisal (Baltimore, Maryland: Johns Hopkins University Press, 1970).

Raiffa, Howard. Decision Analysis: Introductory Lectures on Choices Under Uncertainty (Reading, Massachusetts: Addison-Wesley, 1970).

Ruegg, Rosalie T. Life-Cycle Costing Manual for the Federal Energy Management Program, National Bureau of Standards Handbook 135 (Rev. 1987), November 1987.

Ruegg, Rosalie T. and Petersen, Stephen R. Comprehensive Guide for Least-Cost Energy Decisions, National Bureau of Standards Special Publication 709, January 1987.

Ruegg, Rosalie T., Petersen, Stephen R., and Marshall, Harold E. Recommended Practice for Measuring Life-Cycle Costs of Buildings and Building Systems, National Bureau of Standards Interagency Report 80-2040, June 1980.

SDG Decisions Systems. "Supertree TM Decision Analysis Software," Menlo Park, California.

Seldon, Robert M. Life-Cycle Costing: A Better Method of Government Procurement (Boulder, Colorado: Westview Press, 1979).

Sharpe, W. F. "Capital Asset Prices: A Theory of Market Equilibrium Under Conditions of Risk," Journal of Finance, Vol. 19, No. 4, September 1964.

Spetzler, Carl S. "Establishing a Corporate Risk Policy." 1986 Proceedings of the American Institute of Industrial Engineers (Norcross, Georgia: AIIE, 1986).

Spetzler C. S. and Holstein, C. S. Stael von. "Probability Encoding in Decision Analysis," Readings in Decision Analysis, ed. by Ronald Howard et al. (Menlo Park, California: SRI International, 1977).

Stevenson, James J., Jr. "Determining Meaningful Estate Contingency," Cost Engineering, Vol. 26, No. 1, February 1984.

Swalm, Ralph O. "Utility Theory--Insights into Risk Taking," Harvard Business Review, Nov./Dec. 1966.

U.S. Congress, National Energy Conservation Policy Act, November 1978, Title V, Part 3, Sec. 545(a).

Vegara, J. A. "Probabilistic Estimating and Applications of Portfolio Theory in Construction," Ph.D. Thesis, Graduate College of the University of Illinois at Urbana-Champaign, Urbana, Illinois, 1977.

Weston, F. J. and Brigham, E. F. Managerial Finance (Hinsdale, Illinois: The Dryden Press, 1981). 
Wilson, A. "Risk Analysis in Retail Store Design: A Case Study," Quality and Profit in Building Design, edited by P. S. Brandon and J. A. Powell (London, England: E. \& F. N., Spon, 1984).

Zaheer, S. H. "Contingency and Capital Cost Estimates," Cost Engineers' Notebook, A-1.200, March 1983, American Association of Cost Engineers. 


\section{SUBJECT INDEX}

adjusted internal rate of return $3,11,26-28,49-51,73$

American Society for Testing and Materials 1-2, 71

applications 5-6, 69

benefit-to-cost ratio $3,13-18,24-25,31,35,48,50,73$

beta 67

breakeven analysis 23-24, 62, 64, 69

capital asset pricing model 67

certainty equivalent technique $32-33,65-66,69$

coefficient of variation $33,36,69$

contingency $\quad 52-54$

contour lines 27

cost

estimate $\quad 52-54$

overruns $53-54$

cumulative distribution function $14-15,17-18,35,43,49-55,62-64,69$

decision

analysis $2,37-42,69$

tree $37-43$

deterministic $1,3,5,12,24,29,71$

discounting $8,30-31,34$

economic methods $1,3,5,8$

expected

monetary value 20,41

value analysis $35-36,69$

interdependence $54-55,64-65$

life-cycle cost $3,5,9-10,16,30,32,55,73$

limited budget $\quad 5-7,36$

mathematical/analytical 31, 55-56, 69 
mean-variance criterion $\quad 36,69$

minimum acceptable rate of return $\quad 8-9,11$

net

benefits $3,10,25-26,29,32-34,37-43,48,52,55,65,73$

savings $3,10,73$

non-deterministic 71

normal distribution $13,27-28,47,55,64$

portfolio analysis $\quad 66-67$

probability density function $16,18,35,43,45-46,55,61-62,69$

probability distribution $2-3,13-14,35,42,44,54,58-59$

risk

adjusted discount rate $30-31,34,65-66,69$

analysis $1,13,22,53-54,69$

attitude $2-3,8,13,15-17,19-25,30-32,34,36-37,41-42,54,65-66,69,75,77$

averse $19-21,32,36,41,54,65-66,75-77$

exposure $2-3,8,13-15,23-26,30-37,42,53-54,65-66,69$

neutral $19-20,32,38,54,75-77$

taking $19-21,32,36,41,54,75-77$

savings-to-investment ratio $3,11,73$

sensitivity analysis $2,8,24-29,37,64,69$

simulation $2,43-45,53-54,65,69$

spider diagrams $\quad 26-29$

stochastic dominance $16-17,19,36$

taxes $8,44-45,47$

time value of money $\quad 10,30$

uncertainty $1-3,8,12,23-27,31,35,38,44-45,53,57,65$

utility function $3-4,17,19-21,41,75-77$ 
4. TITLE AND SUBTITLE

Techniques for Treating Uncertainty and Risk in the Economic Evaluation of Building Investments

\section{5. $\operatorname{AUTHOR}(S)$}

Harold E. Marsha11

6. PERFORMING ORGANIZATION (If joint or other than NBS, see instructions)

7. Contract Grant No.

NATIONAL INSTITUTE OF STANDARDS AND TECHNOLOGY

(formerly NATIONAL BUREAU OF STANDARDS)

U.S. DEPARTMENT OF COMMERCE

GATHERSBURG, MD 20899

National Institute of Standards and Technology

U.S. Department of Commerce

Gaithersburg, MD 20899

10. SUPPLEMENTARY NOTES

[Document describes a computer program; SF-185, FIPS Software Summary, is attached.

11. ABSTRACT (A 200-word or less factual summary of mosi significant information. If document includes a significant bibliography or literature survey. mention it here)

Four economic methods--life-cycle costing, net benefits, benefit-cost ratio, and adjusted internal rate of return--are illustrated in a building investment problem. Input values are first assumed to be certain; thus uncertainty and risk are ignored in arriving at measures of project worth. Then the same four methods are examined with techniques for treating uncertainty in input values and for measuring risk exposure (i.e., the probability of failing to achieve predicted investment worth). Risk attitude, the willingness of a decision maker to take a chance or gamble on an investment of uncertain outcome, is also incorporated. Techniques examined include conservative cash flow estimation, sensitivity analysis, breakeven analysis, riskadjusted discount rate, certainty equivalent, input estimation using expected values, mean-variance criterion and coefficient of variation, decision analysis, simulation, and the mathematical/analytical technique. Advantages and disadvantages of each technique are described. The techniques are applicable to any capital budget expenditure whose future stream of benefits, revenues, savings, or costs is uncertain. Guidance is provided for selecting the appropriate technique for any given investment problem.

12. KEY WORDS (Six to twelve entries; alphabetical order; capitalize only proper names; and separate key words by semicolons) building economics; certainty equivalent; decision analysis; economics; mathematical/ analytical technique: risk-adjusted discount rate; risk analysis; risk attitude; risk exposure; sensitivity analysis; simulation; uncertainty

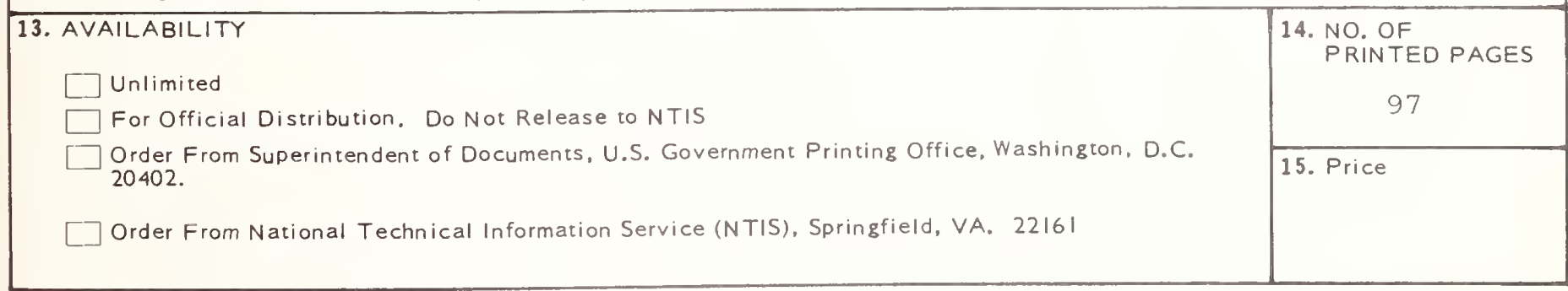




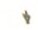





\section{U.S. Department of Commerce}

National Institute of Standards and Technology

(formerly National Bureau of Standards)

Gaithersburg, MD $20899^{\circ}$

Official Business

Penalty for Private Use $\$ 300$

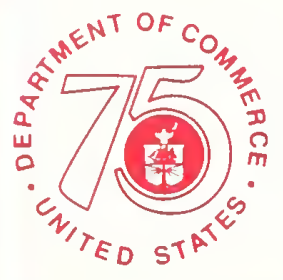

Stımulating America's Progress

$$
\text { 1913.1988 }
$$

